\title{
2016 The American Association for Thoracic Surgery (AATS) consensus guidelines: Surgical treatment of infective endocarditis: Executive summary
}

\author{
AATS Surgical \\ Treatment of \\ Infective \\ Endocarditis \\ Consensus \\ Guidelines Writing \\ Committee Chairs: \\ Gösta B. Pettersson, MD, PhD, ${ }^{\mathrm{a}}$ and \\ Joseph S. Coselli, MD ${ }^{\mathrm{b}, \mathrm{c}}$
}

Writing Committee: Gösta B. Pettersson, $\mathrm{MD}, \mathrm{PhD}$, Joseph S. Coselli, MD, ${ }^{\text {,c }}$ Syed T. Hussain, MD, ${ }^{a}$ Brian Griffin, MD, ${ }^{\mathrm{d}}$ Eugene H. Blackstone, MD, ${ }^{\mathrm{a}}$ Steven M. Gordon, MD, ${ }^{\mathrm{e}}$ Scott A. LeMaire, MD, and Laila E. Woc-Colburn, MD

Invited Experts: $\quad$ See Appendix E1.

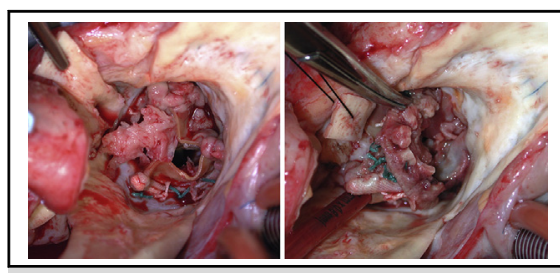

Vegetation and dehiscence in prosthetic valve endocarditis—a surgical disease.

\section{Central Message}

These guidelines describe diagnosis, indications, timing, surgical treatment, and perioperative care for patients with infective endocarditis and early surgeon involvement in team decision-making.

See Editorial Commentary page 1259.

\section{PREAMBLE}

Our mission was to develop evidence-based American Association for Thoracic Surgery (AATS) consensus focused on the surgical treatment of infective endocarditis (IE) and perioperative questions: when to operate, how to prepare the patient for operation, how to operate, and other issues relevant to managing and following patients after surgery. ${ }^{1-8}$ The writing committee included 4 cardiac surgeons, 1 cardiologist, 2 infectious disease specialists, and Dr Eugene H. Blackstone. The draft produced was reviewed by invited additional experts, including 4 cardiac surgeons, 1 anesthesiologist, 1 cardiologist, 2 imaging experts, 3 infectious disease specialists, and 1 neurologist (See Appendix E1).

\footnotetext{
From the Departments of ${ }^{\mathrm{a}}$ Thoracic and Cardiovascular Surgery, ${ }^{\mathrm{d}}$ Cardiovascular Medicine, and ${ }^{\mathrm{e}}$ Infectious Disease, Cleveland Clinic, Cleveland, Ohio; ${ }^{\mathrm{b}}$ Division of Cardiothoracic Surgery, and ${ }^{\mathrm{f}}$ Department of Infectious Diseases, Baylor College of Medicine; ${ }^{\mathrm{c}}$ Texas Heart Institute, Houston, Tex.

This work was supported by institutional funds for the participants and the Cleveland Clinic editorial staff.

Received for publication May 9, 2016; revisions received Sept 12, 2016; accepted for publication Sept 16, 2016; available ahead of print March 30, 2017.

Address for reprints: Gösta B. Pettersson, MD, PhD, Department of Thoracic and Cardiovascular Surgery, Cleveland Clinic, 9500 Euclid Ave/Desk J4-1, Cleveland, OH 44195 (E-mail: petterg@ccf.org).

J Thorac Cardiovasc Surg 2017;153:1241-58

$0022-5223 / \$ 36.00$

Copyright (C) 2017 by The American Association for Thoracic Surgery

http://dx.doi.org/10.1016/j.jtcvs.2016.09.093
}

\section{Methods of Review}

Recommendations of The Institute of Medicine's 2011 Clinical Practice Guidelines We Can Trust: Standards for Developing Trustworthy Clinical Practice Guidelines (www.iom.edu/cpgstandards) were followed, and level of evidence was graded according to standards. ${ }^{2}$

\section{Potential Biases}

Most studies of IE are affected by selection, survival, and referral bias. They make it difficult to study the natural history of IE in the general population, because treated and triaged patients enrich the sample seen at regional high-volume centers. Inferences drawn from results of treating such selected patients may not be helpful to the primary care physician, who is left without a clear picture of natural history until conservative treatment fails or appears futile, and it becomes clear that the patient must be referred. ${ }^{9-29}$

\section{INTRODUCTION}

These AATS consensus guidelines add to current ones related to IE from cardiology, infectious disease, and

Scanning this QR code will take you to supplemental data for this article.

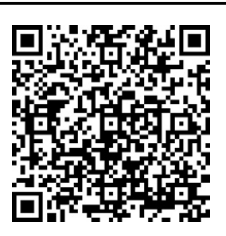




\section{Abbreviations and Acronyms \\ AATS $=$ The American Association for Thoracic Surgery \\ $\mathrm{CT}=$ computed tomography \\ IE = infective endocarditis \\ MRI = magnetic resonance imaging \\ $\mathrm{PCR}=$ polymerase chain reaction \\ PVE $=$ prosthetic valve endocarditis \\ TEE $=$ transesophageal echocardiography}

cardiac surgery societies by creating an easy-to-use set of recommendations addressing specific questions relevant and important to cardiac surgeons before, during, and after operation. $^{3-8}$

IE is the most severe and potentially devastating complication of heart valve disease, ${ }^{30}$ and its prevalence has increased during the last 30 years. Successfully managing IE requires prompt diagnosis, early institution of antimicrobial treatment, and decision-making related to complications, including risk of embolism and need for and timing of high-risk surgery. Even at experienced centers, operations for IE remain associated with the greatest mortality of any valve disease. ${ }^{11,14,31-49}$ The high prevalence of neurologic and other complications requires additional diagnostic and management expertise. ${ }^{3-7,50-53}$

Causative microorganism/pathogen, position (aortic, mitral, or right-sided), and type of infected valve (native or prosthetic) are important for pathology and prognosis. ${ }^{43,45,54,55}$ Bacteria and fungi have a species-specific repertoire of virulence factors that allow them to establish and maintain IE. Staphylococci and streptococci are the most common, aggressive, and destructive bacteria. Recent research has provided a plausible explanation for why IE is notoriously difficult to treat. Bacterial populations live embedded in a self-produced extracellular polysaccharide slime-like matrix called a biofilm that protects bacteria from host immune defenses and impedes antimicrobial efficacy. ${ }^{56}$ Capacity for biofilm production is a hallmark of microorganisms that commonly cause IE, including staphylococci, streptococci, and enterococci.

Toxins and enzymes cause tissue disintegration and invasion, resulting in valve regurgitation, fistulas, paravalvular abscesses, and heart block. Destroyed tissue does not regrow. Disease stage at diagnosis is related to the aggressiveness of the pathogen and disease duration.

Embolic strokes from vegetations, with or without hemorrhagic conversion, are frequent and clinically important. ${ }^{3-5}$ Although rare, systemic septic emboli can cause mycotic aneurysms in any artery, including the aorta. ${ }^{3,4}$ Right-sided IE frequently showers the lungs with septic emboli, but can be responsible for systemic emboli in the case of patent foramen ovale.
Antimicrobials to which the organisms are sensitive clear the bacteremia, may prevent or halt further destruction, and may, if initiated early enough, cure the infection. ${ }^{3-5,7}$ Antimicrobials will, however, not restore integrity of damaged tissue and valves. Surgery mechanically disrupts biofilm and removes vegetations, infected necrotic tissue, and foreign material and drains the infected areas, thereby exposing residual live microorganisms to antimicrobials, antibodies, and immune cells. In addition, surgery restores valve function and cardiac integrity. Microbiologic examination of operative specimens also can help identify the causative microorganism. ${ }^{57,58}$ Still, the final cure always is the result of antimicrobial treatment and the patient's own defenses.

These consensus guidelines primarily address questions related to active and suspected active IE affecting valves and intracardiac structures. It is understood that surgery is beneficial only if complications and other comorbidities do not preclude survival and meaningful recovery.

\section{QUESTIONS}

Recommendations, classification of recommendations, level of evidence, and supporting references are presented in tables referred to after each question. Narratives, abbreviated in this Executive Summary but expanded in the full online document, introduce the questions and provide short comments.

\section{Who Should Care for and Operate on Patients With IE? (Table 1-1)}

Surgery for IE carries the greatest risk of any valve surgery, and outcomes differ widely among centers and surgeons. AATS agrees with the European Society of Cardiology recommendation that specialized endocarditis teams should manage patients with IE at referral centers with access to cardiac surgery input early in its evaluation. ${ }^{3-5}$

Expeditious diagnosis and instituting adequate treatment require access to expertise in cardiology and infectious diseases, and imaging expertise, particularly in echocardiography. The management team should include a cardiac surgeon and other specialists needed to handle complications (eg, neurologist, psychiatrist, nephrologist). The IE surgeon must have enough experience to perform radical debridement and have access to and mastery of the necessary reconstructive procedures.

\section{Diagnosis of IE: What Does the Surgeon Need to Know? (Table 1-2)}

Duke or modified Duke criteria are used to classify certainty of the diagnosis. ${ }^{50,52,53}$ When IE is suspected, blood cultures should be obtained before antimicrobials are initiated. Empiric antibiotic coverage should be broad enough to cover likely organisms. 
TABLE 1. Team approach to patients with IE

\begin{tabular}{|c|c|c|c|}
\hline Recommendations & COR & LOE & References \\
\hline \multicolumn{4}{|l|}{ 1. Who should care for and operate on patients with IE? } \\
\hline $\begin{array}{l}\text { Patients with suspected IE should ideally be cared for at centers with } \\
\text { access to a complete team, including cardiology, infectious disease, } \\
\text { cardiac surgery, and other services needed to handle IE complications }\end{array}$ & I & B & $4,5,7,89$ \\
\hline $\begin{array}{l}\text { Surgeons operating on patients with IE should be well-trained, } \\
\text { experienced valve surgeons who are well versed in the different } \\
\text { reconstruction techniques needed by patients with advanced disease }\end{array}$ & I & $\mathbf{C}$ & $4,5,31,89$ \\
\hline \multicolumn{4}{|l|}{ 2. Diagnosis of IE: What does the surgeon need to know? } \\
\hline $\begin{array}{l}\text { At the time of surgery the patient should be on an effective antimicrobial } \\
\text { regimen (correct dosage and route of administration) to which the } \\
\text { causative microorganism is sensitive, or be broadly covered when } \\
\text { organism and sensitivity are unknown }\end{array}$ & I & B & $3-5,7,55,58$ \\
\hline $\begin{array}{l}\text { For surgery planning, the surgeon should have the best possible } \\
\text { understanding of the pathology. This will usually require advanced } \\
\text { imaging techniques, such as TEE }\end{array}$ & I & B & $3-5,7,90-98$ \\
\hline $\begin{array}{l}\text { Use of imaging modalities other than echocardiography may also be } \\
\text { appropriate in selected cases }\end{array}$ & Ilb & C & $3-5,95,99-103$ \\
\hline
\end{tabular}

COR, Classification of recommendations; $L O E$, level of evidence; $I E$, infective endocarditis; TEE, transesophageal echocardiography.

A transthoracic echocardiogram needs to be supplemented with a transesophageal echocardiogram (TEE) in most cases of suspected prosthetic IE. Real-time, 3-dimensional TEE permits better assessment of vegetation size and detection of complications, such as abscesses and valve leaflet or cusp perforations, than 2-dimensional TEE.

A substantial number of patients with IE go to the operating room before the causative microorganism is identified. The surgeon should secure tissue for microbiologic and histopathologic diagnosis.

\section{What Are the Indications for Surgery in Patients With IE? (Table 2-1)}

There is wide agreement about the indications and role of surgery for IE. ${ }^{3,5}$ Surgical treatment should be considered in patients with signs of heart failure, severe valve dysfunction, prosthetic valve endocarditis (PVE), invasion with paravalvular abscess or cardiac fistulas, recurrent systemic embolization, large mobile vegetations, and persistent sepsis despite adequate antibiotic therapy for more than 5 to 7 days. ${ }^{59,60}$ Approximately one-half of patients develop severe complications that require an operation.

Why and when to operate need to be seen in relation to each other. If there is any disagreement, it relates to the level of aggressiveness and timing of surgery. In patients with active IE and valve regurgitation severe enough to justify an operation had she or he not had IE, waiting for heart failure to develop before operating is not beneficial. ${ }^{47}$ Because the most frequent preventable complication is embolic stroke ${ }^{47}$ the trend is to be more aggressive in patients with large mobile vegetations. Patients with invasive staphylococcal PVE and early PVE also require early surgery, because the chance of cure by antimicrobial therapy alone is low without it.
In right-sided IE, indications for surgery are failure to control the infection, prevention of further septic pulmonary embolism, and, less often, severe tricuspid valve regurgitation. Guidelines of the European Society of Cardiology suggest a vegetation size of $\geq 20 \mathrm{~mm}$ as an indication for surgery. ${ }^{4}$

When Should the Patient Undergo Operation? (See Also "Indications and Neurologic Complications") (Table 2-2)

Once an indication for surgery has been established and effective antimicrobial therapy initiated, there is little reason to delay operation. ${ }^{3,5}$ Surgery to prevent embolism ${ }^{61-65}$ mainly is relevant early, ${ }^{62}$ during the first few days after antimicrobial therapy is initiated, when the risk of embolism is greatest.

What Is the Effect of Neurologic Complications, Embolic Stroke, Brain Hemorrhage, and Mycotic Aneurysm on Indication for and Timing of Surgery? (Table 3-1)

Patients with IE who have neurologic symptoms and require surgery should have a neurologic evaluation and brain imaging by computed tomography $(\mathrm{CT})$ or magnetic resonance imaging (MRI). ${ }^{66-68}$ Imaging should be repeated in case of new or worsening symptoms. The neurologic symptoms, consciousness, location and size of infarct, type (primary or hemorrhagic conversion in infarct), location, size, timing of hemorrhage, and risk and probability of mycotic aneurysm are all factors to consider when deciding on further imaging, management, and timing of surgery and operative risk.

Current recommendations are that surgery should be delayed for 1 to 2 weeks in patients with nonhemorrhagic 
TABLE 2. Indications for, and timing of, surgery for patients with IE

\begin{tabular}{|c|c|c|c|}
\hline Recommendations & COR & LOE & References \\
\hline \multicolumn{4}{|l|}{ 1. What are the indications for surgery in patients with IE? } \\
\hline $\begin{array}{l}\text { Surgery during initial hospitalization independently of the completion of a } \\
\text { full therapeutic course of antibiotics is indicated in patients with IE who } \\
\text { present with valve dysfunction resulting in symptoms of heart failure }\end{array}$ & $\mathbf{I}$ & B & $3-7,9,11,46,104-114$ \\
\hline $\begin{array}{l}\text { Surgery during initial hospitalization independently of the completion of a } \\
\text { full therapeutic course of antibiotics is indicated in patients with left-sided } \\
\text { IE caused by S. aureus, fungal, or other highly resistant microorganisms }\end{array}$ & $\mathbf{I}$ & B & $\begin{array}{l}3-5,7,9,18,31,40,105 \\
110,115-121\end{array}$ \\
\hline $\begin{array}{l}\text { Surgery during initial hospitalization independently of completion of a full } \\
\text { therapeutic course of antibiotics is indicated in patients with IE } \\
\text { complicated by heart block, annular or aortic abscess, or destructive } \\
\text { penetrating lesions }\end{array}$ & $\mathbf{I}$ & B & $\begin{array}{l}3-7,11,43,85,105,106 \\
108-110,122-129\end{array}$ \\
\hline $\begin{array}{l}\text { Surgery during initial hospitalization independently of the completion of a } \\
\text { full therapeutic course of antibiotics for IE is indicated in patients with } \\
\text { evidence of persistent infection as manifested by persistent bacteremia } \\
\text { or fever lasting longer than } 5 \text { to } 7 \text { days after initiation of appropriate } \\
\text { antimicrobial therapy }\end{array}$ & $\mathbf{I}$ & B & $\begin{array}{l}3-5,7,45,105,106,110 \\
118,120,130\end{array}$ \\
\hline $\begin{array}{l}\text { Surgery is recommended for patients with PVE and relapsing infection } \\
\text { (defined as recurrence of bacteremia after a complete course of } \\
\text { appropriate antibiotics and subsequently negative blood cultures) without } \\
\text { other identifiable source for portal of infection }\end{array}$ & Ila & $\mathbf{C}$ & 106 \\
\hline $\begin{array}{l}\text { Surgery during initial hospitalization independently of the completion of a } \\
\text { full therapeutic course of antibiotics is reasonable in patients with IE who } \\
\text { present with recurrent emboli and persistent vegetations despite } \\
\text { appropriate antibiotic therapy }\end{array}$ & Illa & B & $\begin{array}{l}3-6,47,61,63,91 \\
131-134\end{array}$ \\
\hline $\begin{array}{l}\text { Urgent or even emergency surgery may be considered in patients with } \\
\text { NVE or PVE who exhibit mobile vegetations greater than } 10 \mathrm{~mm} \text { in length } \\
\text { with clinical evidence of embolic phenomena despite appropriate } \\
\text { antimicrobial treatment }\end{array}$ & Illb & B & $31,47,63,91,135$ \\
\hline $\begin{array}{l}\text { In patients with right-sided IE in addition to symptomatic severe valve } \\
\text { dysfunction, surgery should be considered for NVE or PVE when large } \\
\text { vegetations are present and there is evidence of persistent infection } \\
\text { manifested by persistent bacteremia or fevers lasting longer than } 5 \text { to } 7 \\
\text { days after initiation of appropriate antimicrobial therapy, or in those with } \\
\text { evidence of septic pulmonary embolism }\end{array}$ & IIb & B & $4,7,136$ \\
\hline \multicolumn{4}{|l|}{ 2. When should the patient undergo operation? } \\
\hline $\begin{array}{l}\text { Once an indication for surgery is established, the patient should be } \\
\text { operated on within days }\end{array}$ & I & B & $3-6$ \\
\hline $\begin{array}{l}\text { Earlier surgery (emergency or within } 48 \text { hours) is reasonable for patients } \\
\text { with large mobile vegetations at imminent risk of embolism }\end{array}$ & Ila & B & $3-6,46,62,133,137,138$ \\
\hline $\begin{array}{l}\text { In patients with stroke and neurologic deficits, timing is decided by } \\
\text { weighing the need for cardiac surgery against the risk of expanding the } \\
\text { stroke or provoking intracranial bleeding during the operation (see } \\
\text { specific question about neurologic complications) }\end{array}$ & Ila & B & $\begin{array}{l}3-6,33,61-63,67,69 \\
104,108,110,125,137 \\
139-154\end{array}$ \\
\hline
\end{tabular}

COR, Classification of recommendations; $L O E$, level of evidence; $I E$, infective endocarditis; $P V E$, prosthetic valve endocarditis; $N V E$, native valve endocarditis.

strokes and for 3 to 4 weeks in patients with hemorrhagic strokes or hemorrhage. Performing surgery 1 to 7 days after an ischemic stroke, however, is not associated with increased in-hospital mortality. ${ }^{69}$ The importance of minimal hemorrhagic conversion in an ischemic stroke is not yet determined. Patients with a severe neurologic deficit should not be operated on until it improves and potential for recovery is established.

\section{Should All Patients With IE Scheduled for Surgery \\ Have Preoperative Brain Imaging? (Table 3-2)}

Whether brain imaging should be performed in all patients with IE remains controversial, ${ }^{66-70}$ but brain embolization has been detected by MRI in $70 \%$ of patients without a neurologic deficit. ${ }^{67}$ Mortality is similar among patients with brain embolization with either clinical or asymptomatic stroke but lower in those with a negative MRI. ${ }^{67}$

\section{What Workup Is Needed for Diagnosing Primary Infectious Focus, Secondary Manifestations and Complications (Other Than Neurologic), and Satellite Infections in Patients With IE? (Table 3-3)}

Screening for infected teeth is routine, as is colonoscopy in patients with Streptococcus gallolyticus IE. ${ }^{71-73}$ The search for other infectious foci, satellite infections, and mycotic aneurysms is guided by symptoms, specific signs, and causative organism. Some recommend routine screening for patients with Staphylococcus aureus or aspergillus IE, 
TABLE 3. Presurgical work-up and management of patients with IE

\begin{tabular}{|c|c|c|c|}
\hline Recommendations & COR & LOE & References \\
\hline \multicolumn{4}{|c|}{$\begin{array}{l}\text { 1. What is the effect of neurologic complications, embolic stroke, brain hemorrhage, and mycotic } \\
\text { aneurysm on indication for and timing of surgery? }\end{array}$} \\
\hline $\begin{array}{l}\text { If a cerebral mycotic aneurysm has been diagnosed, treatment and } \\
\text { follow-up of the patient should be in close collaboration with neurologic } \\
\text { and neurosurgery expertise }\end{array}$ & I & C & $3,4,6,155$ \\
\hline $\begin{array}{l}\text { In patients with a recent intracranial hemorrhage, a delay of operation for } \\
3 \text { or more weeks is reasonable }\end{array}$ & Ila & B & $\begin{array}{l}3-6,138,141 \\
156-159\end{array}$ \\
\hline $\begin{array}{l}\text { Earlier surgery is reasonable for patients with non-hemorrhagic strokes } \\
\text { and a strong cardiac indication for urgent surgery }\end{array}$ & Ila & B & $\begin{array}{l}3-6,69,157 \\
160-162\end{array}$ \\
\hline $\begin{array}{l}\text { Patients with large and multiple strokes and severe neurologic symptoms } \\
\text { should be carefully evaluated by a neurologist before being offered } \\
\text { surgery }\end{array}$ & I & B & $3,4,6$ \\
\hline $\begin{array}{l}\text { For patients with IE and neurologic symptoms and significant intracranial } \\
\text { hemorrhage, angiography should be considered to rule out mycotic } \\
\text { aneurysm }\end{array}$ & Ila & B & $3,4,6,155$ \\
\hline
\end{tabular}

2. Should all patients with IE scheduled for surgery have preoperative brain imaging?

\begin{tabular}{|c|c|c|c|}
\hline $\begin{array}{l}\text { Endocarditis patients with neurologic symptoms should have brain } \\
\text { imaging }\end{array}$ & I & B & $3,4,6$ \\
\hline $\begin{array}{l}\text { It is reasonable to screen patients with left-sided IE for possible stroke or } \\
\text { intracranial bleeding before operation, particularly if they have cardiac } \\
\text { lesions considered high risk for embolic events }\end{array}$ & Ila & B & $66-68,70$ \\
\hline
\end{tabular}

3. What workup is needed for diagnosing primary infectious focus, secondary manifestations and complications (other than neurologic), and satellite infections in patients with IE?

\begin{tabular}{|c|c|c|c|}
\hline $\begin{array}{l}\text { Patients with IE should be screened for primary noncardiac focus of } \\
\text { infection, noncardiac complications, and satellite infections: The choice of } \\
\text { diagnostic procedure (e.g., CT, MRI, ultrasonography) varies, and the } \\
\text { selection should be individualized for each patient based on clinical } \\
\text { symptoms and suspicions }\end{array}$ & I & C & 3,4 \\
\hline
\end{tabular}

\begin{tabular}{|c|c|c|c|}
\hline \multicolumn{4}{|c|}{$\begin{array}{l}\text { 4. How should anticoagulation in patients with IE, with and without stroke or intracranial bleeding, } \\
\text { be managed? }\end{array}$} \\
\hline $\begin{array}{l}\text { Anticoagulation management in patients who have compelling indications } \\
\text { for anticoagulation, e.g., atrial fibrillation, mechanical prosthetic valve, } \\
\text { deep vein thrombosis, or pulmonary embolism, has to seek } \\
\text { compromises, taking all risks and benefits into consideration }\end{array}$ & I & C & $163-176$ \\
\hline $\begin{array}{l}\text { Heparin should be used cautiously in all patients with IE, particularly } \\
\text { when there is evidence of brain hemorrhage, and be temporarily withheld } \\
\text { in patients with higher risk of rebleed }\end{array}$ & I & B & 4,164 \\
\hline
\end{tabular}

COR, Classification of recommendations; $L O E$, level of evidence; $I E$, infective endocarditis; $C T$, computed tomography; $M R I$, magnetic resonance imaging.

which could include CT or (fluorodeoxyglucose) positron emission tomography-CT of the head, chest, and abdomen. $^{74,75}$ Spinal infections in patients with IE are important to keep in mind, because both entities are associated with hematogenous seeding. In a large series of 606 endocarditis cases, concomitant spondylodiscitis was diagnosed in $28(4.6 \%)$. These 28 cases constituted onethird of the 91 patients diagnosed with spondylodiscitis during the same period. ${ }^{76}$

How Should Anticoagulation in Patients With IE, With and Without Stroke or Intracranial Bleeding, Be Managed? (Table 3-4)

In itself, IE is not an indication for anticoagulation. Anticoagulation increases the risk of hemorrhagic conversion of an ischemic stroke and brain hemorrhage. If the patient has a mechanical prosthetic valve or other strong indication for anticoagulation, the treatment team must decide whether anticoagulation is necessary, what to use, and what international normalized ratio or partial thromboplastin time level to target.

\section{What Additional Workup Is Needed Just Before \\ Taking the Patient to Surgery? (Table 4-1)}

Indications for coronary angiography should be according to normal criteria for other surgical conditions. Patient condition, risk of provoking an embolic stroke, and renal function must be taken into consideration. Those with a history of sternotomy need a preoperative CT of the chest without contrast. 
TABLE 4. Additional workup, preoperative antibiotics, and risk of operation for patients with IE

\begin{tabular}{|c|c|c|c|}
\hline Recommendations & COR & LOE & References \\
\hline \multicolumn{4}{|l|}{ 1. What additional workup is needed just before taking the patient to surgery? } \\
\hline $\begin{array}{l}\text { When surgery is decided upon, before going to the operating room, it is } \\
\text { reasonable to obtain brain imaging or repeat brain imaging }\end{array}$ & Ila & B & $67,68,70$ \\
\hline $\begin{array}{l}\text { The need for preoperative coronary angiography should be guided by normal } \\
\text { criteria. This is particularly important if the patient has had coronary artery } \\
\text { bypass grafting. In patients with large aortic valve vegetations, CT angiography } \\
\text { is an alternative to assess the coronary arteries }\end{array}$ & $\mathbf{I}$ & C & $3,4,6,177$ \\
\hline $\begin{array}{l}\text { When repeat sternotomy is required, computed tomography of the chest is } \\
\text { recommended when possible to assess risk of sternal reentry }\end{array}$ & Ila & $\mathbf{C}$ & 178 \\
\hline \multicolumn{4}{|l|}{ 2. Is preoperative duration of antibiotic treatment important? } \\
\hline $\begin{array}{l}\text { The patient should be on an effective antimicrobial regimen at the time of } \\
\text { surgery. Ideally, the sensitivity of the causative organism is known }\end{array}$ & I & B & $3-5,7,55,58$ \\
\hline $\begin{array}{l}\text { Once the patient is on an effective antimicrobial regimen, further delay of } \\
\text { surgery is unlikely to be beneficial }\end{array}$ & Ila & B & $\begin{array}{l}3-5,7,77,104,110 \\
125,179-181\end{array}$ \\
\hline \multicolumn{4}{|l|}{ 3. What is the risk of operation for IE? } \\
\hline $\begin{array}{l}\text { The patient should be quoted a risk, taking into consideration all factors known } \\
\text { to affect the risk of the operation }\end{array}$ & $\mathbf{I}$ & C & $34,78,79,182$ \\
\hline
\end{tabular}

COR, Classification of recommendations; $L O E$, level of evidence; $C T$, computed tomography; $I E$, infective endocarditis.

\section{Is Preoperative Duration of Antibiotic Treatment Important? (Table 4-2)}

It is important for the patient to be on an effective antimicrobial regimen and to have the bacteremia cleared at the time of surgery. The probability of positive cultures from explanted valves decreases with duration of preoperative treatment and reaches its lowest level after 1 week, with no further improvement. ${ }^{77}$ If the pathogen is unknown or difficult to treat and there is evidence of invasion, or if the patient has PVE, there is no evidence that delaying surgery to allow a longer period of preoperative treatment is beneficial.

\section{What Is the Risk of Operation for IE? (Table 4-3)}

The Society of Thoracic Surgeons endocarditis score ${ }^{34}$ and score from De Feo and colleagues ${ }^{78}$ are good predictors of operative mortality after surgery for active IE. Patient comorbidities, disease stage and complications, acuity, as well as the experience of the surgeon and treatment team all affect risk, ${ }^{79}$ which is particularly wide ranging in patients with IE.

\section{SPECIFIC ISSUES RELATED TO CONDUCT OF OPERATIONS FOR ENDOCARDITIS \\ Intraoperative TEE (Table 5-1)}

Intraoperative TEE should be routine and is a Class I recommendation by the American Society of Echocardiography. ${ }^{80}$

\section{Operative Approach (Table 5-2)}

Sternotomy is required for most operations to treat IE.

\section{Removal of Infected Tissue: Radical Debridement (Table 5-3)}

A fundamental surgical principle is to remove infected foreign bodies and necrotic tissue to minimize residual infectious burden and provide access for antimicrobial therapy and host defense. In patients with mitral annular calcification, debridement must include removing infected calcium and exposing migrating infection spreading in and along the calcium. Radical debridement does not mean excision with wide margins. Debridement is followed by generous irrigation.

\section{Choice of Reconstruction and Valve Replacement: General Considerations and Recommendations}

\section{(Table 5-4)}

For the mitral valve in particular, the advantage of valve repair over replacement is well documented. When valve replacement is required, there is little evidence that risk of recurrent infection is different between mechanical and tissue prostheses. The use of bioprosthetic valves or allografts avoids postoperative anticoagulation, lowering the risk of hemorrhagic conversion of strokes and other bleeding complications. $^{81-84}$

\section{Native Aortic Valve IE (Table 5-5)}

Repair is seldom possible. When the disease is invasive and the annulus destroyed, reconstruction and usually root replacement are required, and many surgeons believe that an allograft is a better choice than a prosthetic valved conduit. When additional material is needed, no material has proved superior to autologous pericardium. 


\section{Prosthetic Aortic Valve IE (Table 5-6)}

Prosthetic valve infections often involve the sewing ring. When the infection invades the annulus behind the central fibrous body, it eventually reaches the conduction bundle and atrioventricular node, causing heart block. The more extensive and destructive the infection, the stronger is the argument in favor of an allograft over alternative conduits with prosthetic valves. ${ }^{85}$ In patients with advanced invasive active IE, the primary concerns are survival and cure of the infection.

\section{Native Mitral Valve IE (Table 5-7)}

Invasive and destructive disease is less common in the mitral than aortic position, and when invasion occurs it is more often shallow. When, however, invasion penetrates deeper into the atrioventricular groove, it is more serious, and radical debridement, sterilization, and drainage of the infected area are more difficult.

When valve replacement is required, there is no established alternative to prosthetic valves. When the annulus must be reconstructed, nothing has proved better than autologous pericardium, when available. Patches must be generous to minimize stress on suture lines. Residual communications beneath the valve into infectious cavities must be avoided.

\section{Prosthetic Mitral Valve IE (Table 5-8)}

Differences between options for native and prosthetic valve endocarditis are less obvious for the mitral than aortic valve. Exposure for debridement and removal of the old prosthesis and suture material is worse for mitral valve IE. Deep invasion into the atrioventricular groove is uncommon, in most cases allowing direct implantation of a new prosthesis without additional reconstruction.

\section{Double-Valve IE (Table 5-9)}

IE of both aortic and mitral valves can be managed in accordance with recommendations for each. Advanced pathology with destruction of the fibrous structure between the aortic and mitral valves requires intervalvular fibrosa reconstruction, a high-risk operation even for experienced surgeons.

\section{Right-Sided IE (Table 5-10)}

The primary objective of surgery for right-sided IE most often is to eliminate the cause of persistent sepsis and source of septic emboli to the lung. Valve repair or replacement is a secondary objective.

For patients with tricuspid valve IE, the best possible repair and preservation of the patient's own valve is the first choice. If the patient has increased pulmonary pressure and resistance, excising the valve and leaving severe regurgitation are not advisable. When replacement is required, most surgeons have a preference for bioprosthetic valves.

\section{Should Regular Synthetic Vascular Grafts or Valveless Allografts Be Used When the Aorta Must Be Replaced Beyond the Root? (Table 6-1)}

A regular synthetic vascular graft is the standard for replacing the aorta and arch in patients with IE. Many aortic surgeons soak a gel-impregnated graft with an antimicrobial. The use of a valveless allograft may make sense if the field is grossly infected, but evidence of benefit is lacking.

\section{Should Additional Prostheses and Vascular Grafts Not Proved to Be Infected Be Removed and Replaced? (Table 6-2) \\ A vascular graft surrounded by pus is infected and should be removed. Often, however, there is no obvious sign of infection, and removal or not is a matter of judgment.}

\section{When Should Permanent Pacemaker Systems Be Removed in Patients Undergoing Surgery for IE? (Table 6-3)}

If infected, and in right-sided IE affecting the tricuspid valve, leads and pacemaker should be removed. In the case of left-sided IE with no convincing evidence of pacemaker and lead involvement, removal is still reasonable but adds to complexity postoperatively and the question of if, when, and how the system should be replaced.

\section{Should Patients With a Known Indication for a Pacemaker Receive a Pacemaker System With Epicardial Leads When Undergoing Operation for Active IE? (Table 6-4) \\ Epicardial leads are less likely to become infected than transvenous leads; it is therefore logical to consider placing permanent epicardial leads at the end of the operation. For patients at increased risk of becoming reinfected, for example, those on dialysis, injection drug users, or those with ongoing bacteremia at the time of pacemaker removal, such a strategy is even more attractive. For this decision, many factors must be considered.}

\section{Are There Any Safety Concerns Regarding Use of Mechanical Valves in Patients With IE? (Table 6-5) \\ Committing a patient to anticoagulation adds complexity to postoperative management and increases risk of bleeding. Intracranial bleeding is the primary concern, but sick patients are also at risk of bleeding from the gastroin- testinal tract and other places postoperatively.}


TABLE 5. General features of intraoperative management of patients with IE

\begin{tabular}{|c|c|c|c|}
\hline Recommendations & COR & LOE & References \\
\hline \multicolumn{4}{|l|}{ 1. Intraoperative TEE } \\
\hline Intraoperative TEE is mandatory when performing surgery for IE & I & B & $3-5,80,90,97,183-187$ \\
\hline \multicolumn{4}{|l|}{ 2. Operative approach } \\
\hline Medium sternotomy is the recommended approach, with few exceptions & I & C & \\
\hline \multicolumn{4}{|l|}{ 3. Removal of infected tissue: Radical debridement } \\
\hline $\begin{array}{l}\text { All infected and necrotic tissue and foreign material should be radically debrided } \\
\text { and removed }\end{array}$ & I & B & 43,85 \\
\hline \multicolumn{4}{|c|}{ 4. Choice of reconstruction and valve replacement: General considerations and recommendations } \\
\hline $\begin{array}{l}\text { For patients with NVE and infection limited to the valve cusps or leaflets, repair } \\
\text { is performed whenever possible }\end{array}$ & I & B & $3-6,43,152,188-198$ \\
\hline $\begin{array}{l}\text { When simple valve replacement is required, choice of valve-mechanical or } \\
\text { tissue prosthesis—-should be based on normal criteria: age, life expectancy, } \\
\text { comorbidities, and expected compliance with anticoagulation }\end{array}$ & I & B & $4-6,197,199-201$ \\
\hline $\begin{array}{l}\text { It is reasonable to avoid use of mechanical prostheses in patients with any } \\
\text { intracranial bleeding or those who have suffered a major stroke }\end{array}$ & Ila & C & \\
\hline $\begin{array}{l}\text { For patients with invasive disease and destruction, reconstruction should } \\
\text { depend on the involved valve, severity of destruction, and available options for } \\
\text { cardiac reconstruction }\end{array}$ & I & B & $6,43,44,85,111,202,203$ \\
\hline \multicolumn{4}{|l|}{ 5. Native aortic valve IE } \\
\hline $\begin{array}{l}\text { For patients with native aortic valve IE and infection limited to the valve cusps, } \\
\text { repair may occasionally be possible. Choice of replacement valve-mechanical } \\
\text { or tissue prosthesis-should be based on usual criteria }\end{array}$ & I & B & $4-6,43,83,197-201$ \\
\hline $\begin{array}{l}\text { For invasive and destructive native aortic valve IE requiring root reconstruction } \\
\text { and replacement, using an allograft may be beneficial, but a prosthetic bioroot } \\
\text { or prosthetic valved conduit with a mechanical or bioprosthetic valve are } \\
\text { acceptable alternatives, with choice guided by surgeon training and experience }\end{array}$ & Ila & B & $\begin{array}{l}6,8,44,81,82,199,200 \\
204-208\end{array}$ \\
\hline \multicolumn{4}{|l|}{ 6. Prosthetic aortic valve IE } \\
\hline $\begin{array}{l}\text { If the root and the annulus are preserved after radical debridement, it is } \\
\text { reasonable to implant a new prosthetic valve-mechanical or tissue-based on } \\
\text { normal criteria }\end{array}$ & Ila & B & 6,44 \\
\hline $\begin{array}{l}\text { If there is annulus destruction and invasion outside the aortic root and root } \\
\text { reconstruction and replacement is required, an allograft or a biologic tissue root } \\
\text { is preferable to a prosthetic valved conduit }\end{array}$ & Ila & B & $\begin{array}{l}6,8,44,81-83,85,200 \\
202,204,206-217\end{array}$ \\
\hline \multicolumn{4}{|l|}{ 7. Native mitral valve IE } \\
\hline $\begin{array}{l}\text { Mitral valve repair is the preferred choice whenever possible, including use of a } \\
\text { prosthetic annuloplasty ring when appropriate }\end{array}$ & I & B & $43,152,188-196$ \\
\hline $\begin{array}{l}\text { When valve replacement is required, a prosthetic valve, either mechanical or } \\
\text { tissue, is acceptable, unless there is risk of intracranial bleeding, in which case } \\
\text { a tissue valve is preferred }\end{array}$ & Ila & B & $4-6,199,201$ \\
\hline $\begin{array}{l}\text { When there is annulus destruction and invasion, the mitral annulus is } \\
\text { reconstructed and the valve prosthesis anchored to the ventricular muscle or to } \\
\text { the reconstruction patch in a way that prevents leakage and pseudoaneurysm } \\
\text { development beneath the prosthesis }\end{array}$ & Ila & B & $43,188,192,203$ \\
\hline
\end{tabular}

\section{Prosthetic mitral valve IE}

A new prosthetic mitral valve, mechanical or tissue, is acceptable, unless there

is risk of intracranial bleeding, in which case a tissue valve is preferred

When there is annulus destruction and invasion, the mitral annulus is

reconstructed and the valve prosthesis anchored to the ventricular muscle or to the reconstruction patch in a way that prevents leakage and pseudoaneurysm development beneath the prosthesis

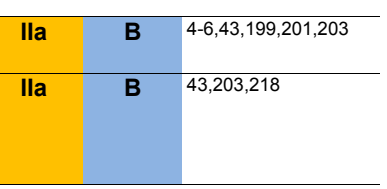

9. Double-valve IE

If the aortic root and aortic and mitral annuli are preserved after radical debridement, it is reasonable to implant mechanical or biologic valves, with the choice based on normal criteria

If there is aortic annulus destruction and invasion, and root reconstruction and replacement is required, an allograft or bioroot may be preferable to a prosthetic valved conduit, and if the mitral annulus shows invasion and destruction, it should be reconstructed to anchor the valve prosthesis to the ventricular muscle or to the annulus reconstruction patch to avoid leakage and pseudoaneurysm development beneath the prosthesis

Infection destroying the intervalvular fibrosa requires reconstruction of this structure, and it is preferable that surgeons taking on these cases master such techniques

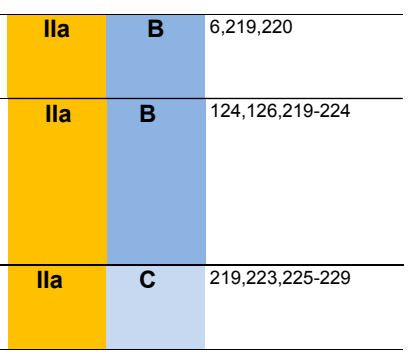

\section{Right-sided IE}

The primary objective of surgery for right-sided IE is radical debridement of infected vegetations and foreign material

Tricuspid valve repair should be attempted whenever possible

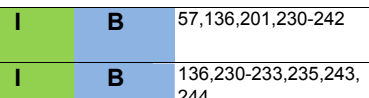

COR, Classification of recommendations; $L O E$, level of evidence; TEE, transesophageal echocardiography; $I E$, infective endocarditis; $N V E$, native valve endocarditis. 
Is There Any Role for Local Antimicrobials or Antiseptics During Surgery for IE? (Table 6-6)

Irrigation removes residual tissue debris and loose infected material and is an integral part of any valve operation. In addition to normal saline irrigation, many surgeons use local antiseptics or antimicrobials, but evidence of benefit is lacking.

\section{How Should Infected Areas Be Drained? (Table 6-7)}

Draining infected areas is a fundamental surgical principle for managing infections. For invasive aortic IE, leaving infected areas open to the pericardium is natural and intuitively better than patching and excluding infected areas and cavities. For mitral valve IE with invasion into the atrioventricular groove, the options are sterilizing the cavity and closing it, allowing it to communicate with the atrium or ventricle (with risk of pseudoaneurysm and rupture), or draining it to the pericardium (with risk of bleeding and rupture).

\section{How Should Operative Specimens Be Handled?}

(Table 6-8)

Operative specimens offer another opportunity to identify the pathogen and test its sensitivity to antimicrobials. In blood culture-negative IE, operative specimens are particularly valuable. Whenever there is uncertainty regarding the causative microorganism, molecular testing with polymerase chain reaction (PCR) should be considered. Pathology, looking for inflammation, neovascularization, and organisms, remains the gold standard for IE. ${ }^{50,52,86}$

\section{What Is the Role of Molecular Testing With PCR in Identifying Pathogens? (Table 6-9)}

Comorbid conditions and prolonged illnesses of patients with IE necessitate careful consideration of culture results before assigning causative status to any microorganism isolated in various cultures. PCR may identify the causative microorganism in many cases in which blood and valve cultures have failed.

\section{QUESTIONS RELATED TO POSTOPERATIVE MANAGEMENT}

What Postoperative Antimicrobial Treatment Is Required, and for How Long Should the Patient Be Treated? (Table 6-10)

Standard duration of postoperative intravenous antimicrobial treatment is 6 weeks when the infection is active at the time of surgery, but clinical scenarios and pathogen may modify this. Longer duration of treatment may be justified for more invasive infections, difficult-to-treat organisms, or presence of hardware and satellite infections, for example, osteomyelitis.

For fungal infections, lifelong oral suppression has been suggested.
What Is the Need for Follow-up and Additional Screening for Infectious Foci That Could Cause Recurrent Infection/IE? (Table 7-1)

Patients with IE should be examined for sources of bacteremia and have those sanitized, for instance, the teeth. Patients with IE caused by $S$ gallolyticus should undergo colonoscopy. In the first 6 postoperative months, there is risk of relapse, so patients should be followed by an infectious disease specialist. After 6 months, continued follow-up with a cardiologist is more appropriate. After surgery for IE, there is risk of valve dehiscence, paravalvular leak, and pseudoaneurysm formation, all good reasons for follow-up echocardiograms.

Drug abuse is associated with increased risk of relapse and recurrent, difficult-to-cure IE. Rehabilitation, seamless transition of care, and mobilization of social support are essential for any chance of success.

\section{What Is the Risk of Relapse and Recurrent IE?}

\section{(Table 7-2)}

Long-term follow-up studies that include a diverse population of patients suggest that patients treated for IE have a high risk of recurrent infection- $1 \%$ to $3 \%$ per patient year. Two phases have been demonstrated, an early hazard phase corresponding to relapse and a constant, long-term phase.

\section{QUESTIONS RELATED TO RESIDUAL CONTROVERSIES}

Should Surgical Treatment Be Offered to Injection

Drug Users With IE? (Table 7-3)

It is well documented that injection drug use is associated with IE, right-sided in particular. Although operative risk is not higher, drug-addicted patients have a greater probability of death in the year after operation than do nonaddicted patients. The injection drug use must be included and weighed in decision-making, and patient treatment must include drug rehabilitation.

\section{Should Surgical Treatment Be Offered to Patients With IE on Dialysis? (Table 7-4)}

Patients on dialysis are 10 to 18 times more likely to develop IE than the general population. Their operative risk is greater and long-term outcomes worse than for patients not on dialysis.

Patients in renal failure calcify biologic implants faster than patients with good renal function.

\section{Should Surgical Treatment Be Offered to Patients With IE and Liver Cirrhosis? (Table 7-5)}

Liver cirrhosis is a risk factor for IE, and its importance should be weighed in decision-making. ${ }^{87}$ The added operative risk is related to its severity, as accessed by the ChildPugh or Model for End-Stage Liver Disease scores. 
TABLE 6. Specific considerations in surgical management of patients with IE

\section{Recommendations}

COR

LOE

References

1. Should regular synthetic vascular grafts or valveless allografts be used when the aorta must be replaced beyond the root?

When distal ascending aorta, hemiarch, or arch replacement is required, a synthetic graft is the standard choice, but a valveless allograft is an alternative in an infected field for replacing the ascending aorta beyond the root

2. Should additional prostheses and vascular grafts not proved to be infected be removed and replaced?

Inspection and removal of additional prostheses and vascular grafts, even if not proved to be infected, should be considered and is reasonable if the causative microorganism is $S$. aureus or fungus, provided that the added difficulty and risk is not prohibitive

3. When should permanent pacemaker systems be removed in patients undergoing surgery for IE?

Complete removal of pacemaker or defibrillator systems, including all leads and the generator, is indicated as part of the early management plan in patients with $\mathrm{IE}$ and likely infection of the device or leads

Complete removal of pacemaker or defibrillator systems, including all leads and the generator, is reasonable in patients with right- or left-sided valvular IE caused by $S$. aureus or fungi, even without evidence of device or lead infection

Complete removal of pacemaker or defibrillator systems, including all leads and the generator, is reasonable in patients undergoing surgery for valvular IE caused by any organism

4. Should patients with a known indication for a pacemaker receive a pacemaker system with epicardial leads when undergoing operation for active IE?

At the time of surgery for IE, implantation of a new pacemaker system with epicardial leads may be considered when the patient is pacer dependent and has effective antimicrobial coverage

5. Are there any safety concerns regarding use of mechanical valves in patients with IE?

Mechanical valves should be avoided in patients with IE and evidence of intracranial bleeding or large brain infarcts, and in patients who are very sick and anticipated to have a prolonged postoperative course

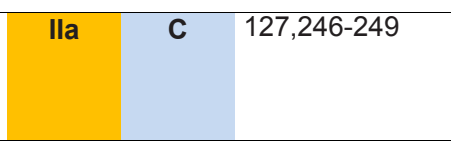

6. Is there any role for local antimicrobials or antiseptics during surgery for IE?

After completed debridement, generous irrigation of the surgical field with normal saline is recommended

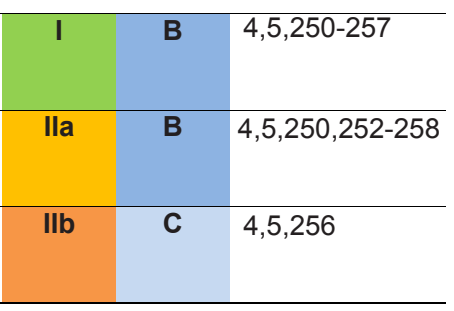

7. How should infected areas be drained?

Whenever feasible, leaving infected areas open to the circulation or the pericardium is optimal from the standpoint of treating the infection

\section{How should operative specimens be handled?}

Operative specimens should be secured for examination by the pathologist to determine presence of organisms and inflammatory activity

Operative specimens should be used for microbiologic and molecular testing to identify or confirm the pathogens and their sensitivity to antimicrobial therapy

9. What is the role of molecular testing with PCR in identifying pathogens?

Whenever there is clinical suspicion of IE and doubt about the causative organism, molecular testing can be useful to identify and confirm the pathogens or causative organisms in the operative specimens

10. What postoperative antimicrobial treatment is required, and for how long should the patient be treated?

When perioperative cultures and organism sensitivity are known, the antimicrobial regimen and duration of treatment are reconsidered and decided upon

After surgery for active IE, standard duration of postoperative intravenous antimicrobial treatment is 6 weeks, counted from the day of surgery, but regimen and duration may be modified and adjusted depending on the organism and its sensitivity to antimicrobials, treatment response, and pathology For fungal IE, lifelong oral suppressive therapy is reasonable

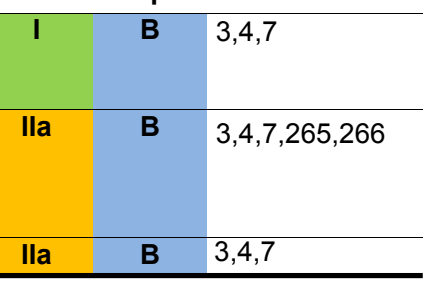

sification of recommendations; $L O E$, level of evidence; $I E$, infective endocarditis; $P C R$, polymerase chain reaction. 
TABLE 7. Surveillance and special considerations for patients with IE

\begin{tabular}{|c|c|c|c|}
\hline Recommendations & COR & LOE & References \\
\hline \multicolumn{4}{|c|}{$\begin{array}{l}\text { 1. What is the need for follow-up and additional screening for infectious foci that could cause } \\
\text { recurrent infection/IE? }\end{array}$} \\
\hline $\begin{array}{l}\text { Primary infectious focus and microorganism portal of entry must be treated } \\
\text { during or just after the IE episode, including follow-up and screening for } \\
\text { underlying infectious foci and morbidities }\end{array}$ & $\mathbf{I}$ & B & $3,4,7$ \\
\hline $\begin{array}{l}\text { IE caused by Streptococcus gallolyticus is an indication for colonoscopy within a } \\
\text { reasonable time after operation }\end{array}$ & I & B & $3,4,71,72,267-270$ \\
\hline Patients with a history of injection drug use should be treated for their addiction & $\mathbf{I}$ & B & $3,4,57,242$ \\
\hline $\begin{array}{l}\text { After surgery for IE, eradication of the pathogen is essential and should be } \\
\text { verified by follow-up for } 6 \text { months with an infectious disease specialist }\end{array}$ & I & $\mathbf{C}$ & 3 \\
\hline $\begin{array}{l}\text { After valve surgery for IE, cure of the infection should be documented by } \\
\text { echocardiogram, and the patient should follow up with a cardiologist }\end{array}$ & $\mathbf{I}$ & $\mathbf{C}$ & 3 \\
\hline \multicolumn{4}{|l|}{ 2. What is the risk of relapse and recurrent IE? } \\
\hline $\begin{array}{l}\text { Patients who have undergone surgery for IE should be informed about the } \\
\text { increased risk of recurrent IE and the need for prophylaxis }\end{array}$ & I & B & $3,179,200,271-277$ \\
\hline \multicolumn{4}{|l|}{ 3. Should surgical treatment be offered to injection drug users with IE? } \\
\hline $\begin{array}{l}\text { Normal indications for surgery are reasonable to apply to patients who are } \\
\text { intravenous drug users. Decision-making must take the addiction into account, } \\
\text { and management must include treatment of the addiction }\end{array}$ & Ila & C & $\begin{array}{l}3,4,7,57,201,238 \\
242,278\end{array}$ \\
\hline \multicolumn{4}{|l|}{ 4. Should surgical treatment be offered to patients with IE on dialysis? } \\
\hline $\begin{array}{l}\text { Normal indications for surgery are also reasonable to apply to patients on } \\
\text { dialysis, but their additional comorbidity must be factored into their risk and } \\
\text { outcome assessment }\end{array}$ & Illa & C & $279-285$ \\
\hline $\begin{array}{l}\text { Patients with renal failure have shorter durability of bioprostheses and allografts } \\
\text { because of early calcification, and this may be considered in the choice of an } \\
\text { allograft or a bioprosthesis versus a mechanical valve }\end{array}$ & Illa & B & 280,281 \\
\hline \multicolumn{4}{|l|}{ 5. Should surgical treatment be offered to patients with IE and liver cirrhosis? } \\
\hline $\begin{array}{l}\text { Normal indications for surgery are reasonable to apply to patients with liver } \\
\text { cirrhosis, but their additional comorbidity must be factored into their risk and } \\
\text { outcome assessment }\end{array}$ & Ila & C & $87,286,287$ \\
\hline \multicolumn{4}{|l|}{ 6. Who should get antibiotic prophylaxis for IE? } \\
\hline $\begin{array}{l}\text { Patients who have undergone surgery for IE constitute a high-risk group for } \\
\text { recurrent IE and should be recommended for IE prophylaxis according to } \\
\text { guidelines }\end{array}$ & IIlb & B & $3-5,88,288$ \\
\hline \multicolumn{4}{|l|}{ 7. How should patients with remote IE be managed? } \\
\hline $\begin{array}{l}\text { Normal indications for valve repair or replacement apply to patients with healed } \\
\text { or remote IE, but conditions predisposing for IE should be diagnosed and } \\
\text { treated }\end{array}$ & I & C & \\
\hline
\end{tabular}

COR, Classification of recommendations; $L O E$, level of evidence; $I E$, infective endocarditis.

\section{Who Should Get Antibiotic Prophylaxis for IE? \\ (Table 7-6)}

Current guidelines recommend restricting prophylaxis to the patients at greatest risk (those with the greatest risk of IE or adverse outcomes from IE): those with prosthetic valves, previous IE, cyanotic congenital heart disease, or congenital heart disease repaired with prosthetic material. ${ }^{3,4}$ Antibiotic prophylaxis is not recommended for other forms of valvular or congenital heart disease. As per guidelines from the American Heart Association, evidence for dental prophylaxis has been found to be reasonable only for procedures involving manipulation of gingival tissue or the periapical region of the teeth, or perforation of the oral mucosa ${ }^{3}$; guidelines from the National Institute for Health and Care Excellence do not recommend prophylaxis for either dental or nondental procedures. ${ }^{88}$

\section{How Should Patients With Remote IE Be Managed?}

(Table 7-7)

Patients with valvular disease and a history of endocarditis or healed IE should be treated on the merits of their functional deficit. Possible sources of bacteria should be searched for and sanitized. No study devoted to remote IE was identified.

\section{Conflict of Interest Statement}

Authors have nothing to disclose with regard to commercial support. 


\section{References}

1. Svensson LG, Gillinov AM, Weisel RD, Keshavjee S, Bacha EA, Moon MR, et al. The American Association for Thoracic Surgery Consensus Guidelines: reasons and purpose. J Thorac Cardiovasc Surg. 2016;151:935-9.e1.

2. Institute of Medicine. Clinical Practice Guidelines We Can Trust. Washington, DC: National Academies Press; 2011.

3. Baddour LM, Wilson WR, Bayer AS, Fowler VG Jr, Tleyjeh IM, Rybak MJ, et al. Infective endocarditis in adults: diagnosis, antimicrobial therapy, and management of complications: a scientific statement for healthcare professionals from the American Heart Association. Circulation. 2015;132: 1435-86.

4. Habib G, Lancellotti P, Antunes MJ, Bongiorni MG, Casalta JP, Del Zotti F, et al. 2015 ESC guidelines for the management of infective endocarditis: The Task Force for the Management of Infective Endocarditis of the European Society of Cardiology (ESC). Endorsed by: European Association for CardioThoracic Surgery (EACTS), the European Association of Nuclear Medicine (EANM). Eur Heart J. 2015;36:3075-128.

5. Nishimura RA, Otto CM, Bonow RO, Carabello BA, Erwin JP III, Guyton RA et al. 2014 AHA/ACC Guideline for the Management of Patients With Valvular Heart Disease: executive summary: a report of the American College of Cardiology/American Heart Association Task Force on Practice Guidelines. Circulation. 2014;129:2440-92

6. Byrne JG, Rezai K, Sanchez JA, Bernstein RA, Okum E, Leacche M, et al. Surgical management of endocarditis: the society of thoracic surgeons clinical practice guideline. Ann Thorac Surg. 2011:91:2012-9.

7. Gould FK, Denning DW, Elliott TS, Foweraker J, Perry JD, Prendergast BD, et al. Guidelines for the diagnosis and antibiotic treatment of endocarditis in adults: a report of the Working Party of the British Society for Antimicrobial Chemotherapy. J Antimicrob Chemother. 2012;67:269-89.

8. Svensson LG, Adams DH, Bonow RO, Kouchoukos NT, Miller DC, O'Gara PT, et al. Aortic valve and ascending aorta guidelines for management and quality measures. Ann Thorac Surg. 2013;95:S1-66.

9. Chirouze C, Alla F, Fowler VG Jr, Sexton DJ, Corey GR, Chu VH, et al. Impact of early valve surgery on outcome of Staphylococcus aureus prosthetic valve infective endocarditis: analysis in the International Collaboration of Endocarditis-Prospective Cohort Study. Clin Infect Dis. 2015;60:741-9.

10. Galvez-Acebal J, Almendro-Delia M, Ruiz J, de Alarcon A, MartinezMarcos FJ, Reguera JM, et al. Influence of early surgical treatment on the prognosis of left-sided infective endocarditis: a multicenter cohort study. Mayo Clin Proc. 2014:89:1397-405.

11. Lalani T, Chu VH, Park LP, Cecchi E, Corey GR, Durante-Mangoni E, et al. Inhospital and 1-year mortality in patients undergoing early surgery for prosthetic valve endocarditis. JAMA Intern Med. 2013;173:1495-504.

12. Sy RW, Kritharides L. Health care exposure and age in infective endocarditis: results of a contemporary population-based profile of 1536 patients in Australia. Eur Heart J. 2010;31:1890-7.

13. Curlier E, Hoen B, Alla F, Selton-Suty C, Schubel L, Doco-Lecompte T, et al. Relationships between sex, early valve surgery and mortality in patients with left-sided infective endocarditis analysed in a population-based cohort study. Heart. 2014;100:1173-8.

14. Tleyjeh IM, Kashour T, Zimmerman V, Steckelberg JM, Wilson WR, Baddour LM. The role of valve surgery in infective endocarditis management: a systematic review of observational studies that included propensity score analysis. Am Heart J. 2008;156:901-9.

15. Tleyjeh IM, Ghomrawi HM, Steckelberg JM, Hoskin TL, Mirzoyev Z, Anavekar NS, et al. The impact of valve surgery on 6-month mortality in left-sided infective endocarditis. Circulation. 2007;115:1721-8.

16. Aksoy O, Sexton DJ, Wang A, Pappas PA, Kourany W, Chu V, et al. Early surgery in patients with infective endocarditis: a propensity score analysis. Clin Infect Dis. 2007;44:364-72.

17. Vikram HR, Buenconsejo J, Hasbun R, Quagliarello VJ. Impact of valve surgery on 6-month mortality in adults with complicated, left-sided native valve endocarditis: a propensity analysis. JAMA. 2003;290:3207-14.

18. Karchmer AW, Bayer AS. Editorial commentary: surgical therapy for Staphylococcus aureus prosthetic valve endocarditis: proceed with caution (Caveat Emptor). Clin Infect Dis. 2015;60:750-2.

19. Fernandez-Hidalgo N, Almirante B, Tornos P, Gonzalez-Alujas MT, Planes AM, Larrosa MN, et al. Prognosis of left-sided infective endocarditis in patients transferred to a tertiary-care hospital-prospective analysis of referral bias and influence of inadequate antimicrobial treatment. Clin Microbiol Infect. 2011;17:769-75.

20. Lalani T, Cabell CH, Benjamin DK, Lasca O, Naber C, Fowler VG Jr, et al. Analysis of the impact of early surgery on in-hospital mortality of native valve endocarditis: use of propensity score and instrumental variable methods to adjust for treatment-selection bias. Circulation. 2010;121:1005-13.

21. Sy RW, Bannon PG, Bayfield MS, Brown C, Kritharides L. Survivor treatment selection bias and outcomes research: a case study of surgery in infective endocarditis. Circ Cardiovasc Qual Outcomes. 2009;2:469-74.

22. Kanafani ZA, Kanj SS, Cabell CH, Cecchi E, de Oliveira Ramos A, LejkoZupanc T, et al. Revisiting the effect of referral bias on the clinical spectrum of infective endocarditis in adults. Eur J Clin Microbiol Infect Dis. 2010;29:1203-10.

23. Steckelberg JM, Melton LJ III, Ilstrup DM, Rouse MS, Wilson WR. Influence of referral bias on the apparent clinical spectrum of infective endocarditis. Am J Med. 1990;88:582-8.

24. Tleyjeh IM, Ghomrawi HM, Steckelberg JM, Montori VM, Hoskin TL, Enders F, et al. Conclusion about the association between valve surgery and mortality in an infective endocarditis cohort changed after adjusting for survivor bias. J Clin Epidemiol. 2010;63:130-5.

25. Kouchoukos NT, Blackstone EH, Hanley FL, Kirklin J. Cardiac Surgery. 4th ed. Philadelphia: Elsevier; 2012.

26. Austin PC, Platt RW. Survivor treatment bias, treatment selection bias, and propensity scores in observational research. J Clin Epidemiol. 2010;63:136-8.

27. Blackstone EH. Comparing apples and oranges. J Thorac Cardiovasc Surg. 2002;123:8-15.

28. Robins JM, Hernan MA, Brumback B. Marginal structural models and causal inference in epidemiology. Epidemiology. 2000;11:550-60.

29. Conn HO, Snyder N, Atterbury CE. The Berkson bias in action. Yale J Biol Med. 1979;52:141-7.

30. Osler W. The Gulstonian lectures, on malignant endocarditis. Br Med J. 1885; 467-70.

31. Murdoch DR, Corey GR, Hoen B, Miro JM, Fowler VG Jr, Bayer AS, et al. Clinical presentation, etiology, and outcome of infective endocarditis in the 21st century: the International Collaboration on Endocarditis-Prospective Cohort Study. Arch Intern Med. 2009;169:463-73.

32. Hoen B, Duval X. Clinical practice. Infective endocarditis. N Engl J Med. 2013; 368:1425-33.

33. Bashore TM, Cabell C, Fowler V Jr. Update on infective endocarditis. Curr Probl Cardiol. 2006;31:274-352.

34. Gaca JG, Sheng S, Daneshmand MA, O'Brien S, Rankin JS, Brennan JM, et al. Outcomes for endocarditis surgery in North America: a simplified risk scoring system. J Thorac Cardiovasc Surg. 2011;141:98-106. e1-2.

35. Bouza E, Menasalvas A, Munoz P, Vasallo FJ, del Mar Moreno M, Garcia Fernandez MA. Infective endocarditis - a prospective study at the end of the twentieth century: new predisposing conditions, new etiologic agents, and still a high mortality. Medicine (Baltimore). 2001;80:298-307.

36. Hoen B, Alla F, Selton-Suty C, Beguinot I, Bouvet A, Briancon S, et al. Changing profile of infective endocarditis: results of a 1-year survey in France. JAMA 2002;288:75-81.

37. Moreillon P, Que YA. Infective endocarditis. Lancet. 2004;363:139-49.

38. Cabell CH, Jollis JG, Peterson GE, Corey GR, Anderson DJ, Sexton DJ, et al Changing patient characteristics and the effect on mortality in endocarditis Arch Intern Med. 2002;162:90-4.

39. Tleyjeh IM, Steckelberg JM, Murad HS, Anavekar NS, Ghomrawi HM, Mirzoyev Z, et al. Temporal trends in infective endocarditis: a populationbased study in Olmsted County, Minnesota. JAMA. 2005;293:3022-8.

40. Hill EE, Herijgers $\mathrm{P}$, Claus $\mathrm{P}$, Vanderschueren S, Herregods MC, Peetermans WE. Infective endocarditis: changing epidemiology and predictors of 6-month mortality: a prospective cohort study. Eur Heart J. 2007;28: 196-203.

41. Mylonakis E, Calderwood SB. Infective endocarditis in adults. $N$ Engl J Med. 2001:345:1318-30.

42. Cabell CH, Abrutyn E, Fowler VG Jr, Hoen B, Miro JM, Corey GR, et al. Use of surgery in patients with native valve infective endocarditis: results from the International Collaboration on Endocarditis Merged Database. Am Heart J. 2005; 150:1092-8.

43. Hussain ST, Shrestha NK, Gordon SM, Houghtaling PL, Blackstone EH, Pettersson GB. Residual patient, anatomic, and surgical obstacles in treating active left-sided infective endocarditis. J Thorac Cardiovasc Surg. 2014;148:981-8.e4. 
44. David TE, Gavra G, Feindel CM, Regesta T, Armstrong S, Maganti MD. Surgical treatment of active infective endocarditis: a continued challenge. J Thorac Cardiovasc Surg. 2007;133:144-9.

45. Manne MB, Shrestha NK, Lytle BW, Nowicki ER, Blackstone E, Gordon SM, et al. Outcomes after surgical treatment of native and prosthetic valve infective endocarditis. Ann Thorac Surg. 2012;93:489-93.

46. Thuny F, Grisoli D, Collart F, Habib G, Raoult D. Management of infective endocarditis: challenges and perspectives. Lancet. 2012;379:965-75.

47. Kang DH, Kim YJ, Kim SH, Sun BJ, Kim DH, Yun SC, et al. Early surgery versus conventional treatment for infective endocarditis. N Engl J Med. 2012; 366:2466-73

48. Gordon SM, Pettersson GB. Native-valve infective endocarditis-when does it require surgery? N Engl J Med. 2012;366:2519-21.

49. Tleyjeh IM, Abdel-Latif A, Rahbi H, Scott CG, Bailey KR, Steckelberg JM, et al. A systematic review of population-based studies of infective endocarditis. Chest. 2007;132:1025-35.

50. Durack DT, Lukes AS, Bright DK. New criteria for diagnosis of infective endocarditis: utilization of specific echocardiographic findings. Duke Endocarditis Service. Am J Med. 1994;96:200-9.

51. Habib G, Derumeaux G, Avierinos JF, Casalta JP, Jamal F, Volot F, et al. Value and limitations of the Duke criteria for the diagnosis of infective endocarditis. J Am Coll Cardiol. 1999;33:2023-9.

52. Li JS, Sexton DJ, Mick N, Nettles R, Fowler VG Jr, Ryan T, et al. Proposed modifications to the Duke criteria for the diagnosis of infective endocarditis. Clin Infect Dis. 2000;30:633-8.

53. Prendergast BD. Diagnostic criteria and problems in infective endocarditis. Heart. 2004;90:611-3.

54. Pettersson GB, Hussain ST, Shrestha NK, Gordon S, Fraser TG, Ibrahim KS, et al. Infective endocarditis: an atlas of disease progression for describing, staging, coding, and understanding the pathology. J Thorac Cardiovasc Surg. 2014;147:1142-9.e2.

55. Lopez J, Sevilla T, Vilacosta I, Sarria C, Revilla A, Ortiz C, et al. Prognostic role of persistent positive blood cultures after initiation of antibiotic therapy in leftsided infective endocarditis. Eur Heart J. 2013;34:1749-54.

56. Elgharably H, Hussain ST, Shrestha NK, Blackstone EH, Pettersson GB. Current hypotheses in cardiac surgery: biofilm in infective endocarditis. Semin Thorac Cardiovasc Surg. 2016;28:56-9.

57. Shrestha NK, Jue J, Hussain ST, Jerry JM, Pettersson GB, Menon V, et al. Injection drug use and outcomes after surgical intervention for infective endocarditis. Ann Thorac Surg. 2015;100:875-82.

58. Houpikian P, Raoult D. Blood culture-negative endocarditis in a reference center: etiologic diagnosis of 348 cases. Medicine (Baltimore). 2005;84:162-73.

59. Neugarten J, Baldwin DS. Glomerulonephritis in bacterial endocarditis. Am J Med. 1984;77:297-304.

60. Hussain ST, Blackstone EH, Pettersson GB. Successful allograft root rereplacement for prosthetic valve endocarditis with improvement of renal function in a Jehovah's Witness patient. J Thorac Cardiovasc Surg. 2014;148: e199-200.

61. Dickerman SA, Abrutyn E, Barsic B, Bouza E, Cecchi E, Moreno A, et al. The relationship between the initiation of antimicrobial therapy and the incidence of stroke in infective endocarditis: an analysis from the ICE Prospective Cohort Study (ICE-PCS). Am Heart J. 2007;154:1086-94.

62. Hubert S, Thuny F, Resseguier N, Giorgi R, Tribouilloy C, Le Dolley Y, et al. Prediction of symptomatic embolism in infective endocarditis: construction and validation of a risk calculator in a multicenter cohort. J Am Coll Cardiol. 2013; 62:1384-92.

63. Thuny F, Di Salvo G, Belliard O, Avierinos JF, Pergola V, Rosenberg V, et al. Risk of embolism and death in infective endocarditis: prognostic value of echocardiography: a prospective multicenter study. Circulation. 2005;112: 69-75.

64. Di Salvo G, Habib G, Pergola V, Avierinos JF, Philip E, Casalta JP, et al. Echocardiography predicts embolic events in infective endocarditis. J Am Coll Cardiol. 2001;37:1069-76.

65. Leitman M, Dreznik Y, Tyomkin V, Fuchs T, Krakover R, Vered Z. Vegetation size in patients with infective endocarditis. Eur Heart J Cardiovasc Imaging. 2012;13:330-8.

66. Hess A, Klein I, Iung B, Lavallee P, Ilic-Habensus E, Dornic Q, et al. Brain MRI findings in neurologically asymptomatic patients with infective endocarditis. AJNR Am J Neuroradiol. 2013:34:1579-84.

67. Cooper HA, Thompson EC, Laureno R, Fuisz A, Mark AS, Lin M, et al. Subclinical brain embolization in left-sided infective endocarditis: results from the evaluation by MRI of the brains of patients with left-sided intra- cardiac solid masses (EMBOLISM) pilot study. Circulation. 2009;120: 585-91.

68. Duval X, Iung B, Klein I, Brochet E, Thabut G, Arnoult F, et al. Effect of early cerebral magnetic resonance imaging on clinical decisions in infective endocarditis: a prospective study. Ann Intern Med. 2010;152:497-504, W175.

69. Barsic B, Dickerman S, Krajinovic V, Pappas P, Altclas J, Carosi G, et al. Influence of the timing of cardiac surgery on the outcome of patients with infective endocarditis and stroke. Clin Infect Dis. 2013;56:209-17.

70. Patel FM, Das A, Banerjee AK. Neuropathological complications of infective endocarditis : study of autopsy material. Neurol India. 2001;49:41-6.

71. Leport C, Bure A, Leport J, Vilde JL. Incidence of colonic lesions in Streptococcus bovis and enterococcal endocarditis. Lancet. 1987;1:748.

72. Reynolds JG, Silva E, McCormack WM. Association of Streptococcus bovis bacteremia with bowel disease. J Clin Microbiol. 1983;17:696-7.

73. Murray HW, Roberts RB. Streptococcus bovis bacteremia and underlying gastrointestinal disease. Arch Intern Med. 1978;138:1097-9.

74. Desch S, Freund A, de Waha S, Eitel I, Lurz P, Stiermaier T, et al. Outcome in patients with left-sided native-valve infective endocarditis and isolated large vegetations. Clin Cardiol. 2014;37:626-33.

75. Orvin K, Goldberg E, Bernstine H, Groshar D, Sagie A, Kornowski R, et al. The role of FDG-PET/CT imaging in early detection of extra-cardiac complications of infective endocarditis. Clin Microbiol Infect. 2015;21:69-76.

76. Pigrau C, Almirante B, Flores X, Falco V, Rodriguez D, Gasser I, et al. Spontaneous pyogenic vertebral osteomyelitis and endocarditis: incidence, risk factors, and outcome. Am J Med. 2005;118:1287.

77. Mekontso Dessap A, Zahar JR, Voiriot G, Ali F, Aissa N, Kirsch M, et al. Influence of preoperative antibiotherapy on valve culture results and outcome of endocarditis requiring surgery. $J$ Infect. 2009;59:42-8.

78. De Feo M, Cotrufo M, Carozza A, De Santo LS, Amendolara F, Giordano $\mathrm{S}$, et al. The need for a specific risk prediction system in native valve infective endocarditis surgery. ScientificWorldJournal. 2012;2012: 307571.

79. Wang TK, Oh T, Voss J, Gamble G, Kang N, Pemberton J. Comparison of contemporary risk scores for predicting outcomes after surgery for active infective endocarditis. Heart Vessels. 2015;30:227-34.

80. Cheitlin MD, Armstrong WF, Aurigemma GP, Beller GA, Bierman FZ, Davis JL, et al. ACC/AHA/ASE 2003 Guideline Update for the Clinical Application of Echocardiography: summary article. A report of the American College of Cardiology/American Heart Association Task Force on Practice Guidelines (ACC/AHA/ASE Committee to Update the 1997 Guidelines for the Clinical Application of Echocardiography). J Am Soc Echocardiogr. 2003;16:1091-110.

81. Jassar AS, Bavaria JE, Szeto WY, Moeller PJ, Maniaci J, Milewski RK, et al Graft selection for aortic root replacement in complex active endocarditis: does it matter? Ann Thorac Surg. 2012;93:480-7.

82. Kim JB, Ejiofor JI, Yammine M, Camuso JM, Walsh CW, Ando M, et al. Are homografts superior to conventional prosthetic valves in the setting of infective endocarditis involving the aortic valve? J Thorac Cardiovasc Surg. 2016;151: 1239-48.

83. Savage EB, Saha-Chaudhuri P, Asher CR, Brennan JM, Gammie JS. Outcomes and prosthesis choice for active aortic valve infective endocarditis: analysis of the Society of Thoracic Surgeons Adult Cardiac Surgery Database. Ann Thorac Surg. 2014;98:806-14.

84. Kirklin JK. Challenging homografts as the holy grail for aortic valve endocarditis. J Thorac Cardiovasc Surg. 2016;151:1230-1.

85. Sabik JF, Lytle BW, Blackstone EH, Marullo AG, Pettersson GB Cosgrove DM. Aortic root replacement with cryopreserved allograft for prosthetic valve endocarditis. Ann Thorac Surg. 2002;74:650-9; discussion 9 .

86. Von Reyn CF, Levy BS, Arbeit RD, Friedland G, Crumpacker CS. Infective endocarditis: an analysis based on strict case definitions. Ann Intern Med. 1981; 94:505-18.

87. Ruiz-Morales J, Ivanova-Georgieva R, Fernandez-Hidalgo N, GarciaCabrera E, Miro JM, Munoz P, et al. Left-sided infective endocarditis in patients with liver cirrhosis. J Infect. 2015;71:627-41.

88. National Institute for Health and Care Excellence. Prophylaxis against infective endocarditis: antimicrobial prophylaxis against infective endocarditis in adults and children undergoing interventional procedures (CG64). National Institute for Health and Care Excellence; 2008. Available at: http://www.nice.org.uk/ guidance/CG64. 
89. Botelho-Nevers E, Thuny F, Casalta JP, Richet H, Gouriet F, Collart F, et al. Dramatic reduction in infective endocarditis-related mortality with a management-based approach. Arch Intern Med. 2009;169:1290-8.

90. Habib G, Badano L, Tribouilloy C, Vilacosta I, Zamorano JL, Galderisi M, et al Recommendations for the practice of echocardiography in infective endocarditis. Eur J Echocardiogr. 2010;11:202-19.

91. Mugge A, Daniel WG, Frank G, Lichtlen PR. Echocardiography in infective en docarditis: reassessment of prognostic implications of vegetation size deter mined by the transthoracic and the transesophageal approach. J Am Coll Cardiol. 1989; 14:631-8.

92. Reynolds HR, Jagen MA, Tunick PA, Kronzon I. Sensitivity of transthoracic versus transesophageal echocardiography for the detection of native valve vegetations in the modern era. J Am Soc Echocardiogr. 2003;16:67-70.

93. Ronderos RE, Portis M, Stoermann W, Sarmiento C. Are all echocardiographic findings equally predictive for diagnosis in prosthetic endocarditis? J Am Soc Echocardiogr. 2004;17:664-9.

94. Tanis W, Teske AJ, van Herwerden LA, Chamuleau S, Meijboom F, Budde RP, et al. The additional value of three-dimensional transesophageal echocardiography in complex aortic prosthetic heart valve endocarditis. Echocardiography. 2015;32:114-25.

95. Bruun NE, Habib G, Thuny F, Sogaard P. Cardiac imaging in infectious endocarditis. Eur Heart J. 2014;35:624-32.

96. San Roman JA, Vilacosta I, Lopez J, Revilla A, Arnold R, Sevilla T, et al. Role of transthoracic and transesophageal echocardiography in right-sided endocarditis: one echocardiographic modality does not fit all. J Am Soc Echocardiogr. 2012;25:807-14.

97. Shapira Y, Weisenberg DE, Vaturi M, Sharoni E, Raanani E, Sahar G, et al. The impact of intraoperative transesophageal echocardiography in infective endocarditis. Isr Med Assoc J. 2007;9:299-302.

98. Knudsen JB, Fuursted K, Petersen E, Wierup P, Molgaard H, Poulsen SH, et al Failure of clinical features of low probability endocarditis. The early echo remains essential. Scand Cardiovasc J. 2011;45:133-8.

99. Feuchtner GM, Stolzmann P, Dichtl W, Schertler T, Bonatti J, Scheffel H, et al. Multislice computed tomography in infective endocarditis: comparison with transesophageal echocardiography and intraoperative findings. J Am Coll Cardiol. 2009;53:436-44.

100. Fagman E, Perrotta S, Bech-Hanssen O, Flinck A, Lamm C, Olaison L, et al. ECG-gated computed tomography: a new role for patients with suspected aortic prosthetic valve endocarditis. Eur Radiol. 2012;22:2407-14.

101. Saby L, Laas O, Habib G, Cammilleri S, Mancini J, Tessonnier L, et al. Positron emission tomography/computed tomography for diagnosis of prosthetic valve endocarditis: increased valvular 18F-fluorodeoxyglucose uptake as a novel major criterion. J Am Coll Cardiol. 2013;61:2374-82.

102. Pizzi MN, Roque A, Fernandez-Hidalgo N, Cuellar-Calabria H, FerreiraGonzalez I, Gonzalez-Alujas MT, et al. Improving the diagnosis of infective endocarditis in prosthetic valves and intracardiac devices With $18 \mathrm{~F}$-fluordeoxyglucose positron emission tomography/computed tomography angiography: initial results at an infective endocarditis referral center. Circulation. 2015; 132:1113-26.

103. Lancellotti P, Habib G, Oury C, Nchimi A. Positron emission tomography/ computed tomography imaging in device infective endocarditis: ready for prime time. Circulation. 2015;132:1076-80.

104. Jault F, Gandjbakhch I, Rama A, Nectoux M, Bors V, Vaissier E, et al. Active native valve endocarditis: determinants of operative death and late mortality. Ann Thorac Surg. 1997;63:1737-41.

105. Nagpal A, Sohail M, Steckelberg JM. Prosthetic valve endocarditis: state of the heart. Clin Invest. 2012;2:803-17.

106. Wang A, Athan E, Pappas PA, Fowler VG Jr, Olaison L, Pare C, et al. Contemporary clinical profile and outcome of prosthetic valve endocarditis. JAMA 2007:297:1354-61.

107. Hasbun R, Vikram HR, Barakat LA, Buenconsejo J, Quagliarello VJ. Complicated left-sided native valve endocarditis in adults: risk classification for mortality. JAMA. 2003;289:1933-40.

108. Funakoshi S, Kaji S, Yamamuro A, Tani T, Kinoshita M, Okada Y, et al. Impact of early surgery in the active phase on long-term outcomes in left-sided native valve infective endocarditis. J Thorac Cardiovasc Surg. 2011;142:836-42.e1.

109. Musci M, Siniawski H, Pasic M, Weng Y, Loforte A, Kosky S, et al. Surgical therapy in patients with active infective endocarditis: seven-year single centre experience in a subgroup of 255 patients treated with the Shelhigh stentless bioprosthesis. Eur J Cardiothorac Surg. 2008;34:410-7.
110. Prendergast BD, Tornos P. Surgery for infective endocarditis: who and when? Circulation. 2010;121:1141-52.

111. Bedeir K, Reardon M, Ramlawi B. Infective endocarditis: perioperative management and surgical principles. J Thorac Cardiovasc Surg. 2014;147:1133-41.

112. Olaison L, Pettersson G. Current best practices and guidelines indications for surgical intervention in infective endocarditis. Infect Dis Clin North Am. 2002; 16:453-75, xi.

113. Kiefer T, Park L, Tribouilloy C, Cortes C, Casillo R, Chu V, et al. Association between valvular surgery and mortality among patients with infective endocarditis complicated by heart failure. JAMA. 2011;306:2239-47.

114. Yu VL, Fang GD, Keys TF, Harris AA, Gentry LO, Fuchs PC, et al. Prosthetic valve endocarditis: superiority of surgical valve replacement versus medical therapy only. Ann Thorac Surg. 1994;58:1073-7.

115. Miro JM, Anguera I, Cabell CH, Chen AY, Stafford JA, Corey GR, et al. Staphylococcus aureus native valve infective endocarditis: report of 566 episodes from the International Collaboration on Endocarditis Merged Database. Clin Infect Dis. 2005;41:507-14.

116. Remadi JP, Habib G, Nadji G, Brahim A, Thuny F, Casalta JP, et al. Predictors of death and impact of surgery in Staphylococcus aureus infective endocarditis Ann Thorac Surg. 2007;83:1295-302.

117. Sohail MR, Martin KR, Wilson WR, Baddour LM, Harmsen WS, Steckelberg JM. Medical versus surgical management of Staphylococcus aureus prosthetic valve endocarditis. Am J Med. 2006;119:147-54.

118. Chirouze C, Cabell CH, Fowler VG Jr, Khayat N, Olaison L, Miro JM, et al. Prognostic factors in 61 cases of Staphylococcus aureus prosthetic valve infective endocarditis from the International Collaboration on Endocarditis merged database. Clin Infect Dis. 2004;38:1323-7.

119. Attaran S, Chukwuemeka A, Punjabi PP, Anderson J. Do all patients with prosthetic valve endocarditis need surgery? Interact Cardiovasc Thorac Surg. 2012; 15:1057-61.

120. Wolff M, Witchitz S, Chastang C, Regnier B, Vachon F. Prosthetic valve endocarditis in the ICU. Prognostic factors of overall survival in a series of 122 cases and consequences for treatment decision. Chest. 1995;108:688-94.

121. Melgar GR, Nasser RM, Gordon SM, Lytle BW, Keys TF, Longworth DL. Fungal prosthetic valve endocarditis in 16 patients. An 11-year experience in a tertiary care hospital. Medicine (Baltimore). 1997;76:94-103.

122. Habib G, Avierinos JF, Thuny F. Aortic valve endocarditis: is there an optimal surgical timing? Curr Opin Cardiol. 2007;22:77-83.

123. Spiliopoulos K, Haschemi A, Fink G, Kemkes BM. Infective endocarditis complicated by paravalvular abscess: a surgical challenge. An 11-year single center experience. Heart Surg Forum. 2010;13:E67-73.

124. David TE, Regesta T, Gavra G, Armstrong S, Maganti MD. Surgical treatment of paravalvular abscess: long-term results. Eur J Cardiothorac Surg. 2007;31: 43-8.

125. Thuny F, Beurtheret S, Mancini J, Gariboldi V, Casalta JP, Riberi A, et al. The timing of surgery influences mortality and morbidity in adults with severe complicated infective endocarditis: a propensity analysis. Eur Heart J. 2011; 32:2027-33

126. Yankah AC, Pasic M, Klose H, Siniawski H, Weng Y, Hetzer R. Homograft reconstruction of the aortic root for endocarditis with periannular abscess: a 17-year study. Eur J Cardiothorac Surg. 2005;28:69-75.

127. Lytle BW, Sabik JF, Blackstone EH, Svensson LG, Pettersson GB, Cosgrove DM 3rd. Reoperative cryopreserved root and ascending aorta replace ment for acute aortic prosthetic valve endocarditis. Ann Thorac Surg. 2002;74 S1754-7; discussion S92-9.

128. d'Udekem Y, David TE, Feindel CM, Armstrong S, Sun Z. Long-term results of operation for paravalvular abscess. Ann Thorac Surg. 1996;62:48-53.

129. Alonso-Valle H, Farinas-Alvarez C, Garcia-Palomo JD, Bernal JM, MartinDuran R, Gutierrez Diez JF, et al. Clinical course and predictors of death in prosthetic valve endocarditis over a 20-year period. J Thorac Cardiovasc Surg. 2010;139:887-93.

130. Hill EE, Herijgers P, Claus P, Vanderschueren S, Peetermans WE, Herregods MC. Abscess in infective endocarditis: the value of transesophageal echocardiography and outcome: a 5-year study. Am Heart J. 2007;154: 923-8.

131. Rohmann S, Erbel R, Darius H, Gorge G, Makowski T, Zotz R, et al. Prediction of rapid versus prolonged healing of infective endocarditis by monitoring vegetation size. J Am Soc Echocardiogr. 1991;4:465-74.

132. Habib G. Embolic risk in subacute bacterial endocarditis: determinants and role of transesophageal echocardiography. Curr Infect Dis Rep. 2005;7:264-71. 
133. Vilacosta I, Graupner C, San Roman JA, Sarria C, Ronderos R, Fernandez C, et al. Risk of embolization after institution of antibiotic therapy for infective endocarditis. J Am Coll Cardiol. 2002;39:1489-95.

134. Okonta KE, Adamu YB. What size of vegetation is an indication for surgery in endocarditis? Interact Cardiovasc Thorac Surg. 2012;15:1052-6.

135. Sanfilippo AJ, Picard MH, Newell JB, Rosas E, Davidoff R, Thomas JD, et al. Echocardiographic assessment of patients with infectious endocarditis: prediction of risk for complications. J Am Coll Cardiol. 1991;18: 1191-9.

136. Musci M, Siniawski H, Pasic M, Grauhan O, Weng Y, Meyer R, et al. Surgical treatment of right-sided active infective endocarditis with or without involvement of the left heart: 20-year single center experience. Eur J Cardiothorac Surg. 2007;32:118-25.

137. Thuny F, Avierinos JF, Tribouilloy C, Giorgi R, Casalta JP, Milandre L, et al. Impact of cerebrovascular complications on mortality and neurologic outcome during infective endocarditis: a prospective multicentre study. Eur Heart J. 2007;28:1155-61.

138. Garcia-Cabrera E, Fernandez-Hidalgo N, Almirante B, Ivanova-Georgieva R, Noureddine M, Plata A, et al. Neurological complications of infective endocarditis: risk factors, outcome, and impact of cardiac surgery: a multicenter observational study. Circulation. 2013;127:2272-84.

139. Thuny F, Habib G. When should we operate on patients with acute infective endocarditis? Heart. 2010;96:892-7.

140. Angstwurm K, Borges AC, Halle E, Schielke E, Einhaupl KM, Weber JR. Timing the valve replacement in infective endocarditis involving the brain. $J$ Neurol. 2004;251:1220-6.

141. Eishi K, Kawazoe K, Kuriyama Y, Kitoh Y, Kawashima Y, Omae T. Surgical management of infective endocarditis associated with cerebral complications. Multi-center retrospective study in Japan. J Thorac Cardiovasc Surg. 1995; 110:1745-55.

142. Gillinov AM, Shah RV, Curtis WE, Stuart RS, Cameron DE, Baumgartner WA, et al. Valve replacement in patients with endocarditis and acute neurologic deficit. Ann Thorac Surg. 1996;61:1125-9; discussion 30.

143. Ting W, Silverman N, Levitsky S. Valve replacement in patients with endocarditis and cerebral septic emboli. Ann Thorac Surg. 1991;51:18-21; discussion 2.

144. Kanter MC, Hart RG. Neurologic complications of infective endocarditis. Neurology. 1991;41:1015-20.

145. Piper C, Wiemer M, Schulte HD, Horstkotte D. Stroke is not a contraindication for urgent valve replacement in acute infective endocarditis. J Heart Valve Dis. 2001;10:703-11.

146. Ruttmann E, Willeit J, Ulmer H, Chevtchik O, Hofer D, Poewe W, et al. Neurological outcome of septic cardioembolic stroke after infective endocarditis. Stroke. 2006;37:2094-9.

147. Chu VH, Park LP, Athan E, Delahaye F, Freiberger T, Lamas C, et al. Association between surgical indications, operative risk, and clinical outcome in infective endocarditis: a prospective study from the International Collaboration on Endocarditis. Circulation. 2015;131:131-40.

148. Ohara T, Nakatani S, Kokubo Y, Yamamoto H, Mitsutake K, Hanai S, et al. Clinical predictors of in-hospital death and early surgery for infective endocarditis: results of CArdiac Disease REgistration (CADRE), a nation-wide survey in Japan. Int J Cardiol. 2013;167:2688-94.

149. Gelsomino S, Maessen JG, van der Veen F, Livi U, Renzulli A, Luca F, et al. Emergency surgery for native mitral valve endocarditis: the impact of septic and cardiogenic shock. Ann Thorac Surg. 2012;93:1469-76.

150. Sonneville R, Mirabel M, Hajage D, Tubach F, Vignon P, Perez P, et al. Neurologic complications and outcomes of infective endocarditis in critically ill patients: the ENDOcardite en REAnimation prospective multicenter study. Crit Care Med. 2011;39:1474-81.

151. Bannay A, Hoen B, Duval X, Obadia JF, Selton-Suty C, Le Moing V, et al. The impact of valve surgery on short- and long-term mortality in left-sided infective endocarditis: do differences in methodological approaches explain previous conflicting results? Eur Heart J. 2011;32:2003-15.

152. Shang E, Forrest GN, Chizmar T, Chim J, Brown JM, Zhan M, et al. Mitral valve infective endocarditis: benefit of early operation and aggressive use of repair. Ann Thorac Surg. 2009;87:1728-33; discussion 34.

153. Heiro M, Nikoskelainen J, Engblom E, Kotilainen E, Marttila R, Kotilainen P. Neurologic manifestations of infective endocarditis: a 17-year experience in a teaching hospital in Finland. Arch Intern Med. 2000;160:2781-7.

154. Anderson DJ, Goldstein LB, Wilkinson WE, Corey GR, Cabell CH, Sanders LL, et al. Stroke location, characterization, severity, and outcome in mitral vs aortic valve endocarditis. Neurology. 2003;61:1341-6.
155. Hui FK, Bain M, Obuchowski NA, Gordon S, Spiotta AM, Moskowitz S, et al Mycotic aneurysm detection rates with cerebral angiography in patients with infective endocarditis. J Neurointerv Surg. 2015;7:449-52.

156. Sorabella RA, Han SM, Grbic M, Wu YS, Takyama H, Kurlansky P, et al. Early operation for endocarditis complicated by preoperative cerebral emboli is not associated with worsened outcomes. Ann Thorac Surg. 2015;100:501-8.

157. Okita Y, Minakata K, Yasuno S, Uozumi R, Sato T, Ueshima K, et al. Optima timing of surgery for active infective endocarditis with cerebral complications: a Japanese multicentre studydagger. Eur J Cardiothorac Surg. 2016; 50:374-82.

158. Yoshioka D, Toda K, Sakaguchi T, Okazaki S, Yamauchi T, Miyagawa S, et al Valve surgery in active endocarditis patients complicated by intracranial haemorrhage: the influence of the timing of surgery on neurological outcomes. Eur J Cardiothorac Surg. 2014;45:1082-8.

159. Masuda J, Yutani C, Waki R, Ogata J, Kuriyama Y, Yamaguchi T. Histopathological analysis of the mechanisms of intracranial hemorrhage complicating infective endocarditis. Stroke. 1992;23:843-50.

160. Morita K, Sasabuchi Y, Matsui H, Fushimi K, Yasunaga H. Outcomes after early or late timing of surgery for infective endocarditis with ischaemic stroke: a retrospective cohort study. Interact Cardiovasc Thorac Surg. 2015; 21:604-9.

161. Yoshioka D, Sakaguchi T, Yamauchi T, Okazaki S, Miyagawa S, Nishi H, et al Impact of early surgical treatment on postoperative neurologic outcome for active infective endocarditis complicated by cerebral infarction. Ann Thorac Surg. 2012;94:489-95; discussion 96

162. Misfeld M, Girrbach F, Etz CD, Binner C, Aspern KV, Dohmen PM, et al. Surgery for infective endocarditis complicated by cerebral embolism: a consecutive series of 375 patients. $J$ Thorac Cardiovasc Surg. 2014;147:1837-44.

163. Kamalakannan D, Muhammed B, Gardin J. Anticoagulation in infective endocarditis. A survey of infectious disease specialists and cardiologists. Infect Dis Clin Pract. 2005;13:122-6.

164. Goldstein JN, Greenberg SM. Should anticoagulation be resumed after intracerebral hemorrhage? Cleve Clin J Med. 2010;77:791-9.

165. Immediate anticoagulation of embolic stroke: brain hemorrhage and management options. Cerebral Embolism Study Group. Stroke. 1984;15:779-89.

166. Tunkel AR, Kaye D. Neurologic complications of infective endocarditis. Neurol Clin. 1993;11:419-40.

167. Ananthasubramaniam K, Beattie JN, Rosman HS, Jayam V, Borzak S. How safely and for how long can warfarin therapy be withheld in prosthetic heart valve patients hospitalized with a major hemorrhage? Chest. 2001;119:478-84.

168. Wilson WR, Geraci JE, Danielson GK, Thompson RL, Spittell JA Jr Washington JR 2nd, et al. Anticoagulant therapy and central nervous system complications in patients with prosthetic valve endocarditis. Circulation. 1978;57:1004-7.

169. Lieberman A, Hass WK, Pinto R, Isom WO, Kupersmith M, Bear G, et al. Intracranial hemorrhage and infarction in anticoagulated patients with prosthetic heart valves. Stroke. 1978;9:18-24.

170. Carpenter JL, McAllister CK. Anticoagulation in prosthetic valve endocarditis South Med J. 1983;76:1372-5.

171. Tornos P, Almirante B, Mirabet S, Permanyer G, Pahissa A, Soler-Soler J. Infective endocarditis due to Staphylococcus aureus: deleterious effect of anticoagulant therapy. Arch Intern Med. 1999;159:473-5.

172. Snygg-Martin U, Gustafsson L, Rosengren L, Alsio A, Ackerholm P Andersson R, et al. Cerebrovascular complications in patients with left-sided infective endocarditis are common: a prospective study using magnetic resonance imaging and neurochemical brain damage markers. Clin Infect Dis. 2008:47:23-30.

173. Rasmussen RV, Snygg-Martin U, Olaison L, Buchholtz K, Larsen CT, Hassager C, et al. Major cerebral events in Staphylococcus aureus infective endocarditis: is anticoagulant therapy safe? Cardiology. 2009;114:284-91.

174. Anavekar NS, Tleyjeh IM, Mirzoyev Z, Steckelberg JM, Haddad C, Khandaker $\mathrm{MH}$, et al. Impact of prior antiplatelet therapy on risk of embolism in infective endocarditis. Clin Infect Dis. 2007;44:1180-6.

175. Chan KL, Dumesnil JG, Cujec B, Sanfilippo AJ, Jue J, Turek MA, et al. A randomized trial of aspirin on the risk of embolic events in patients with infective endocarditis. J Am Coll Cardiol. 2003;42:775-80.

176. Chan KL, Tam J, Dumesnil JG, Cujec B, Sanfilippo AJ, Jue J, et al. Effect of long-term aspirin use on embolic events in infective endocarditis. Clin Infect Dis. 2008;46:37-41

177. Kung VW, Jarral OA, Shipolini AR, McCormack DJ. Is it safe to perform coronary angiography during acute endocarditis? Interact Cardiovasc Thorac Surg. 2011;13:158-67. 
178. Roselli EE, Pettersson GB, Blackstone EH, Brizzio ME, Houghtaling PL, Hauck R, et al. Adverse events during reoperative cardiac surgery: frequency, characterization, and rescue. J Thorac Cardiovasc Surg. 2008;135:316-23, e1-6.

179. Voldstedlund M, Fuursted K, Bruun NE, Arpi M. Comparison of heart valve culture between two Danish endocarditis centres. Scand J Infect Dis. 2012;44: 405-13.

180. Olaison L, Hogevik H, Myken P, Oden A, Alestig K. Early surgery in infective endocarditis. QJM. 1996;89:267-78.

181. Fayad G, Vincentelli A, Leroy G, Devos P, Amr G, Prat A, et al. Impact of antimicrobial therapy on prognosis of patients requiring valve surgery during active infective endocarditis. J Thorac Cardiovasc Surg. 2014;147: 254-8.

182. Pettersson GB, Martino D, Blackstone EH, Nowicki ER, Houghtaling PL, Sabik JF 3rd, et al. Advising complex patients who require complex heart operations. J Thorac Cardiovasc Surg. 2013;145:1159-69.e3.

183. Oxorn DC. Intraoperative echocardiography. Heart. 2008;94:1236-43.

184. Yao F, Han L, Xu ZY, Zou LJ, Huang SD, Wang ZN, et al. Surgical treatment of multivalvular endocarditis: twenty-one-year single center experience. J Thorac Cardiovasc Surg. 2009;137:1475-80.

185. Grimm RA, Stewart WJ. The role of intraoperative echocardiography in valve surgery. Cardiol Clin. 1998;16:477-89. ix.

186. Eltzschig HK, Rosenberger P, Loffler M, Fox JA, Aranki SF, Shernan SK. Impact of intraoperative transesophageal echocardiography on surgical deci sions in 12,566 patients undergoing cardiac surgery. Ann Thorac Surg. 2008 $85: 845-52$.

187. Silva F, Arruda R, Nobre A, Mendes M, Lemos A, Gallego J, et al. Impact of intraoperative transesophageal echocardiography in cardiac surgery: retrospective analysis of a series of 850 examinations. Rev Port Cardiol. 2010;29: 1363-82.

188. de Kerchove L, Vanoverschelde JL, Poncelet A, Glineur D, Rubay J, Zech F, et al. Reconstructive surgery in active mitral valve endocarditis: feasibility, safety and durability. Eur J Cardiothorac Surg. 2007;31:592-9.

189. Shimokawa T, Kasegawa H, Matsuyama S, Seki H, Manabe S, Fukui T, et al Long-term outcome of mitral valve repair for infective endocarditis. Ann Thorac Surg. 2009;88:733-9; discussion 9.

190. Doukas G, Oc M, Alexiou C, Sosnowski AW, Samani NJ, Spyt TJ. Mitral valve repair for active culture positive infective endocarditis. Heart. 2006;92:361-3.

191. Feringa HH, Shaw LJ, Poldermans D, Hoeks S, van der Wall EE, Dion RA, et al Mitral valve repair and replacement in endocarditis: a systematic review of literature. Ann Thorac Surg. 2007;83:564-70.

192. Ruttmann E, Legit C, Poelzl G, Mueller S, Chevtchik O, Cottogni M, et al Mitral valve repair provides improved outcome over replacement in active infective endocarditis. J Thorac Cardiovasc Surg. 2005;130:765-71.

193. Zegdi R, Debieche M, Latremouille C, Lebied D, Chardigny C, Grinda JM, et al Long-term results of mitral valve repair in active endocarditis. Circulation. 2005;111:2532-6.

194. Feringa HH, Bax JJ, Klein P, Klautz RJ, Braun J, van der Wall EE, et al. Outcome after mitral valve repair for acute and healed infective endocarditis. Eur J Cardiothorac Surg. 2006;29:367-73.

195. Iung B, Rousseau-Paziaud J, Cormier B, Garbarz E, Fondard O, Brochet E, et al . Contemporary results of mitral valve repair for infective endocarditis. J Am Coll Cardiol. 2004;43:386-92.

196. Muehrcke DD, Cosgrove DM 3rd, Lytle BW, Taylor PC, Burgar AM Durnwald $\mathrm{CP}$, et al. Is there an advantage to repairing infected mitral valves? Ann Thorac Surg. 1997:63:1718-24.

197. David TE. Aortic valve repair for active infective endocarditis. Eur J Cardiothorac Surg. 2012:42:127-8.

198. Mayer K, Aicher D, Feldner S, Kunihara T, Schafers HJ. Repair versus replacement of the aortic valve in active infective endocarditis. Eur J Cardiothorac Surg. 2012;42:122-7.

199. Moon MR, Miller DC, Moore KA, Oyer PE, Mitchell RS, Robbins RC, et al Treatment of endocarditis with valve replacement: the question of tissue versus mechanical prosthesis. Ann Thorac Surg. 2001;71:1164-71.

200. Haydock D, Barratt-Boyes B, Macedo T, Kirklin JW, Blackstone E. Aortic valve replacement for active infectious endocarditis in 108 patients. A comparison of freehand allograft valves with mechanical prostheses and bioprostheses. $J$ Thorac Cardiovasc Surg. 1992;103:130-9.

201. Kaiser SP, Melby SJ, Zierer A, Schuessler RB, Moon MR, Moazami N, et al Long-term outcomes in valve replacement surgery for infective endocarditis. Ann Thorac Surg. 2007:83:30-5.
202. Lytle BW, Priest BP, Taylor PC, Loop FD, Sapp SK, Stewart RW, et al. Surgical treatment of prosthetic valve endocarditis. J Thorac Cardiovasc Surg. 1996; 111:198-207; discussion 10.

203. Sheikh AM, Elhenawy AM, Maganti M, Armstrong S, David TE, Feindel CM. Outcomes of surgical intervention for isolated active mitral valve endocarditis. $J$ Thorac Cardiovasc Surg. 2009;137:110-6.

204. Grinda JM, Mainardi JL, D'Attellis N, Bricourt MO, Berrebi A, Fabiani JN, et al. Cryopreserved aortic viable homograft for active aortic endocarditis. Ann Thorac Surg. 2005;79:767-71.

205. El-Hamamsy I, Clark L, Stevens LM, Sarang Z, Melina G, Takkenberg JJ, et al. Late outcomes following freestyle versus homograft aortic root replacement: results from a prospective randomized trial. J Am Coll Cardiol. 2010; 55:368-76.

206. Musci M, Weng Y, Hubler M, Amiri A, Pasic M, Kosky S, et al. Homograft aortic root replacement in native or prosthetic active infective endocarditis: twenty-year single-center experience. J Thorac Cardiovasc Surg. 2010;139: 665-73.

207. Siniawski H, Lehmkuhl H, Weng Y, Pasic M, Yankah C, Hoffmann M, et al Stentless aortic valves as an alternative to homografts for valve replacemen in active infective endocarditis complicated by ring abscess. Ann Thorac Surg. 2003;75:803-8; discussion 8.

208. Perrotta S, Lentini S. In patients with severe active aortic valve endocarditis, is a stentless valve as good as the homograft? Interact Cardiovasc Thorac Surg. 2010;11:309-13.

209. McGiffin DC, Galbraith AJ, McLachlan GJ, Stower RE, Wong ML, Stafford EG, et al. Aortic valve infection. Risk factors for death and recurrent endocarditis after aortic valve replacement. J Thorac Cardiovasc Surg. 1992;104:511-20.

210. Avierinos JF, Thuny F, Chalvignac V, Giorgi R, Tafanelli L, Casalta JP, et al. Surgical treatment of active aortic endocarditis: homografts are not the cornerstone of outcome. Ann Thorac Surg. 2007;84:1935-42.

211. Mihaljevic T. Invited commentary. It would not be wise to completely abandon the use of homograft root replacement in particular in patients with pros thetic valve endocarditis and aortic root abscess. Ann Thorac Surg. 2007;84 1942.

212. Leyh RG, Knobloch K, Hagl C, Ruhparwar A, Fischer S, Kofidis T, et al Replacement of the aortic root for acute prosthetic valve endocarditis: prosthetic composite versus aortic allograft root replacement. J Thorac Cardiovasc Surg. 2004;127:1416-20.

213. Dearani JA, Orszulak TA, Schaff HV, Daly RC, Anderson BJ, Danielson GK. Results of allograft aortic valve replacement for complex endocarditis. J Thorac Cardiovasc Surg. 1997;113:285-91.

214. Moon MR. Prosthetic valve selection in patients with left-sided endocarditis: bioprosthetic or mechanical valves? Curr Opin Cardiol. 2014;29: 127-32.

215. Gross C, Klima U, Mair R, Brucke P. Aortic homografts versus mechanica valves in aortic valve replacement in young patients: a retrospective study Ann Thorac Surg. 1998;66:S194-7.

216. Gulbins H, Kilian E, Roth S, Uhlig A, Kreuzer E, Reichart B. Is there an advan tage in using homografts in patients with acute infective endocarditis of the aortic valve? J Heart Valve Dis. 2002;11:492-7.

217. Klieverik LM, Yacoub MH, Edwards S, Bekkers JA, Roos-Hesselink JW, Kappetein AP, et al. Surgical treatment of active native aortic valve endocarditis with allografts and mechanical prostheses. Ann Thorac Surg. 2009;88:1814-21.

218. Evans CF, Gammie JS. Surgical management of mitral valve infective endocarditis. Semin Thorac Cardiovasc Surg. 2011;23:232-40.

219. Sheikh AM, Elhenawy AM, Maganti M, Armstrong S, David TE, Feindel CM Outcomes of double valve surgery for active infective endocarditis. J Thorac Cardiovasc Surg. 2009;138:69-75.

220. Gillinov AM, Diaz R, Blackstone EH, Pettersson GB, Sabik JF, Lytle BW, et al Double valve endocarditis. Ann Thorac Surg. 2001;71:1874-9.

221. David TE. Surgical management of aortic root abscess. J Card Surg. 1997;12 262-6; discussion 6-9.

222. Siniawski H, Grauhan O, Hofmann M, Pasic M, Weng Y, Yankah C, et al. Aortic root abscess and secondary infective mitral valve disease: results of surgical endocarditis treatment. Eur J Cardiothorac Surg. 2005;27:434-40.

223. Pettersson GB, Hussain ST, Ramankutty RM, Lytle BW, Blackstone EH. Reconstruction of fibrous skeleton: technique, pitfalls and results. Multimed Man Cardiothorac Surg. 2014;2014.

224. Leontyev S, Borger MA, Modi P, Lehmann S, Seeburger J, Doenst T, et al. Surgical management of aortic root abscess: a 13-year experience in 172 patients with 100\% follow-up. J Thorac Cardiovasc Surg. 2012;143:332-7. 
225. De Oliveira NC, David TE, Armstrong S, Ivanov J. Aortic and mitral valve replacement with reconstruction of the intervalvular fibrous body: an analysis of clinical outcomes. J Thorac Cardiovasc Surg. 2005;129:286-90.

226. David TE, Kuo J, Armstrong S. Aortic and mitral valve replacement with reconstruction of the intervalvular fibrous body. J Thorac Cardiovasc Surg. 1997;114: 766-71; discussion 71-2.

227. Davierwala PM, Binner C, Subramanian S, Luehr M, Pfannmueller B, Etz C, et al. Double valve replacement and reconstruction of the intervalvular fibrous body in patients with active infective endocarditis. Eur J Cardiothorac Surg. 2014:45:146-52.

228. Kim SW, Park PW, Kim WS, Sung K, Lee YT, Jun TG, et al. Long-term results of aortomitral fibrous body reconstruction with double-valve replacement. Ann Thorac Surg. 2013;95:635-41.

229. Navia JL, Al-Ruzzeh S, Gordon S, Fraser T, Aguero O, Rodriguez L. The incorporated aortomitral homograft: a new surgical option for double valve endocarditis. J Thorac Cardiovasc Surg. 2010;139:1077-81.

230. Akinosoglou K, Apostolakis E, Koutsogiannis N, Leivaditis V, Gogos CA. Right-sided infective endocarditis: surgical management. Eur J Cardiothorac Surg. 2012;42:470-9.

231. Gaca JG, Sheng S, Daneshmand M, Rankin JS, Williams ML, O’Brien SM, et al. Current outcomes for tricuspid valve infective endocarditis surgery in North America. Ann Thorac Surg. 2013;96:1374-81.

232. Jiang SL, Li BJ, Zhang T, Ren CL, Wang Y, Chen TT, et al. Surgical treatment of isolated right-sided infective endocarditis. Tex Heart Inst J. 2011;38:639-42.

233. Dawood MY, Cheema FH, Ghoreishi M, Foster NW, Villanueva RM, Salenger R, et al. Contemporary outcomes of operations for tricuspid valve infective endocarditis. Ann Thorac Surg. 2015;99:539-46.

234. Miro JM, del Rio A, Mestres CA. Infective endocarditis and cardiac surgery in intravenous drug abusers and HIV-1 infected patients. Cardiol Clin. 2003;21: 167-84, v-vi.

235. Baraki H, Saito S, Al Ahmad A, Fleischer B, Schmitto J, Haverich A, et al. Surgical treatment for isolated tricuspid valve endocarditis- long-term follow-up at a single institution. Circ J. 2013;77:2032-7.

236. Carozza A, De Santo LS, Romano G, Della Corte A, Ursomando F, Scardone M, et al. Infective endocarditis in intravenous drug abusers: patterns of presentation and long-term outcomes of surgical treatment. J Heart Valve Dis. 2006;15: 125-31.

237. Frontera JA, Gradon JD. Right-side endocarditis in injection drug users: review of proposed mechanisms of pathogenesis. Clin Infect Dis. 2000;30:374-9.

238. Thalme A, Westling K, Julander I. In-hospital and long-term mortality in infective endocarditis in injecting drug users compared to non-drug users: a retrospective study of 192 episodes. Scand J Infect Dis. 2007;39:197-204.

239. Yamane K, Hirose H, Bogar LJ, Cavarocchi NC, Diehl JT. Surgical treatment of infective endocarditis in patients undergoing chronic hemodialysis. J Heart Valve Dis. 2012;21:774-82.

240. Arbulu A, Holmes RJ, Asfaw I. Surgical treatment of intractable right-sided infective endocarditis in drug addicts: 25 years experience. $J$ Heart Valve Dis. 1993;2:129-37; discussion 38-9.

241. Kamaledeen A, Young C, Attia RQ. What are the differences in outcomes between right-sided active infective endocarditis with and without left-sided infection? Interact Cardiovasc Thorac Surg. 2012;14:205-8.

242. Rabkin DG, Mokadam NA, Miller DW, Goetz RR, Verrier ED, Aldea GS. Longterm outcome for the surgical treatment of infective endocarditis with a focus on intravenous drug users. Ann Thorac Surg. 2012;93:51-7.

243. Tarola CL, Losenno KL, Chu MW. Complex tricuspid valve repair for infective endocarditis: leaflet augmentation, chordae and annular reconstruction. Multimed Man Cardiothorac Surg. 2015;2015.

244. Gottardi R, Bialy J, Devyatko E, Tschernich H, Czerny M, Wolner E, et al. Midterm follow-up of tricuspid valve reconstruction due to active infective endocarditis. Ann Thorac Surg. 2007;84:1943-8.

245. Hagl C, Galla JD, Lansman SL, Fink D, Bodian CA, Spielvogel D, et al. Replacing the ascending aorta and aortic valve for acute prosthetic valve endocarditis: is using prosthetic material contraindicated? Ann Thorac Surg. 2002;74: S1781-5; discussion S92-9.

246. LeMaire SA, Coselli JS. Options for managing infected ascending aortic grafts. J Thorac Cardiovasc Surg. 2007;134:839-43.

247. Tang GH, Pinney SP, Broumand SR, Adams DH, Anyanwu AC. Excellent outcomes with use of synthetic vascular grafts for treatment of mycotic aortic pseudoaneurysms after heart transplantation. Ann Thorac Surg. 2011;92:2112-6.

248. Shah DK, Li Z, Park SJ, Daly RC, Dearani JA, Schaff HV, et al. Replacement of the infected composite aortic root prosthesis. Ann Thorac Surg. 2011;92:1651-5.
249. Tossios P, Karatzopoulos A, Tsagakis K, Sapalidis K, Grosomanidis V, Kalogera A, et al. Treatment of infected thoracic aortic prosthetic grafts with the in situ preservation strategy: a review of its history, surgical technique, and results. Heart Lung Circ. 2014;23:24-31.

250. Sohail MR, Uslan DZ, Khan AH, Friedman PA, Hayes DL, Wilson WR, et al. Infective endocarditis complicating permanent pacemaker and implantable cardioverter-defibrillator infection. Mayo Clin Proc. 2008;83:46-53.

251. Tarakji KG, Wilkoff BL. Cardiac implantable electronic device infections: facts, current practice, and the unanswered questions. Curr Infect Dis Rep. 2014; $16: 425$.

252. Athan E, Chu VH, Tattevin P, Selton-Suty C, Jones P, Naber C, et al. Clinical characteristics and outcome of infective endocarditis involving implantable cardiac devices. JAMA. 2012;307:1727-35.

253. Viganego F, O’Donoghue S, Eldadah Z, Shah MH, Rastogi M, Mazel JA, et al Effect of early diagnosis and treatment with percutaneous lead extraction on survival in patients with cardiac device infections. Am J Cardiol. 2012;109: 1466-71.

254. Pichlmaier M, Knigina L, Kutschka I, Bara C, Oswald H, Klein G, et al. Complete removal as a routine treatment for any cardiovascular implantable electronic device-associated infection. J Thorac Cardiovasc Surg. 2011;142: 1482-90.

255. Rundstrom H, Kennergren C, Andersson R, Alestig K, Hogevik H. Pacemaker endocarditis during 18 years in Goteborg. Scand J Infect Dis. 2004:36:674-9.

256. Baddour LM, Epstein AE, Erickson CC, Knight BP, Levison ME, Lockhart PB et al. Update on cardiovascular implantable electronic device infections and their management: a scientific statement from the American Heart Association. Circulation. 2010;121:458-77.

257. Baddour LM, Cha YM, Wilson WR. Clinical practice. Infections of cardiovascular implantable electronic devices. N Engl J Med. 2012;367:842-9.

258. Madhavan M, Sohail MR, Friedman PA, Hayes DL, Steckelberg JM Wilson WR, et al. Outcomes in patients with cardiovascular implantable electronic devices and bacteremia caused by Gram-positive cocci other than Staphylococcus aureus. Circ Arrhythm Electrophysiol. 2010;3:639-45.

259. Shrestha NK, Ledtke CS, Wang H, Fraser TG, Rehm SJ, Hussain ST, et al. Heart valve culture and sequencing to identify the infective endocarditis pathogen in surgically treated patients. Ann Thorac Surg. 2015;99:33-7.

260. Fournier PE, Thuny F, Richet H, Lepidi H, Casalta JP, Arzouni JP, et al Comprehensive diagnostic strategy for blood culture-negative endocarditis: a prospective study of 819 new cases. Clin Infect Dis. 2010;51:131-40.

261. Boussier R, Rogez S, Francois B, Denes E, Ploy MC, Garnier F. Two-step bacterial broad-range polymerase chain reaction analysis of heart valve tissue improves bacteriological diagnosis of infective endocarditis. Diagn Microbiol Infect Dis. 2013;75:240-4.

262. Greub G, Lepidi H, Rovery C, Casalta JP, Habib G, Collard F, et al. Diagnosis of infectious endocarditis in patients undergoing valve surgery. Am J Med. 2005; 118:230-8.

263. Marin M, Munoz P, Sanchez M, del Rosal M, Alcala L, Rodriguez-Creixems M, et al. Molecular diagnosis of infective endocarditis by real-time broad-range polymerase chain reaction (PCR) and sequencing directly from heart valve tissue Medicine (Baltimore). 2007;86:195-202.

264. Vollmer T, Piper C, Horstkotte D, Korfer R, Kleesiek K, Dreier J. 23S rDNA real-time polymerase chain reaction of heart valves: a decisive tool in the diagnosis of infective endocarditis. Eur Heart J. 2010;31:1105-13.

265. Dahl A, Rasmussen RV, Bundgaard H, Hassager C, Bruun LE, Lauridsen TK et al. Enterococcus faecalis infective endocarditis: a pilot study of the relationship between duration of gentamicin treatment and outcome. Circulation. 2013; 127:1810-7.

266. Olaison L, Schadewitz K. Swedish Society of Infectious Diseases Quality Assurance Study Group for E. Enterococcal endocarditis in Sweden, 1995 1999: can shorter therapy with aminoglycosides be used? Clin Infect Dis. 2002:34:159-66.

267. Thomsen RW, Farkas DK, Friis S, Svaerke C, Ording AG, Norgaard M, et al. Endocarditis and risk of cancer: a Danish nationwide cohort study. Am J Med. 2013;126:58-67.

268. Gupta A, Madani R, Mukhtar H. Streptococcus bovis endocarditis, a silent sign for colonic tumour. Colorectal Dis. 2010;12:164-71.

269. Rusniok C, Couve E, Da Cunha V, El Gana R, Zidane N, Bouchier C, et al Genome sequence of Streptococcus gallolyticus: insights into its adaptation to the bovine rumen and its ability to cause endocarditis. J Bacteriol. 2010; 192:2266-76. 
270. Boleij A, van Gelder MM, Swinkels DW, Tjalsma H. Clinical Importance of Streptococcus gallolyticus infection among colorectal cancer patients: systematic review and meta-analysis. Clin Infect Dis. 2011;53:870-8.

271. Thuny F, Giorgi R, Habachi R, Ansaldi S, Le Dolley Y, Casalta JP, et al. Excess mortality and morbidity in patients surviving infective endocarditis. Am Heart J. 2012;164:94-101.

272. Hasegawa MI, Kyo S, Asano H, Imanaka K. Surgery for active, culture negative endocarditis. Asian Cardiovasc Thorac Ann. 2004:12:316-9.

273. Mullany CJ, Chua YL, Schaff HV, Steckelberg JM, Ilstrup DM, Orszulak TA, et al. Early and late survival after surgical treatment of culture-positive active endocarditis. Mayo Clin Proc. 1995;70:517-25.

274. Fedoruk LM, Jamieson WR, Ling H, Macnab JS, Germann E, Karim SS, et al. Predictors of recurrence and reoperation for prosthetic valve endocarditis after valve replacement surgery for native valve endocarditis. J Thorac Cardiovasc Surg. 2009; 137:326-33.

275. Martinez-Selles M, Munoz P, Estevez A, del Castillo R, Garcia-Fernandez MA, Rodriguez-Creixems M, et al. Long-term outcome of infective endocarditis in non-intravenous drug users. Mayo Clin Proc. 2008;83:1213-7.

276. Mansur AJ, Dal Bo CM, Fukushima JT, Issa VS, Grinberg M, Pomerantzeff PM Relapses, recurrences, valve replacements, and mortality during the long-term follow-up after infective endocarditis. Am Heart J. 2001;141:78-86.

277. Tornos MP, Permanyer-Miralda G, Olona M, Gil M, Galve E, Almirante B, et al. Long-term complications of native valve infective endocarditis in non-addicts. A 15-year follow-up study. Ann Intern Med. 1992;117:567-72.

278. Westling K, Aufwerber E, Ekdahl C, Friman G, Gardlund B, Julander I, et al. Swedish guidelines for diagnosis and treatment of infective endocarditis. Scand J Infect Dis. 2007;39:929-46.

279. Nori US, Manoharan A, Thornby JI, Yee J, Parasuraman R, Ramanathan V. Mortality risk factors in chronic haemodialysis patients with infective endocarditis. Nephrol Dial Transplant. 2006;21:2184-90.

280. Rankin JS, Milford-Beland S, O’Brien SM, Edwards FH, Peterson ED, Glower DD, et al. The risk of valve surgery for endocarditis in patients with dialysis-dependent renal failure. J Heart Valve Dis. 2007;16:617-22; discussion 22.
281. Leither MD, Shroff GR, Ding S, Gilbertson DT, Herzog CA. Long-term survival of dialysis patients with bacterial endocarditis undergoing valvular replacement surgery in the United States. Circulation. 2013; 128:344-51.

282. Abbott KC, Agodoa LY. Hospitalizations for bacterial endocarditis after initiation of chronic dialysis in the United States. Nephron. 2002:91:203-9.

283. Doulton T, Sabharwal N, Cairns HS, Schelenz S, Eykyn S, O’Donnell P, et al Infective endocarditis in dialysis patients: new challenges and old. Kidney Int. 2003;64:720-7.

284. Maraj S, Jacobs LE, Maraj R, Kotler MN. Bacteremia and infective endocarditis in patients on hemodialysis. Am J Med Sci. 2004;327:242-9.

285. McCarthy JT, Steckelberg JM. Infective endocarditis in patients receiving longterm hemodialysis. Mayo Clin Proc. 2000;75:1008-14.

286. Hung TH, Hsieh YH, Tseng KC, Tsai CC. The risk for bacterial endocarditis in cirrhotic patients: a population-based 3-year follow-up study. Int J Infect Dis. 2013;17:e391-3.

287. Jacob KA, Hjortnaes J, Kranenburg G, de Heer F, Kluin J. Mortality after cardiac surgery in patients with liver cirrhosis classified by the Child-Pugh score. Interact Cardiovasc Thorac Surg. 2015;20:520-30.

288. Wilson W, Taubert KA, Gewitz M, Lockhart PB, Baddour LM, Levison M, et al. Prevention of infective endocarditis: guidelines from the American Heart Association: a guideline from the American Heart Association Rheumatic Fever, Endocarditis, and Kawasaki Disease Committee, Council on Cardiovascular Disease in the Young, and the Council on Clinical Cardiology, Council on Cardiovascular Surgery and Anesthesia, and the Quality of Care and Outcomes Research Interdisciplinary Working Group. Circulation. 2007; 116:1736-54.

Key Words: AATS guidelines, infective endocarditis, infection, valve disease, cardiac surgery, native valve endocarditis, prosthetic valve endocarditis

Readers who found these articles interesting may also like to read the following papers found in recent and future issues of our sister publications, Seminars in Thoracic and Cardiovascular Surgery and Operative Techniques in Thoracic and Cardiovascular Surgery!

\section{Acquired: Endocarditis}

Aminoglycosides For Surgically Treated Enterococcal Endocarditis. Jona M. Banzon. Semin Thoracic Surg 2016: 331-338.

Aminoglycosides for Surgically Treated Enterococcal Endocarditis: A Contemporary Reassessment. David D. Yuh. Semin Thoracic Surg 2016: 339-340. 


\section{APPENDIX E1. INVITED EXPERTS}

\section{Cardiac Surgery}

Michael A. Borger, MD, PhD

Director, Cardiovascular Institute

Columbia University Medical Center

New York, NY

James S. Gammie, MD

Chair, Division of Cardiac Surgery

University of Maryland

Baltimore, Md

Hartzell V. Schaff, MD

Chair, Division of Cardiovascular Surgery

Mayo Clinic College of Medicine

Rochester, Minn

Thoralf M. Sundt III, MD

Chair, Division of Cardiac Surgery

Massachusetts General Hospital

Boston, Mass

\section{Cardiology}

James D. Thomas, MD

Director, Center for Heart Valve Disease

Northwestern University Feinberg School of

Medicine

Chicago, Ill

\section{Anesthesiology}

Colleen G. Koch, MD, MS, MBA

Chair, Department of Anesthesiology and Critical Care Medicine

Johns Hopkins Medicine

Baltimore, Md

\section{Imaging}

Xavier Duval, MD, PhD

Hôpital Universitaire Bichat

Départment d'Epidémiologie et Recherche Clinique

Université Paris Diderot

Paris, France

Benjamin Y. Cheong, MD

CHI St. Luke's Health

Baylor St. Luke's Medical Center

Houston, Tex

\section{Infectious Disease}

Larry M. Baddour, MD

Professor of Medicine

Division of Infectious Diseases

Mayo Clinic College of Medicine

Rochester, Minn

Adolf W. Karchmer, MD

Chief, Division of Infectious Diseases

Beth Israel Deaconess Medical Center

Harvard Medical School

Boston, Mass

Vance G. Fowler, MD

Professor of Medicine and Molecular Genetics and Microbiology

Department of Medicine

Duke University Medical Center

Durham, NC

\section{Neurology}

Amy A. Pruitt, MD

Professor of Neurology and Division Chief, General Neurology Unit

Hospital of the University of Pennsylvania

Philadelphia, $\mathrm{Pa}$ 


\section{The American Association for Thoracic Surgery (AATS) consensus guidelines: Surgical treatment of infective endocarditis}

\author{
AATS Surgical \\ Treatment of \\ Infective \\ Endocarditis \\ Consensus \\ Guidelines Writing \\ Committee Chairs: \\ Gösta B. Pettersson, $\mathrm{MD}, \mathrm{PhD},{ }^{\mathrm{a}}$ and \\ Joseph S. Coselli, MD ${ }^{\mathrm{b}, \mathrm{c}}$
}

Writing Committee: Gösta B. Pettersson, $\mathrm{MD}, \mathrm{PhD},{ }^{\mathrm{a}}$

Joseph S. Coselli, MD, ${ }^{\text {b,c }}$ Syed T. Hussain, MD, ${ }^{a}$ Brian Griffin, MD, ${ }^{\mathrm{d}}$ Eugene H. Blackstone, MD, Steven M. Gordon, MD, ${ }^{\mathrm{e}}$ Scott A. LeMaire, MD, and Laila E. Woc-Colburn, $\mathrm{MD}^{\mathrm{f}}$

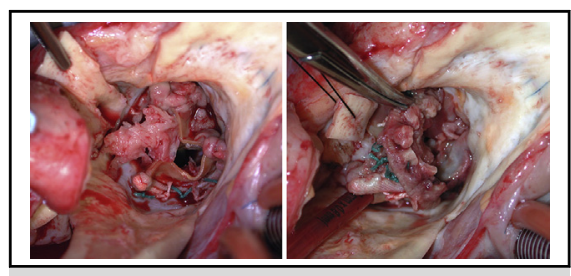

Vegetation and dehiscence in prosthetic valve endocarditis—a surgical disease.

Central Message

These guidelines describe diagnosis, indications, timing, surgical treatment, and perioperative care for patients with infective endocarditis and early surgeon involvement in team decision-making

See Editorial Commentary page 1259.

Invited Experts: See Appendix E1.

\section{PREAMBLE}

Our mission was to develop evidence-based consensus guidelines for surgical treatment of infective endocarditis (IE). ${ }^{1}$ The writing committee included 4 cardiac surgeons, 1 cardiologist, 2 infectious disease specialists, and Dr Eugene H. Blackstone. An additional group of experts, including 4 cardiac surgeons, 1 anesthesiologist, 1 cardiologist, 2 imaging experts, 3 infectious disease specialists, and 1 neurologist, were invited to comment. See Appendix E1 for the list of members.

\section{Methods of Review}

In developing the guidelines, we followed recommendations of The Institute of Medicine's 2011 Clinical Practice Guidelines We Can Trust: Standards for Developing

From the Departments of ${ }^{\mathrm{a}}$ Thoracic and Cardiovascular Surgery, ${ }^{\mathrm{d}}$ Cardiovascular Medicine, and ${ }^{\mathrm{e}}$ Infectious Disease, Cleveland Clinic, Cleveland, Ohio; ${ }^{\mathrm{b}}$ Division of Cardiothoracic Surgery, and ${ }^{\mathrm{f}}$ Department of Infectious Diseases, Baylor College of Medicine; ${ }^{\mathrm{c}}$ Texas Heart Institute, Houston, Tex.

This work was supported by institutional funds for the participants and the Cleveland Clinic editorial staff.

Received for publication May 9, 2016; revisions received Sept 12, 2016; accepted for publication Sept 16, 2016; available ahead of print March 30, 2017.

Address for reprints: Gösta B. Pettersson, MD, PhD, Department of Thoracic and Cardiovascular Surgery, Cleveland Clinic, 9500 Euclid Ave/Desk J4-1, Cleveland, OH 44195 (E-mail: petterg@ccf.org).

J Thorac Cardiovasc Surg 2017;153:1258.e2-29

$0022-5223 / \$ 36.00$

Copyright (c) 2017 by The American Association for Thoracic Surgery

http://dx.doi.org/10.1016/j.jtcvs.2016.09.093
Trustworthy Clinical Practice Guidelines (www.iom.edu/ cpgstandards), and graded level of evidence according to published standards (Table 1). ${ }^{2}$ Members of the writing committee and invited experts were tasked with making recommendations based on a review of the literature, grading the quality of evidence supporting the recommendations, and assessing the risk-benefit profile for each recommendation. Literature searches were conducted using PubMed, and all articles published since 2000 were reviewed while also including older landmark publications. Original articles and all contributions by committee members and invited experts were made available to each writing committee member. Regular conference calls were held, and brief minutes were circulated via e-mail. Each writing committee member and invited expert was asked to consider every recommendation with regard to class and level of evidence. Controversies were discussed and resolved via e-mail discussions. A final draft was prepared by the chairmen, Dr Hussain, and Dr Blackstone. Writing committee members and invited experts were given a final opportunity to review, comment, and approve the draft before it was submitted to The American Association for Thoracic Surgery (AATS) Guidelines Committee for approval.

\section{Audience, Focus, and Distinguishing Features}

Patients with IE are cared for by a team of physicians with expertise in various aspects of the disease. Thus, 


\section{Abbreviations and Acronyms \\ AATS $=$ The American Association for Thoracic Surgery \\ ACC $=$ American College of Cardiology \\ AHA $=$ American Heart Association \\ $\mathrm{CT}=$ computed tomography \\ ESC $=$ European Society of Cardiology \\ IE $=$ infective endocarditis \\ MDCT $=$ multidetector computed tomography \\ MRI = magnetic resonance imaging \\ NVE = native valve endocarditis \\ PCR = polymerase chain reaction \\ PET = positron emission tomography \\ PVE $=$ prosthetic valve endocarditis \\ SPECT $=$ single-photon emission computed tomography \\ TEE $=$ transesophageal echocardiography}

many guidelines have been produced by societies representing the corresponding specialties. This AATS guidelines document focuses on surgical treatment and perioperative issues: when to operate, how to prepare the patient for operation, how to operate, and other issues relevant to managing and following patients after surgery. ${ }^{3-8}$

\section{Selection, Survival, and Referral Bias}

Most studies of IE are affected by selection, survival, and referral bias. Do these biases matter? ${ }^{9-29}$ They make it difficult to study the natural history of IE in the general population, because treated and triaged patients enrich the sample seen at regional high-volume centers. Inferences drawn from results of treating such patients are valid for the selected, living, and referred patients but may not be helpful to the primary care physician, who is left without a clear picture of natural history until conservative treatment fails or appears futile, and it becomes clear that the patient must be referred.

So-called "referral bias" represents desirable decisions to consolidate complex care in regional centers of excellence with expertise and experience surpassing that available locally. ${ }^{29}$ This is desirable to maximize salvage of patients. It also means that the spectrum of disease seen in these centers will be skewed to the sickest patients, and physicians and surgeons at these institutions may not appreciate potentially safe and curative conservative therapy for patients with less invasive or curable disease. Given the national trend toward large consolidated hospital systems, combining primary care up to quaternary care, opportunity exists to investigate a more complete spectrum of IE and establish guidelines for its medical management and optimal timing of surgery.

\section{INTRODUCTION}

IE is the most severe and potentially devastating complication of heart valve disease, be it native valve endocarditis (NVE), prosthetic valve endocarditis (PVE), or infection on another cardiac device. ${ }^{3-8}$ Without treatment, IE is uniformly fatal; the old categories of acute, subacute, and chronic endocarditis referred only to the time it was anticipated to take before the patient died. ${ }^{30}$ Even in the current therapeutic era, with appropriate antimicrobial therapy and surgical intervention, multicenter studies report in-hospital mortality of $15 \%$ to $20 \%$ and 1-year mortality approaching 40\%. ${ }^{11,14,31-49}$ Patients with valve disease, prosthetic valves, cardiac devices, a history of IE, immune suppression, dialysis, drug abuse, and other medical situations are at increased risk of IE. As a paradoxical effect of advances in medical and surgical therapy, an increasingly elderly population with degenerative heart valve disease, and an increase in staphylococcal infections, the prevalence of IE has increased during the last 30 years. Although it is uncommon for normal valves to become infected, it does happen, especially with Staphylococcus aureus. Thus, approximately $50 \%$ of IE occurs in patients with no previously diagnosed predisposing cardiac condition. ${ }^{3,4}$

We add to current guidelines from cardiology, infectious disease, and cardiac surgery societies by creating an easyto-use set of guidelines addressing specific questions of relevance and importance to cardiac surgeons before, during, and after operation. ${ }^{3-8}$ The recent American College of Cardiology/American Heart Association (ACC/AHA) guidelines emphasize the importance of an early, team approach to patients with IE. ${ }^{3}$ The high prevalence of neurologic and other complications requires additional diagnostic and management expertise. ${ }^{3-7}$ Patients with IE frequently have comorbidities (often injection drug use in younger patients). ${ }^{3,4}$ These comorbidities and primary and secondary infectious foci require diagnostic attention and treatment.

Clinical scenarios presented by patients with IE often are complex. ${ }^{50-53}$ IE requires prompt diagnosis for early institution of antibiotic treatment and decision-making related to complications, including risk of embolism and need for and timing of high-risk surgery. ${ }^{3-7}$ Patients with IE require a multispecialty team approach. ${ }^{3-7}$ The AATS recommends that the IE treatment team include an infectious disease specialist, a cardiologist, and a cardiac surgeon, with input from other specialties such as neurology and nephrology when needed. Execution of the operation, with radical debridement and reconstruction of 
TABLE 1. Team approach to patients with IE

\begin{tabular}{|c|c|c|c|}
\hline Recommendations & COR & LOE & References \\
\hline \multicolumn{4}{|l|}{ 1. Who should care for and operate on patients with IE? } \\
\hline $\begin{array}{l}\text { Patients with suspected IE should ideally be cared for at centers with } \\
\text { access to a complete team, including cardiology, infectious disease, } \\
\text { cardiac surgery, and other services needed to handle IE complications }\end{array}$ & I & B & $4,5,7,89$ \\
\hline $\begin{array}{l}\text { Surgeons operating on patients with IE should be well-trained, } \\
\text { experienced valve surgeons who are well versed in the different } \\
\text { reconstruction techniques needed by patients with advanced disease }\end{array}$ & $\mathbf{I}$ & $\mathbf{C}$ & $4,5,31,89$ \\
\hline \multicolumn{4}{|l|}{ 2. Diagnosis of IE: What does the surgeon need to know? } \\
\hline $\begin{array}{l}\text { At the time of surgery the patient should be on an effective antimicrobial } \\
\text { regimen (correct dosage and route of administration) to which the } \\
\text { causative microorganism is sensitive, or be broadly covered when } \\
\text { organism and sensitivity are unknown }\end{array}$ & I & B & $3-5,7,55,58$ \\
\hline $\begin{array}{l}\text { For surgery planning, the surgeon should have the best possible } \\
\text { understanding of the pathology. This will usually require advanced } \\
\text { imaging techniques, such as TEE }\end{array}$ & $\mathbf{I}$ & B & $3-5,7,90-98$ \\
\hline $\begin{array}{l}\text { Use of imaging modalities other than echocardiography may also be } \\
\text { appropriate in selected cases }\end{array}$ & IIlb & C & $3-5,95,99-103$ \\
\hline
\end{tabular}

COR, Classification of recommendations; $L O E$, level of evidence; $I E$, infective endocarditis; TEE, transesophageal echocardiography.

the heart and heart valves, requires experience and special expertise, yet operations for IE remain associated with the greatest mortality of any valve disease. ${ }^{11,31,32,34,43-46}$

Causative microorganism or pathogen, position (aortic, mitral, or right-sided), and type of infected valve (native or prosthetic) are of great importance to pathology and prognosis. ${ }^{43,45,54}$ Prosthetic valves also can become infected at the time of valve replacement. Bacteria and fungi have a species-specific repertoire of virulence factors that allows them to establish and maintain IE. These factors mediate adhesion of the bacteria to endovascular surfaces (eg, cardiac valves), allow the pathogen to evade the host immune response, and are able to destroy host tissues. Circulating organisms adhere to damaged endothelium of a native or prosthetic valve. The organisms elicit formation of vegetations composed almost entirely of host cells and proteins, multiply within this "sanctuary site," and produce toxins and enzymes that disintegrate valve tissue and allow extravascular invasion. ${ }^{54}$ Severity of invasion and destruction seems to be a function of virulence and time, with $S$ aureus being most aggressive and effective.

A great variety of microorganisms can cause IE, and they differ with regard to virulence factors that determine their aggressiveness. The microbiology of IE depends on whether the valve is native or prosthetic and whether the infection is community acquired or health careassociated (including nosocomial IE). ${ }^{3-5,7}$ Staphylococci, streptococci, and enterococci are the most important causative organisms, responsible for approximately $85 \%$ of all IE. Staphylococci and streptococci are the most common aggressive and destructive bacteria causing IE. Although $S$ aureus is more common in NVE,
Staphylococcus epidermidis is a more common cause of PVE. Fungi form large vegetations or balls, but are usually less invasive, although aspergillus IE is associated with the development of mycotic aneurysms and easily becomes disseminated. Pettersson and colleagues ${ }^{54}$ recently described the progression and pathology stages of NVE and PVE in an atlas.

Despite introduction of antimicrobials, IE remains notoriously difficult to treat, and even extended courses of highdose antimicrobials often fail to cure the infection. ${ }^{55}$ Recent research has provided a plausible explanation for this: the biofilm concept. ${ }^{56}$ Biofilm development and quorum sensing are social bacterial behaviors. Bacterial populations live embedded in a self-produced extracellular polysaccharide slime-like matrix, and quorum sensing (a chemical cell-to-cell communication mechanism) synchronizes gene expression and activates assembly and maturation of the biofilm. Once established, biofilm protects bacteria from host immune defenses and impedes antimicrobial efficacy, dramatically reducing the ability of medical therapy alone to eradicate the infection. The capacity for biofilm production is a hallmark of the microorganisms commonly causing IE, including staphylococci, streptococci, and enterococci, but also less common pathogens such as Candida species and Pseudomonas aeruginosa.

Tissue disintegration and invasion caused by toxins and enzymes result in serious complications, including heart failure from valve regurgitation or fistulas. ${ }^{54}$ Extravascular invasion causes paravalvular abscesses and heart block, and emboli from vegetations cause stroke, mycotic aneurysms, and other related phenomena. Destroyed tissue does not regrow, and valves made leaky by bacterial destruction will continue to leak even if the infection ultimately is 
eradicated. Stage of the disease at the time of diagnosis is related to pathogen aggressiveness and disease duration. ${ }^{54}$

Outcomes after IE treatment often are related to whether it is a native or prosthetic valve infection. Prosthetic valve infections generally are more invasive and more difficult to treat and cure with antibiotics alone. ${ }^{43}$ The formation of a biofilm protecting the organisms represents a biologic basis for the frequent need for surgery for PVE. ${ }^{56}$ When comparing aortic and mitral valve IE, aortic valve IE is more invasive (true for both NVE and PVE) and has a greater proportion of prosthetic valve infection. ${ }^{43}$ Despite this, outcomes are worse after surgical treatment of mitral valve IE than aortic valve IE. Three factors contribute to this: (1) patients with mitral valve IE have a greater prevalence of comorbidities than patients with aortic IE; (2) for invasive IE, the surgical anatomy of mitral valve IE is less favorable; and (3) no allograft valve alternative for severe invasive disease currently exists for the mitral valve. ${ }^{43}$ Right-sided IE typically is less invasive, although it is caused by the same aggressive organisms, including $S$ aureus.

Systemic emboli are common in patients with left-sided IE. Embolic strokes, with or without hemorrhagic conversion, are the most frequent and clinically important. ${ }^{3-5}$ Although rare, systemic septic emboli can cause mycotic aneurysms in any artery, including the aorta. ${ }^{3,4}$ Rightsided IE frequently showers septic emboli to the lungs, leading to development of pulmonary abscesses or empyema if treatment is not instituted early, and also can be responsible for systemic emboli in patients with patent foramen ovale.

All patients diagnosed with IE are first treated with antimicrobials, initially broad spectrum and then adjusted to the sensitivity pattern once it is known. ${ }^{3-5,7}$ Antimicrobials to which the organisms are sensitive clear the bacteremia, may prevent or halt further destruction, and, if treatment is initiated early enough, cure the infection. Antimicrobials will, however, not restore the integrity of damaged tissue and valves, and recurrence after a complete course of antibiotics is common.

The hypothesis that IE is a biofilm-associated infection offers plausible explanations as to why endocarditisrelated infections are difficult to treat, why recurrence may occur after seemingly successful medical treatment, and why surgery often is required. ${ }^{56}$ Surgery effectively disrupts the biofilm; removes vegetations, infected necrotic tissue, and foreign material; and drains the infected areas, thereby exposing residual live microorganisms and making them vulnerable to antimicrobials and the patient's immune system. In addition, valve repair or replacement restores valve function and cardiac integrity. Nevertheless, final cure is always the result of antimicrobial treatment and the patient's own defense mechanisms.
Many experienced groups are becoming increasingly aggressive in advocating early surgery rather than waiting for complications. ${ }^{43-46}$ Kang and colleagues ${ }^{47}$ recently published a randomized study specifically looking at timing of surgery and provided evidence supporting surgery within 48 hours rather than waiting for onset of heart failure or other clinical symptoms. This evolution is based on improved outcomes after surgery and the growing conviction that the penalty for operating on patients with active infection is minimal and that duration of preoperative antibiotic treatment has no or little effect on outcomes.

In the case of blood culture-negative IE, surgery also can help to identify the causative microorganism thanks to microbiologic examination of the operative specimen, including molecular testing with polymerase chain reaction (PCR). ${ }^{57,58}$

These new AATS consensus guidelines primarily address questions related to active and suspected active IE affecting valves and intracardiac structures. Management of concomitant device infections is addressed but not management of isolated infections of devices, including pacemakers, defibrillators, ventricular assist devices, and others. It is understood that surgery is beneficial only if the patient's complications and other comorbidities do not preclude survival and meaningful recovery.

\section{QUESTIONS}

\section{Who Should Care for and Operate on Patients With}

IE? (Table 1-1)

Surgery for IE carries the greatest risk of any valve surgery, and outcomes differ widely among centers and surgeons. Expeditious diagnosis and institution of adequate treatment require access to substantial expertise in cardiology and infectious diseases. Imaging expertise, particularly in echocardiography, is essential to early diagnosis. Transesophageal echocardiography (TEE) often is needed to diagnose and adequately stage the disease, supplemented selectively by computed tomography (CT) scanning, magnetic resonance imaging (MRI), and positron emission tomography (PET) scanning. Once the diagnosis has been made, the management team also should include a cardiac surgeon and other specialists with the expertise needed to handle complications (eg, neurologist, psychiatrist, nephrologist). Once surgery is decided on, an anesthesiologist is added to the management team.

The team approach to IE is emphasized in the most recent 2015 ACC/AHA guidelines, and the 2015 European Society of Cardiology (ESC) guidelines recommend that patients with IE should be managed at reference centers by a specialized "endocarditis team." 3-5 Surgical input should be solicited early in the evaluation. When dealing with invasive disease, the surgeon must have enough experience to perform radical debridement and 
reconstruction and have access to and mastery of the necessary reconstructive procedures.

\section{Diagnosis of IE: What Does the Surgeon Need to \\ Know? (Table 1-2)}

The diagnosis of IE is based on clinical symptoms, physical findings, microbiology results, echocardiography, and other studies. Duke or modified Duke criteria are used to classify certainty of the diagnosis. ${ }^{50,52,53}$

When IE is suspected, 3 sets of blood cultures should be collected before antibiotics are initiated. At least 2 sets $(2$ bottles, aerobic and anaerobic) should be obtained immediately from different peripheral sites. An additional set should be obtained a few hours later. Unless the patient is septic, it is reasonable to withhold antibiotics until an adequate number of blood cultures have been collected. Colony-forming units per milliliter of microbial pathogens do not differ between venous and arterial blood. However, some pathogens require prolonged incubation (Propionibacterium acnes) or special media (histoplasmosis) or are too fastidious to grow in blood culture (Tropheryma whipplei, Coxiella burnetii, Bartonella species) and require nonculture techniques (eg, PCR in serum, valve specimens, or paired serologies).

A transthoracic echocardiogram must be supplemented with TEE in most cases of suspected prosthetic IE. A TEE should be considered early when organisms with a high likelihood of pyogenic complications are implicated or when there is a question about the presence or absence of valve infection based on the quality of the transthoracic echocardiogram images. Over the last decade, technological advances have permitted real-time 3-dimensional TEE to provide volumetric data and better morphologic evaluation of cardiac valve leaflets and cusps and the surrounding structures, improving assessment of vegetation size and detection of complications, such as abscesses and valve leaflet or cusp perforations.

The diagnostic performance of electrocardiogram-gated $\mathrm{CT}$ is comparable to TEE and may be a valuable complement in the preoperative evaluation of patients with aortic PVE. The need for additional imaging also will depend on local availability of such expertise. With the latest generation of multidetector computed tomography (MDCT), the entire heart and thorax can be imaged in just a few heartbeats, and even faster with a dual-source CT scanner. MDCT can be used to detect abscesses and pseudoaneurysms with a diagnostic accuracy similar to TEE and is possibly superior in providing information about the extent and consequences of any perivalvular extension, including the anatomy of pseudoaneurysms, abscesses, and fistulas.

Promising results have likewise been observed for singlephoton emission computed tomography (SPECT) imaging with radiolabeled leukocytes and 18F-fluorodeoxyglucose
PET-CT imaging in IE. The main added value of these techniques is reduction in misdiagnosed IE, classified as "possible IE" using the Duke criteria, and detection of peripheral embolic and metastatic infectious events. Compared with Duke criteria alone, combined Duke criteria and PET-CT data result in a substantial increase in sensitivity without a loss of specificity.

Although complementary imaging, including MDCT, SPECT, PET-CT, and MRI, appears to be promising, a large multicenter trial has yet to be performed, and the added value of the additional imaging technologies is yet to be determined.

Once an indication to operate has been established, the surgeon's focus is on the antimicrobial treatment coverage and the pathology as a determinant of the needed operation. Empiric antimicrobial coverage should be broad enough to cover all likely organisms. If the patient requires urgent surgery when the pathogen and its sensitivity pattern are unknown, the surgeon and patient must be aware and take this uncertainty into account in calculating the risk and timing of surgery.

Before the operation, the surgeon should carefully review the echocardiograms and other imaging studies to better understand the pathology and stage of the disease, which determine the operative approach, especially if invasion is suspected. It is important to remember, however, that even TEE is not perfectly accurate, particularly in patients with mechanical valves.

It also needs to be pointed out that the operation itself contributes to the diagnosis. A substantial number of patients with IE go to the operating room before the causative microorganism is identified as culture negative or before results of the cultures are available. It is critically important that the surgeon secure tissue for microbiologic and histopathologic diagnosis. Even if cultures remain negative, molecular testing with PCR of operative specimens has proven effective in identifying the pathogen, sometimes revising preoperative culture results.

\section{What Are the Indications for Surgery in Patients With IE? (Table 2-1)}

There is wide agreement about the role of and indications for surgery in patients with IE, and currently there is little to add to the indications. Surgical treatment should be considered in patients with signs of heart failure, severe valve dysfunction, PVE, invasion with paravalvular abscess or cardiac fistulas, recurrent systemic embolization, large mobile vegetations, or persistent sepsis despite adequate antibiotic therapy for more than 5 to 7 days.

The ACC/AHA guidelines combine indication and timing and other factors related to complications, primarily neurologic and comorbidities, and other circumstances that must be considered and weighed in the decision-making process. ${ }^{3,5}$ Why and when to operate cannot be separated 
TABLE 2. Indications for, and timing of, surgery for patients with IE

\begin{tabular}{|c|c|c|c|}
\hline Recommendations & COR & LOE & References \\
\hline \multicolumn{4}{|l|}{ 1. What are the indications for surgery in patients with IE? } \\
\hline $\begin{array}{l}\text { Surgery during initial hospitalization independently of the completion of a } \\
\text { full therapeutic course of antibiotics is indicated in patients with IE who } \\
\text { present with valve dysfunction resulting in symptoms of heart failure }\end{array}$ & I & B & $3-7,9,11,46,104-114$ \\
\hline $\begin{array}{l}\text { Surgery during initial hospitalization independently of the completion of a } \\
\text { full therapeutic course of antibiotics is indicated in patients with left-sided } \\
\text { IE caused by S. aureus, fungal, or other highly resistant microorganisms }\end{array}$ & $\mathbf{I}$ & B & $\begin{array}{l}3-5,7,9,18,31,40,105 \\
110,115-121\end{array}$ \\
\hline $\begin{array}{l}\text { Surgery during initial hospitalization independently of completion of a full } \\
\text { therapeutic course of antibiotics is indicated in patients with IE } \\
\text { complicated by heart block, annular or aortic abscess, or destructive } \\
\text { penetrating lesions }\end{array}$ & $\mathbf{I}$ & B & $\begin{array}{l}3-7,11,43,85,105,106 \\
108-110,122-129\end{array}$ \\
\hline $\begin{array}{l}\text { Surgery during initial hospitalization independently of the completion of a } \\
\text { full therapeutic course of antibiotics for IE is indicated in patients with } \\
\text { evidence of persistent infection as manifested by persistent bacteremia } \\
\text { or fever lasting longer than } 5 \text { to } 7 \text { days after initiation of appropriate } \\
\text { antimicrobial therapy }\end{array}$ & $\mathbf{I}$ & B & $\begin{array}{l}3-5,7,45,105,106,110 \\
118,120,130\end{array}$ \\
\hline $\begin{array}{l}\text { Surgery is recommended for patients with PVE and relapsing infection } \\
\text { (defined as recurrence of bacteremia after a complete course of } \\
\text { appropriate antibiotics and subsequently negative blood cultures) without } \\
\text { other identifiable source for portal of infection }\end{array}$ & Ila & $\mathbf{C}$ & 106 \\
\hline $\begin{array}{l}\text { Surgery during initial hospitalization independently of the completion of a } \\
\text { full therapeutic course of antibiotics is reasonable in patients with IE who } \\
\text { present with recurrent emboli and persistent vegetations despite } \\
\text { appropriate antibiotic therapy }\end{array}$ & Ila & B & $\begin{array}{l}3-6,47,61,63,91 \\
131-134\end{array}$ \\
\hline $\begin{array}{l}\text { Urgent or even emergency surgery may be considered in patients with } \\
\text { NVE or PVE who exhibit mobile vegetations greater than } 10 \mathrm{~mm} \text { in length } \\
\text { with clinical evidence of embolic phenomena despite appropriate } \\
\text { antimicrobial treatment }\end{array}$ & IIlb & $\mathbf{B}$ & $31,47,63,91,135$ \\
\hline $\begin{array}{l}\text { In patients with right-sided IE in addition to symptomatic severe valve } \\
\text { dysfunction, surgery should be considered for NVE or PVE when large } \\
\text { vegetations are present and there is evidence of persistent infection } \\
\text { manifested by persistent bacteremia or fevers lasting longer than } 5 \text { to } 7 \\
\text { days after initiation of appropriate antimicrobial therapy, or in those with } \\
\text { evidence of septic pulmonary embolism }\end{array}$ & IIlb & B & $4,7,136$ \\
\hline
\end{tabular}

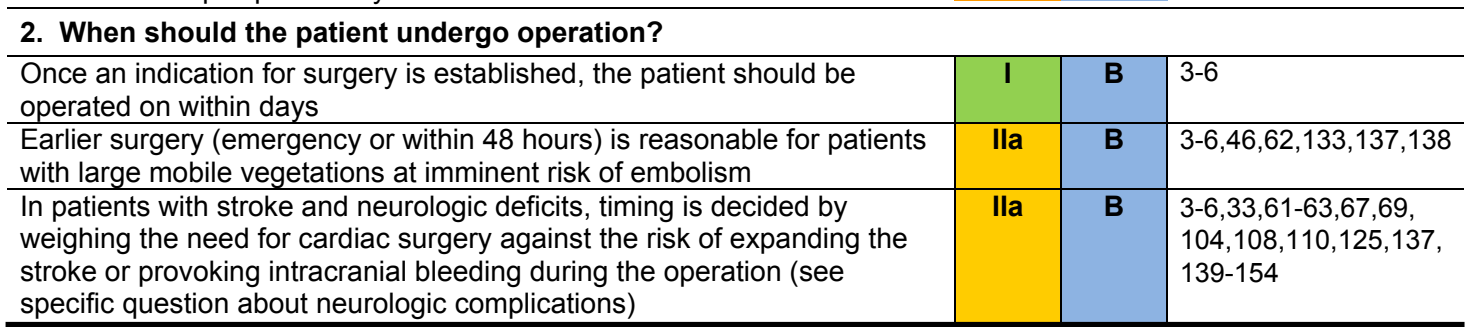

$C O R$, Classification of recommendations; $L O E$, level of evidence; $I E$, infective endocarditis; $P V E$, prosthetic valve endocarditis; $N V E$, native valve endocarditis.

but must be seen in relation to each other. The final decision to operate should be a consensus decision by the treating team.

If there is any disagreement, it relates to the level of aggressiveness and definition of early surgery. In patients with NVE, heart failure is the most frequent and severe complication; the main question is whether waiting for heart failure symptoms in a patient with severe valve regurgitation offers any benefit (see additional discussion under questions about timing of surgery and duration of preoperative antimicrobials). Approximately one-half of patients with IE develop severe complications that sooner or later require operation. Early surgery, as advocated by Kang and colleagues ${ }^{47}$ and many other experienced groups, means operating before heart failure has developed and is manifest. In the study by Kang and colleagues, the most frequent complication in the conventional treatment group was embolic stroke. For this reason, once a surgical indication is evident, surgery should not be delayed.

Patients with invasive staphylococcal PVE and early PVE require early surgery. S aureus and Staphylococcus lugdunensis can be very invasive, with metastatic lesions, compared with PVE with coagulase-negative staphylococcus; however, duration of infection before diagnosis and initiation of appropriate antibiotics also influence pathology of IE. Delaying surgery allows destruction to 
progress and increases the risk of heart block and embolism. For patients with uncomplicated, nonstaphylococcal, and late PVE, treatment with antibiotics alone may be worth trying, but often the infection will recur within a few months. When the infected valve is prosthetic, the chance of cure by antimicrobial therapy alone is far less, particularly when the pathogen is aggressive, like $S$ aureus. In patients with less aggressive bacteria, such as enterococci, vegetations may be miniscule and the infection noninvasive, thus making the diagnosis difficult. The decision about whether and when to replace the valve becomes one based on exclusion of other probable sources of infection.

Surgery to prevent embolism in patients with large mobile vegetations has been a more controversial indication, but the controversy seems to have been resolved. Location, size, and mobility of the vegetation, previous embolism, type of organism, and duration of antimicrobial therapy all influence the associated risk of another embolic event. Large mobile vegetations $->10 \mathrm{~mm}$ on the anterior mitral valve leaflet-have been proven to be associated with greater embolic risk. The latest ESC guidelines suggest a vegetation size of $20 \mathrm{~mm}$ as an indication for surgery. ${ }^{4}$ The trend is to be more aggressive in these cases, because the penalty for operating on patients with active IE is low, and it frequently is possible to preserve the valve, more often the mitral than the aortic valve. There is little logic in waiting for recurrent embolic events that may be devastating.

The general indications may or may not be applicable to right-sided IE, but include symptomatic severe valve dysfunction. When multiple valves, left- and right-sided, are infected, the indication for surgery is usually the left-sided IE. In right-sided IE, invasion is almost never an issue, but indications for surgery are most often failure to control the infection and septic pulmonary embolism and, less often, tricuspid valve regurgitation. Patients with septic pulmonary emboli present with scattered pulmonic infiltrates and abscesses. One consequence of pulmonary embolism is increasing pulmonary vascular resistance and reduced ability to tolerate valve regurgitation, resulting in congestion and right-heart failure symptoms.

Patients with IE often are sick, and the development of renal failure is not uncommon. Renal injury can be caused by acute tubular necrosis, antimicrobial drug toxicity, and immune complex-mediated glomerulonephritis. ${ }^{59}$ The latter can respond promptly to surgical control of IE, and progressive renal failure can be a reason to move up the operation rather than postpone it. ${ }^{60}$ Pathogens causing IE associated with glomerulonephritis include $S$ aureus and epidermidis and Streptococcus viridans.

The AATS recommendations, although similar, are not identical to the ACC/AHA recommendations. ${ }^{3,5}$ Minor changes and nuances have been added. It is assumed that the patient is operable and has not contraindication to heparin and cardiopulmonary bypass, for example, intracranial hemorrhage.

\section{When Should the Patient Undergo Operation? (See Also "Indications and Neurologic Complications") (Table 2-2)}

The ACC/AHA guidelines define early surgery as surgery "during initial hospitalization independently of completion of a full therapeutic course of antibiotics." A common belief is that very few cases of IE are true emergencies requiring same-day surgery.

Embolic events, however, are completely unpredictable as to timing and severity. For the indication "prevention of embolism," sooner is better, and an argument for sameday surgery can be made. According to Dickerman and colleagues, ${ }^{61}$ the risk of embolism is highest during the first 2 weeks of antibiotic therapy and is clearly related to size and mobility of the vegetations, although other risk factors exist. The risk of stroke in IE decreases dramatically each day after initiation of effective antimicrobial therapy. Reduction in size of vegetations with appropriate antimicrobial therapy also appears to be associated with reduced embolic risk. Surgery undertaken for the prevention of embolism is therefore mainly relevant early, during the first few days after initiating antimicrobial therapy (emergency or urgent), when the risk of embolism is highest.

Several observational studies have identified vegetation length $>10 \mathrm{~mm}$ as an independent predictor of embolic events or other complications; the risk of embolism in patients with these large lesions is further increased by factors such as severe vegetation mobility, intravenous drug abuse, and staphylococcal infection. ${ }^{62-65}$ When Hubert and colleagues $^{62}$ developed their "embolic risk calculator," a vegetation length $>10 \mathrm{~mm}$ emerged as a key factor. Vegetation length $>15 \mathrm{~mm}$ has been found to be associated with particularly high risks of IE and death. ${ }^{63,64}$ Such studies have been used to include vegetation size as a factor when considering surgery to prevent embolic complications. For example, the newest ESC guidelines recommend urgent surgery for patients with large vegetations $(>10 \mathrm{~mm})$ involving the aortic or mitral valve if they have had an embolic event despite appropriate antibiotic treatment or have other complications, such as heart failure, abscess, or persistent infection. ${ }^{4}$

Kang and colleagues ${ }^{47}$ demonstrated that patients with large $(>10 \mathrm{~mm})$ left-sided vegetations plus severe valve dysfunction benefit from early surgery by conducting a randomized trial in which 37 patients underwent surgery within 48 hours of diagnosis and 39 underwent conventional treatment (with surgery reserved for those who developed complications or persistent infection). Patients who underwent early surgery had a significantly lower incidence 
of embolic events than those who received conventional treatment ( 0 vs $21 \% ; P=.005)$. It is less clear, however, whether a large left-sided vegetation constitutes an indication for surgery in the absence of embolic events, severe valve regurgitation, or other complicating factors.

If the patient has PVE with annulus involvement, antimicrobial treatment alone is unlikely to cure the infection and may even fail to prevent progression. Once effective antimicrobial therapy has been initiated and an indication for surgery established, delaying the operation may invite and allow new complications.

\section{What Is the Effect of Neurologic Complications, Embolic Stroke, Brain Hemorrhage, and Mycotic Aneurysm on Indication for and Timing of Surgery? (Table 3-1)}

Patients with IE who require surgery but have neurologic symptoms should have a neurologic evaluation and brain imaging, either by CT or MRI, before the planned operation. Imaging should be repeated in case of new or worsening symptoms. The neurologic symptoms, consciousness, location and size of infarct, type (primary or hemorrhagic conversion in infarct), location, size, and timing of hemorrhage, and risk and probability of mycotic aneurysm are all factors to consider when deciding on further imaging, surgery and timing of surgery, and operative risk. An operation that includes cardiopulmonary bypass will increase swelling of the brain, and heparin may provoke new bleeding.

Because embolic events and strokes are so common in patients with IE, routine preoperative screening of asymptomatic patients, particularly those with high-risk vegetations, may be justified. In patients without neurologic symptoms, MRI shows occult cerebral lesions in at least one-half, most often small ischemic lesions. ${ }^{66,67}$ Cerebral MRI has a greater sensitivity than CT in detecting cerebral lesions. Cerebral MRI also can affect the diagnosis of IE by adding 1 minor Duke criterion and can upgrade the diagnosis in up to $25 \%$ of patients presenting initially with nondefinite IE, leading to earlier diagnosis. ${ }^{68}$

Current recommendations are that surgery should be delayed for 1 to 2 weeks in patients with nonhemorrhagic strokes and for 3 to 4 weeks in patients with hemorrhagic strokes. Patients with severe neurologic deficits, unconscious patients, and those unable to follow simple commands should not be operated on until neurologic improvement has been demonstrated and potential for recovery established.

The etiology of intracranial hemorrhage in patients with IE includes hemorrhagic conversion of ischemic infarct, pyogenic arteritis, and rupture of mycotic aneurysm. Consequently, the associated risk of another bleed during a heart operation and the safe interval between onset of bleeding and surgery is likely to be specific to each causative etiology. To exclude a mycotic aneurysm, patients with intracranial bleeding must undergo cerebral angiography; however, the yield is low even in patients with bleeding, and indications for angiography are not well established. The presence of a mycotic aneurysm increases the risk of bleeding, and the neurologist and neurosurgeon should decide whether to treat and secure the aneurysm before the heart operation.

For those with nonhemorrhagic embolic strokes, the main concerns are worsening the neurologic damage and hemorrhagic conversion of the infarct during operation. The rationale for delaying operation is that the risk of worsening neurologic symptoms as a consequence of operation is time related, decreasing with increasing interval from the initial neurologic event. The risk of worsening the stroke symptoms must be weighed against the indications for surgery and the risk of additional emboli during the waiting period. If the patient is stable and risk of additional embolism is deemed to be low, delaying surgery for 1 to 2 weeks probably is beneficial, with repeat brain imaging before operation. Barsic and colleagues, ${ }^{69}$ however, found that performing surgery within 1 to 7 days after an ischemic stroke was not associated with increased in-hospital mortality. The importance of minimal hemorrhagic conversion in an ischemic stroke is yet to be determined. The endocarditis and stroke groups at Cleveland Clinic have agreed on a risk stratification algorithm in patients presenting with aortic or mitral IE: limited stroke $<3 \mathrm{~cm}$ and no or microhemorrhage $=$ low risk, acute stroke $>3 \mathrm{~cm}$ without or with small hemorrhagic conversion $=$ moderate risk, and large acute hemorrhage $=$ high risk (evidence level C).

\section{Should All Patients With IE Scheduled for Surgery Have Preoperative Brain Imaging? (Table 3-2)}

There is no argument about the need for brain imaging in all patients with neurologic deficits. Whether brain imaging should be performed in all patients with IE remains controversial. The yield in asymptomatic patients is lower but still significant. The presence of lesions was demonstrated in 35 of 44 brains from cases with proven IE in an autopsy study by Patel and colleagues. ${ }^{70}$ Cooper and colleagues ${ }^{67}$ reported detection of brain embolization in $70 \%$ of patients in whom clinical evaluation did not reveal a neurologic deficit. Importantly, in their study, mortality seemed to be similar among patients with clinical stroke or with subclinical brain embolization (62\% and 53\%, respectively), whereas it was significantly lower $(12 \%)$ in those with a negative MRI. Many centers routinely image the brain with CT or MRI before operation to identify patients who may harbor embolic lesions that could pose a higher risk of intracranial bleeding with heparin administration and cardiopulmonary bypass. Optimal imaging requires use of contrast, with its renal toxicity. If surgery must be delayed 
TABLE 3. Presurgical work-up and management of patients with IE

Recommendations

COR LOE References

1. What is the effect of neurologic complications, embolic stroke, brain hemorrhage, and mycotic aneurysm on indication for and timing of surgery?

\begin{tabular}{|c|c|c|c|}
\hline $\begin{array}{l}\text { If a cerebral mycotic aneurysm has been diagnosed, treatment and } \\
\text { follow-up of the patient should be in close collaboration with neurologic } \\
\text { and neurosurgery expertise }\end{array}$ & I & C & $3,4,6,155$ \\
\hline $\begin{array}{l}\text { In patients with a recent intracranial hemorrhage, a delay of operation for } \\
3 \text { or more weeks is reasonable }\end{array}$ & Ila & B & $\begin{array}{l}3-6,138,141 \\
156-159\end{array}$ \\
\hline $\begin{array}{l}\text { Earlier surgery is reasonable for patients with non-hemorrhagic strokes } \\
\text { and a strong cardiac indication for urgent surgery }\end{array}$ & Ila & B & $\begin{array}{l}3-6,69,157 \\
160-162\end{array}$ \\
\hline $\begin{array}{l}\text { Patients with large and multiple strokes and severe neurologic symptoms } \\
\text { should be carefully evaluated by a neurologist before being offered } \\
\text { surgery }\end{array}$ & I & B & $3,4,6$ \\
\hline $\begin{array}{l}\text { For patients with IE and neurologic symptoms and significant intracranial } \\
\text { hemorrhage, angiography should be considered to rule out mycotic } \\
\text { aneurysm }\end{array}$ & Ila & B & $3,4,6,155$ \\
\hline
\end{tabular}
aneurysm

2. Should all patients with IE scheduled for surgery have preoperative brain imaging?

\begin{tabular}{l|cc}
\hline $\begin{array}{l}\text { Endocarditis patients with neurologic symptoms should have brain } \\
\text { imaging }\end{array}$ & I & $3,4,6$ \\
\hline $\begin{array}{l}\text { It is reasonable to screen patients with left-sided IE for possible stroke or } \\
\text { intracranial bleeding before operation, particularly if they have cardiac } \\
\text { lesions considered high risk for embolic events }\end{array}$ & Bla & $66-68,70$ \\
\hline
\end{tabular}

3. What workup is needed for diagnosing primary infectious focus, secondary manifestations and complications (other than neurologic), and satellite infections in patients with IE?

\begin{tabular}{|c|c|c|c|}
\hline $\begin{array}{l}\text { Patients with IE should be screened for primary noncardiac focus of } \\
\text { infection, noncardiac complications, and satellite infections: The choice of } \\
\text { diagnostic procedure (e.g., CT, MRI, ultrasonography) varies, and the } \\
\text { selection should be individualized for each patient based on clinical } \\
\text { symptoms and suspicions }\end{array}$ & I & C & 3,4 \\
\hline
\end{tabular}

4. How should anticoagulation in patients with IE, with and without stroke or intracranial bleeding, be managed?

\begin{tabular}{l|cc}
\hline $\begin{array}{l}\text { Anticoagulation management in patients who have compelling indications } \\
\text { for anticoagulation, e.g., atrial fibrillation, mechanical prosthetic valve, } \\
\text { deep vein thrombosis, or pulmonary embolism, has to seek } \\
\text { compromises, taking all risks and benefits into consideration }\end{array}$ & I & 163-176 \\
\hline $\begin{array}{l}\text { Heparin should be used cautiously in all patients with IE, particularly } \\
\text { when there is evidence of brain hemorrhage, and be temporarily withheld } \\
\text { in patients with higher risk of rebleed }\end{array}$ & I & B \\
\hline
\end{tabular}

$C O R$, Classification of recommendations; $L O E$, level of evidence; $I E$, infective endocarditis; $C T$, computed tomography; $M R I$, magnetic resonance imaging.

to obtain additional imaging, the indication for additional imaging must be weighed against the risk of delaying the operation.

\section{What Workup Is Needed for Diagnosing Primary Infectious Focus, Secondary Manifestations and Complications (Other Than Neurologic), and Satellite Infections in Patients With IE? (Table 3-3)}

Screening for infected teeth is routine, as is colonoscopy in patients with IE caused by Streptococcus bovis (now Streptococcus gallolyticus). ${ }^{71-73}$ The search for other sources of bacteremia and satellite infections and mycotic aneurysms is guided by symptoms, specific signs, and causing organism. The 2015 AHA Scientific Statement notes the following regarding screening for metastatic foci of infection: "The choice of diagnostic modality or procedure (eg, CT, MRI, ultrasonography) varies, and the selection should be individualized for each patient (Class I; Level of Evidence C)." 3 There are currently no other recommendations for routinely evaluating all patients with IE for primary or metastatic foci of infection, although many clinicians recommend routine screening for all cases of $S$ aureus IE. Rather, a directed workup is advocated on the basis of localizing signs or symptoms. Patients with aspergillus IE have a greater risk of mycotic aneurysms. In recent years, studies have shown the diagnostic value of other imaging strategies and body imaging in patients with suspected or proven IE in identifying "silent emboli" and helping clinicians stage the "metastatic" lesions that may occur. ${ }^{74,75}$

1258.e10 The Journal of Thoracic and Cardiovascular Surgery • June 2017 
Desch and colleagues ${ }^{74}$ systematically performed wholebody CT scanning on admission in 64 patients and found systemic embolization in $62 \%$ (cerebral $36 \%$, splenic $46 \%$, and renal $24 \%$ ). Basic screening could include 18F-fluorodeoxyglucose PET/CT of the head, chest, and abdomen.

Spinal infections in patients with IE are important to keep in mind because both entities are associated with hematogenous seeding. In a large series of 606 IE cases, concomitant spondylodiscitis was diagnosed in 28 (4.6\%), constituting a one-third of 91 patients diagnosed with spondylodiscitis during the same period. ${ }^{76}$ The organisms implicated in both valvular and spinal seeding are mostly gram-positive bacteria and fungi. The clinical importance of screening patients with spinal infections for IE lies in the fact that oral therapy may be an option for uncomplicated pyogenic vertebral osteomyelitis, whereas it will not suffice for treating IE.

If the patient with IE is diagnosed with another infectious focus or abscess, spinal, splenic, or other, the treatment team has to take this into consideration and decide timing of intervention for this versus timing of the heart operation. The scenario with presence of large abscesses requiring immediate intervention is, however, very rare, and there is limited literature on which to base firm recommendations.

\section{How Should Anticoagulation in Patients With IE, With and Without Stroke or Intracranial Bleeding, Be Managed? (Table 3-4)}

In itself, IE is not an indication for anticoagulation therapy. The belief that vegetations consist of platelets, cells, and fibrin suggests that anticoagulation could prevent further growth of the vegetations and embolism. Current evidence, however, is to the contrary. The biofilm hypothesis, which suggests that the organisms themselves produce and "build" the vegetations, offers an explanation as to why this is the case. ${ }^{56}$ Not only is anticoagulation ineffective in preventing embolism, being on anticoagulation increases the risk of hemorrhagic conversion of an ischemic stroke and brain hemorrhage.

If the patient has a mechanical prosthetic valve or other strong indication for anticoagulation, the treatment team must decide whether anticoagulation is necessary, what to use, and what international normalized ratio or partial thromboplastin time level to target. There are many scenarios in which compromise is preferable, ie, less anticoagulation rather than more seems safer. If the patient has suffered a stroke, any anticoagulation adds to the risk of hemorrhagic conversion, and if bleeding already has occurred, this risk increases even more. Managing a patient with an infected rocking mechanical valve and intracranial bleeding remains a difficult dilemma requiring a consensus team approach to decision-making.

\section{What Additional Workup Is Needed Just Before Taking the Patient to Surgery? (Table 4-1)}

The high yield of brain imaging even in patients without obvious neurologic symptoms already has been discussed. When the decision has been made to operate, however, repeat brain imaging may be needed, depending on new neurologic symptoms, interval since the last examination, risk of embolism based on organism, vegetations, and pathology, and whether previous brain imaging demonstrated a stroke or hemorrhage. If the patient has a large stroke(s) and serious neurologic deficit, a neurologist should evaluate the perioperative risk of worsening symptoms and the prognosis and potential for recovery and rehabilitation. In cases with intracranial bleeding, the probability of mycotic aneurysm and need for cerebral angiography should be considered. A formal baseline preoperative neurologic examination should be documented for patients sustaining neurologic injury in the event that further neurologic injury is incurred during and after surgery.

Indications for coronary angiography should follow normal criteria for other surgical conditions. Previous coronary artery bypass grafting is a strong indication. The cardiologist about to perform the coronary catheterization often is justifiably concerned about provoking an embolic event and stroke, and this risk, the risk of worsening renal function with contrast, and the general condition of the patient must be taken into consideration. In patients who are undergoing surgery for aortic valve IE and need coronary artery evaluation, cardiac $\mathrm{CT}$ angiography could be a viable alternative to invasive coronary angiography in assessing coronary artery disease, especially when there are aortic vegetations that may be dislodged during catheterization.

Patients with a history of sternotomy need a preoperative CT of the chest; a CT without contrast provides the best information about cardiac structures and their proximity to the chest wall. For this purpose, MRI does not provide equally precise information. Contrast is not needed unless there are grafts to be localized as well, but in patients with grafts, coronary angiography also provides information about location and mobility of the grafts, indicating adherence or not to the sternum and chest wall.

\section{Is Preoperative Duration of Antibiotic Treatment Important? (Table 4-2)}

Clearing the bacteremia and having the patient on an effective antimicrobial regimen at the time of surgery is important. During the active phase, the operation itself is likely to provoke entry of new bacteria into the bloodstream. Experienced surgeons have operated on patients in whom the organisms turned out to be insensitive to the perioperative antimicrobial regimen, resulting in early relapse and progressive prosthetic valve infection despite changing to 
TABLE 4. Additional workup, preoperative antibiotics, and risk of operation for patients with IE

\begin{tabular}{|c|c|c|c|}
\hline Recommendations & COR & LOE & References \\
\hline \multicolumn{4}{|l|}{ 1. What additional workup is needed just before taking the patient to surgery? } \\
\hline $\begin{array}{l}\text { When surgery is decided upon, before going to the operating room, it is } \\
\text { reasonable to obtain brain imaging or repeat brain imaging }\end{array}$ & Ila & B & $67,68,70$ \\
\hline $\begin{array}{l}\text { The need for preoperative coronary angiography should be guided by normal } \\
\text { criteria. This is particularly important if the patient has had coronary artery } \\
\text { bypass grafting. In patients with large aortic valve vegetations, CT angiography } \\
\text { is an alternative to assess the coronary arteries }\end{array}$ & I & C & $3,4,6,177$ \\
\hline $\begin{array}{l}\text { When repeat sternotomy is required, computed tomography of the chest is } \\
\text { recommended when possible to assess risk of sternal reentry }\end{array}$ & Illa & C & 178 \\
\hline \multicolumn{4}{|l|}{ 2. Is preoperative duration of antibiotic treatment important? } \\
\hline $\begin{array}{l}\text { The patient should be on an effective antimicrobial regimen at the time of } \\
\text { surgery. Ideally, the sensitivity of the causative organism is known }\end{array}$ & I & B & $3-5,7,55,58$ \\
\hline $\begin{array}{l}\text { Once the patient is on an effective antimicrobial regimen, further delay of } \\
\text { surgery is unlikely to be beneficial }\end{array}$ & Illa & B & $\begin{array}{l}3-5,7,77,104,110 \\
125,179-181\end{array}$ \\
\hline \multicolumn{4}{|l|}{ 3. What is the risk of operation for IE? } \\
\hline $\begin{array}{l}\text { The patient should be quoted a risk, taking into consideration all factors known } \\
\text { to affect the risk of the operation }\end{array}$ & I & C & $34,78,79,182$ \\
\hline
\end{tabular}

COR, Classification of recommendations; $L O E$, level of evidence; $C T$, computed tomography; $I E$, infective endocarditis.

an effective regimen within a few days after operation, as soon as the organism and sensitivity were known. It is up to the infectious disease physician on the team to calculate the probability of this happening and advise the surgeon to proceed with the operation or wait for the cultures and sensitivity to be determined if that is possible.

As demonstrated by Mekontso Dessap and colleagues, ${ }^{77}$ the probability of positive cultures from explanted valves decreases with duration of preoperative treatment, but reaches its lowest level after 1 week and does not improve further. If a patient has moderate or severe aortic or mitral regurgitation and an indication for surgery (if he does not have active IE) but is stable, the decision about when to operate is a matter of clinical judgment depending on IE context (NVE vs PVE), stage (noninvasive vs invasive), and pathogen accessibility and sensitivity to antimicrobial treatment. If the patient has NVE, no evidence of invasive disease, and the pathogen is sensitive and responsive to the antimicrobial treatment, the chance of curing the infection is good, and delaying surgery until after a completed course of treatment is reasonable. If, on the other hand, the pathogen is unknown or difficult to treat and evidence of invasion exists, or if the patient has PVE, there is no evidence that delaying surgery to allow a longer period of preoperative treatment is beneficial.

\section{What Is the Risk of Operation for IE? (Table 4-3)}

Risk scores specific to IE surgery have been developed from the Society of Thoracic Surgeons database, ${ }^{34}$ and an additional NVE risk score from a single center by De Feo and colleagues. ${ }^{78}$ Wang and colleagues ${ }^{79}$ compared the prognostic utility of these contemporary risk scores for mortality and morbidity after IE surgery in 146 patients. The Society of Thoracic Surgeons IE score and the De Feo and colleagues ${ }^{78}$ NVE score were good predictors of operative mortality after surgery for active IE. Both these and the European System for Cardiac Operative Risk Evaluation II were also good discriminators of postoperative morbidities, particularly permanent stroke and prolonged ventilation ( $>24$ hours).

It is important for the infectious disease and cardiology teams first diagnosing and treating these patients to recognize the stage of the disease and the patient's potential need for surgery and to involve the cardiac surgeon early in the course. Patient comorbidities, disease stage, complications, acuity, as well as surgeon and treatment team experience, all will affect risk. The risk spectrum is particularly wide in this group of patients. At one end of the spectrum we have the patient who has double PVE, dehisced valves and abscesses, and is septic and very sick; and at the other end is the patient with 1 large mobile vegetation on a native valve without valve dysfunction. The first patient must undergo operation to have any chance of survival. The other patient presently is asymptomatic clinically but at risk of suffering a major embolic event. Surgically, taking the first patient on is a very high-risk, difficult, technical undertaking, while taking the second patient on is a simple low-risk procedure. When the patient is sick in the acute phase, the risk may change hour by hour and often in an unfavorable direction. 


\section{SPECIFIC ISSUES RELATED TO CONDUCT OF OPERATIONS FOR ENDOCARDITIS \\ Intraoperative TEE (Table 5-1)}

Echocardiography at the time of surgery is an important diagnostic adjunct in patients with IE and is a Class I recommendation by the American Society of Echocardiography. ${ }^{80}$ Because there may be an interval from initial diagnostic imaging to surgery, the findings on intraoperative echocardiography may differ in degree and extent from the original findings. Furthermore, it may be possible to perform a more extensive and detailed study when the patient is fully asleep. It is important that the intraoperative echocardiogram before surgery be comprehensive and use the most advanced technology possible, including 3-dimensional echocardiography when available. A thorough evaluation by an experienced echocardiographer of not only the valve(s) known to be affected, but of all valves, should be performed, because extension of infection by primary or secondary spread is common and may be overlooked. Abscess and fistula formation and progression in severity of regurgitation should be sought. Findings should be recorded, reported, and discussed with the surgeon performing the operation. On completion of operation, a comprehensive echocardiogram should again be performed to detect any important residual pathology or complications and should be video recorded to provide images that serve as a source of comparison should subsequent concerns about relapse or recurrence of infection arise.

\section{Operative Approach (Table 5-2)}

Sternotomy usually is required for operations to treat IE, because unexpected findings and discovery of more advanced disease than anticipated are common. Good exposure is required for radical debridement.

Surgeons who are comfortable with less invasive operations and experienced enough with IE can approach aortic valve IE via ministernotomy or mitral valve IE via rightsided minithoracotomy, but if unsuspected, more advanced, or invasive disease is present, these approaches are likely to provide insufficient exposure.

\section{Removal of Infected Tissue: Radical Debridement (Table 5-3)}

When treating infections, it is a fundamental surgical principle to remove infected material, foreign bodies, and necrotic tissue to minimize the residual infectious burden and provide optimal access for host-defense and antimicrobial therapy by surrounding the area with healthy wellvascularized tissue. Because it is easy to overlook pockets of infection, debridement requires good exposure. The surgeon must have an excellent understanding of the anatomy and pathology and review the TEE in the operating room with an expert echocardiographer. Vegetations, necrotic tissue, and foreign material may hold onto, hide, and protect viable organisms. The biofilm hypothesis offers a good explanation of why its surgical disruption and removal improve the ability of antimicrobials to cure the infection. ${ }^{56}$

Radical debridement means complete removal of foreign material, necrotic tissue, vegetations, and biofilm. "Radical" does not mean excision with wide margins, which may jeopardize valve repair, injure coronaries, cause permanent heart block, and make reconstruction of the heart more difficult.

Infected areas must be opened and unroofed and all infected pockets cleaned out. In patients with PVE, debridement should include removal of the old prosthesis and suture material. Mitral annular calcification often is present in patients with mitral valve IE, and the calcium itself may be the site of infection. In these cases, debridement has to remove infected calcium and expose migrating infection spreading in and along it; however, it must not be so radical that reconstruction is jeopardized. Whenever entering infected areas, having a "dirty" noncardiotomy suction available is mandatory to avoid contamination of the entire field. Use of cardiotomy suction is avoided until the field is clean to minimize blood contamination.

Debridement is followed by generous irrigation. Many surgeons use local antiseptics and antimicrobials, but no studies specific to IE support the value of this practice. Surgical instruments and gloves should be exchanged after removing all infected tissue and completing irrigation.

\section{Choice of Reconstruction and Valve Replacement: General Considerations and Recommendations (Table 5-4)}

For NVE, and for the mitral valve in particular, the advantage of valve repair over replacement is well documented, although this finding is open to the critique that patients requiring replacement have more advanced disease and are sicker. For patients requiring valve replacement, there is little evidence that risk of recurrent infection is different between mechanical and tissue prostheses. Several studies have suggested that use of an allograft in patients with aortic valve IE is associated with better survival and lower risk of relapse (no early phase of recurrent infection). Recent publications have questioned the superiority of allografts and highlight their inferior durability compared with alternatives. ${ }^{81,82}$ The national trend is to use biologic valves rather than mechanical valves and allografts ${ }^{83}$; however, allografts still are used more often in cases of invasive PVE. Also, the Ross operation has been used in selected patients with aortic valve and root IE.

Patients with IE often are very sick and have suffered strokes; therefore, the use of allografts or bioprosthetic valves simplifies management and avoids postoperative 
TABLE 5. General features of intraoperative management of patients with IE

\begin{tabular}{|c|c|c|c|}
\hline Recommendations & COR & LOE & References \\
\hline \multicolumn{4}{|l|}{ 1. Intraoperative TEE } \\
\hline Intraoperative TEE is mandatory when performing surgery for IE & I & B & $3-5,80,90,97,183-187$ \\
\hline \multicolumn{4}{|l|}{ 2. Operative approach } \\
\hline Medium sternotomy is the recommended approach, with few exceptions & I & C & \\
\hline \multicolumn{4}{|l|}{ 3. Removal of infected tissue: Radical debridement } \\
\hline $\begin{array}{l}\text { All infected and necrotic tissue and foreign material should be radically debrided } \\
\text { and removed }\end{array}$ & $\mathbf{I}$ & B & 43,85 \\
\hline \multicolumn{4}{|c|}{ 4. Choice of reconstruction and valve replacement: General considerations and recommendations } \\
\hline $\begin{array}{l}\text { For patients with NVE and infection limited to the valve cusps or leaflets, repair } \\
\text { is performed whenever possible }\end{array}$ & I & B & $3-6,43,152,188-198$ \\
\hline $\begin{array}{l}\text { When simple valve replacement is required, choice of valve-mechanical or } \\
\text { tissue prosthesis-should be based on normal criteria: age, life expectancy, } \\
\text { comorbidities, and expected compliance with anticoagulation }\end{array}$ & I & B & $4-6,197,199-201$ \\
\hline $\begin{array}{l}\text { It is reasonable to avoid use of mechanical prostheses in patients with any } \\
\text { intracranial bleeding or those who have suffered a major stroke }\end{array}$ & Ila & C & \\
\hline $\begin{array}{l}\text { For patients with invasive disease and destruction, reconstruction should } \\
\text { depend on the involved valve, severity of destruction, and available options for } \\
\text { cardiac reconstruction }\end{array}$ & $\mathbf{I}$ & B & $6,43,44,85,111,202,203$ \\
\hline \multicolumn{4}{|l|}{ 5. Native aortic valve IE } \\
\hline $\begin{array}{l}\text { For patients with native aortic valve IE and infection limited to the valve cusps, } \\
\text { repair may occasionally be possible. Choice of replacement valve-mechanical } \\
\text { or tissue prosthesis-should be based on usual criteria }\end{array}$ & I & B & $4-6,43,83,197-201$ \\
\hline $\begin{array}{l}\text { For invasive and destructive native aortic valve IE requiring root reconstruction } \\
\text { and replacement, using an allograft may be beneficial, but a prosthetic bioroot } \\
\text { or prosthetic valved conduit with a mechanical or bioprosthetic valve are } \\
\text { acceptable alternatives, with choice guided by surgeon training and experience }\end{array}$ & Ila & B & $\begin{array}{l}6,8,44,81,82,199,200 \\
204-208\end{array}$ \\
\hline \multicolumn{4}{|l|}{ 6. Prosthetic aortic valve IE } \\
\hline $\begin{array}{l}\text { If the root and the annulus are preserved after radical debridement, it is } \\
\text { reasonable to implant a new prosthetic valve-mechanical or tissue-based on } \\
\text { normal criteria }\end{array}$ & Ila & B & 6,44 \\
\hline $\begin{array}{l}\text { If there is annulus destruction and invasion outside the aortic root and root } \\
\text { reconstruction and replacement is required, an allograft or a biologic tissue root } \\
\text { is preferable to a prosthetic valved conduit }\end{array}$ & Ila & B & $\begin{array}{l}6,8,44,81-83,85,200 \\
202,204,206-217\end{array}$ \\
\hline \multicolumn{4}{|l|}{ 7. Native mitral valve IE } \\
\hline $\begin{array}{l}\text { Mitral valve repair is the preferred choice whenever possible, including use of a } \\
\text { prosthetic annuloplasty ring when appropriate }\end{array}$ & I & B & $43,152,188-196$ \\
\hline $\begin{array}{l}\text { When valve replacement is required, a prosthetic valve, either mechanical or } \\
\text { tissue, is acceptable, unless there is risk of intracranial bleeding, in which case } \\
\text { a tissue valve is preferred }\end{array}$ & Ila & B & $4-6,199,201$ \\
\hline $\begin{array}{l}\text { When there is annulus destruction and invasion, the mitral annulus is } \\
\text { reconstructed and the valve prosthesis anchored to the ventricular muscle or to } \\
\text { the reconstruction patch in a way that prevents leakage and pseudoaneurysm } \\
\text { development beneath the prosthesis }\end{array}$ & Ila & B & $43,188,192,203$ \\
\hline
\end{tabular}

\section{Prosthetic mitral valve IE}

A new prosthetic mitral valve, mechanical or tissue, is acceptable, unless there

is risk of intracranial bleeding, in which case a tissue valve is preferred

When there is annulus destruction and invasion, the mitral annulus is

reconstructed and the valve prosthesis anchored to the ventricular muscle or to the reconstruction patch in a way that prevents leakage and pseudoaneurysm development beneath the prosthesis

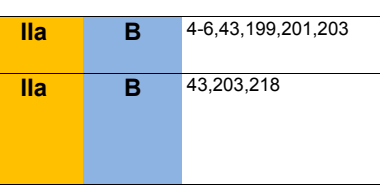

9. Double-valve IE

If the aortic root and aortic and mitral annuli are preserved after radical debridement, it is reasonable to implant mechanical or biologic valves, with the choice based on normal criteria

If there is aortic annulus destruction and invasion, and root reconstruction and replacement is required, an allograft or bioroot may be preferable to a prosthetic valved conduit, and if the mitral annulus shows invasion and destruction, it should be reconstructed to anchor the valve prosthesis to the ventricular muscle or to the annulus reconstruction patch to avoid leakage and pseudoaneurysm development beneath the prosthesis

Infection destroying the intervalvular fibrosa requires reconstruction of this structure, and it is preferable that surgeons taking on these cases master such techniques

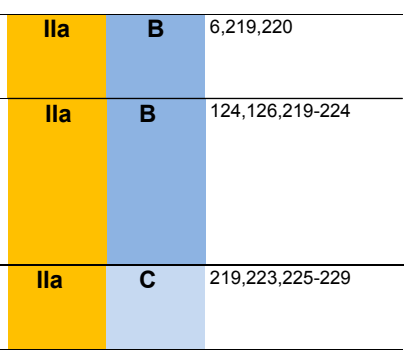

\section{Right-sided IE}

The primary objective of surgery for right-sided IE is radical debridement of infected vegetations and foreign material

Tricuspid valve repair should be attempted whenever possible

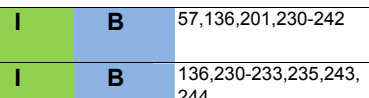


anticoagulation, lowering the risk of hemorrhagic conversion of strokes and other bleeding complications.

\section{Native Aortic Valve IE (Table 5-5)}

For disease confined to the cusps, repair may occasionally be possible. Choice of replacement valve-mechanical or tissue prosthesis - should be based on the usual criteria. When the disease is invasive and the annulus destroyed, reconstruction and usually root replacement are required. For invasive disease, many surgeons believe that an allograft is a better choice than a prosthetic valved conduit. (This is discussed further under "Prosthetic Valve Endocarditis."')

When additional material is needed, autologous pericardium, bovine pericardium, and other material have been used. The choice is according to surgeon preference, but no material has proven superior to autologous pericardium. In patients with invasive aortic valve IE, the destruction most often leaves the left ventricular outflow tract intact, and no additional material is needed.

\section{Prosthetic Aortic Valve IE (Table 5-6)}

Prosthetic valve infections often involve the sewing ring circumferentially, and deeper invasion and destruction can be anywhere around the circumference, but the usual areas are posterior and toward the left under the pulmonary artery or toward the right atrium. Occasionally the sewing ring is infected, but the infection has not yet penetrated deeper and outside the root. When that is the case and the debridement is adequate, it is possible and feasible to implant another prosthetic valve of choice.

More often, though, pockets of infection outside the root need to be opened, unroofed, and debrided. When the infection invades toward the right behind the central fibrous body, it reaches the conduction bundle and the atrioventricular node, and damage to these structures results in heart block. The more extensive and destructive the infection, the stronger is the argument in favor of an allograft over alternative conduits with prosthetic valves. Bioroots, porcine aortic roots, or bovine pericardium roots also may work well if allografts are unavailable. Allograft durability is an issue, maybe even in relation to bioprosthetic roots, but in patients with advanced invasive active IE the primary concern is immediate survival and cure of the infection, and in this subgroup there is still strong support for use of allografts. Kim and colleagues ${ }^{82}$ and Kirklin ${ }^{84}$ question the superiority of allografts for IE based on no difference in mortality and worse durability. The cited studies, however, all report a fairly high mortality. The $3.5 \%$ morality for PVE presented by Sabik and colleagues ${ }^{85}$ is yet to be matched. Experience and mastery of the technique used is a condition for good outcomes, and it may be that the surgeon is as important as the choice for reconstruction. Several classic studies have shown that allografts prevent the early hazard phase of relapse, and in the study by Sabik and colleagues, ${ }^{85}$ use of an allograft for PVE was associated with medium-term survival comparable with that of patients undergoing operation for aortic valve disease other than IE. Direct comparisons of allografts and other replacement alternatives are difficult because allografts have primarily been used for patients with more invasive and destructive disease. It also may be that greater awareness of the importance of radical debridement has reduced the added benefit of allografts.

\section{Native Mitral Valve IE (Table 5-7)}

Invasive and destructive disease is less common in the mitral than aortic position, and when invasion occurs it often is shallow. When, however, invasion penetrates deeper into the atrioventricular groove, it is much more serious, and radical debridement and sterilization and drainage of the infected area are more difficult. The surgeon needs to be aware that the ability of echocardiograms, including TEE, to demonstrate invasive disease is less for the mitral valve.

When valve replacement is required, there is no established alternative to prosthetic valves. To anchor the prosthesis, the annulus must be reconstructed. Autologous pericardium and bovine pericardium have been used, as well as commercially available matrix membranes. No follow-up data are available to indicate the best choice. When available, however, nothing has proved better than autologous pericardium. When reconstructing the mitral annulus and patching entry sites into pseudoaneurysms, patches must be generous to minimize stress on the suture lines. Residual communications beneath the valve into infectious cavities must be avoided. Infected cavities in the atrioventricular groove can be drained to the pericardium or atrium, but most often, neither of these alternatives comes naturally to the surgeon, and the risks associated with both are not well known.

\section{Prosthetic Mitral Valve IE (Table 5-8)}

Differences between the options for NVE and PVE are less obvious for the mitral than the aortic valve. Again, the surgeon must be aware that the ability of TEE to disclose the full extent of the pathology is even worse for PVE, particularly when the prosthesis is mechanical. The main difference is that exposure for debridement and removal of the old prosthesis and suture material is worse than for the aortic valve and left ventricular outflow tract. A dual approach from the left atrium and aorta often is helpful. Again, deep invasion into the atrioventricular groove is uncommon, allowing direct implantation of a new prosthesis without additional reconstruction in most cases. When annulus reconstruction is needed, autologous pericardium, bovine pericardium, and other material have been used. Anchorage to the ventricular muscle to prevent communication and entry into paravalvular cavities beneath the valve is 
important. Again, repair patches must be generous to minimize tension on the suture lines.

\section{Double-Valve IE (Table 5-9)}

In most cases, IE of both the aortic and mitral valve can be managed in accordance with the recommendations given for each of these valves separately. Destruction of the fibrous structure between the aortic and mitral valves-the intervalvular fibrosa or aortomitral curtain - requires reconstruction, and this advanced pathology and the reconstructive surgery have been associated with high risk. Several techniques for performing the reconstruction have been described. These operations are technically demanding, high risk, and require a very experienced valve surgeon.

\section{Right-Sided IE (Table 5-10)}

The primary objective of surgery for right-sided IE most often is to eliminate the cause of persistent sepsis and a source of septic emboli to the lung and less often to repair the valve. This means removing infected vegetations and foreign material. Valve repair or replacement is a secondary objective.

Patients with right-sided IE often are injection drug users and poorly compliant patients. For patients with tricuspid valve IE, the best possible repair and preservation of the patient's own valve is the primary choice. If the patient has low or normal pulmonary pressures and low or normal pulmonary vascular resistance, excising the valve and leaving free tricuspid valve regurgitation may allow the patient to survive but will leave him or her symptomatic with right-sided congestion or even overt right heart failure. If the patient has increased pulmonary pressure and resistance, excising the valve is not advisable.

On the right side of the heart, most surgeons have a preference for bioprosthetic valves, although this preference is not based on any comparative studies. With mechanical valves, access to the right ventricle and pulmonary artery for catheterization and pacemaker leads is lost. The risk of valve thrombosis may be increased on the right side of the heart, because valve irrigation is not as vigorous. Any prosthetic valve in the tricuspid position is associated with increased risk of recurrent IE, particularly in patients who resume injection drug use.

\section{Should Regular Synthetic Vascular Grafts or Valveless Allografts Be Used When the Aorta Must Be Replaced Beyond the Root? (Table 6-1)}

The standard choice is to use a regular synthetic graft to replace the ascending aorta and arch when needed. Many aortic surgeons soak a gel-impregnated graft with rifampin, amphotericin, or aminoglycoside, depending on the organism. The gel binds the antimicrobial in 4 to 6 days. We found no evidence to support this practice.
Following the argument that allografts may be more resistant than regular synthetic vascular grafts to reinfection, some surgeons consider it logical to extend an allograft with another valveless allograft, but evidence of benefit is lacking. The use of an allograft may make sense if the root has been replaced with an allograft and the field is grossly infected. Extending an allograft into the arch may set up a more difficult reoperation if the allograft has had time to calcify.

\section{Should Additional Prostheses and Vascular Grafts Not Proved to Be Infected Be Removed and Replaced? (Table 6-2)}

A vascular graft surrounded by pus is infected and should be removed. Often, however, it is not easy to decide if a graft or device is infected.

What is the chance that these other implants are infected even if we see no macroscopic evidence of such? This risk is related to the causative microorganism and duration of disease and bacteremia. A pragmatic approach is that if it is easy and associated with limited added risk, removing and replacing them is reasonable, whereas if it would be difficult and add importantly to operative risk, those implants could be left alone. If the operation is for mitral PVE, removing an aortic prosthesis may facilitate the operation. The final decisions can be made only by the surgeon at the time of surgery.

\section{When Should Permanent Pacemaker Systems Be Removed in Patients Undergoing Surgery for IE? (Table 6-3)}

The answer is easy when the system is infected and in right-sided IE affecting the tricuspid valve, but less clear in the case of left-sided IE and no convincing evidence of pacemaker and lead involvement. In the operating room, leads in the right atrium always have tissue-fibrin and clot deposits around them that are indistinguishable from infective vegetations. We do not have any additional recommendation beyond those given by ACC/AHA. ${ }^{5}$ Removal of leads and the pacemaker is reasonable but adds to complexity postoperatively and to the question of if, when, and how the system should be replaced. Insertion of a new epicardial system in the operating room facilitates postoperative management and is reasonable unless the field is grossly infected. (In the ACC/AHA guidelines, these recommendations are found under "Indications.."

\section{Should Patients With a Known Indication for a Pacemaker Receive a Pacemaker System With Epicardial Leads When Undergoing Operation for Active IE? (Table 6-4)}

This question is related to the previous question about removing endocardial pacemaker systems. Epicardial leads are less likely to become infected than transvenous leads, 
TABLE 6. Specific considerations in surgical management of patients with IE

\begin{tabular}{|c|c|c|c|}
\hline Recommendations & COR & LOE & References \\
\hline \multicolumn{4}{|c|}{$\begin{array}{l}\text { 1. Should regular synthetic vascular grafts or valveless allografts be used when the aorta must } \\
\text { be replaced beyond the root? }\end{array}$} \\
\hline $\begin{array}{l}\text { When distal ascending aorta, hemiarch, or arch replacement is required, a } \\
\text { synthetic graft is the standard choice, but a valveless allograft is an alternative } \\
\text { in an infected field for replacing the ascending aorta beyond the root }\end{array}$ & Illb & B & 127,245 \\
\hline \multicolumn{4}{|c|}{$\begin{array}{l}\text { 2. Should additional prostheses and vascular grafts not proved to be infected be removed and } \\
\text { replaced? }\end{array}$} \\
\hline $\begin{array}{l}\text { Inspection and removal of additional prostheses and vascular grafts, even if not } \\
\text { proved to be infected, should be considered and is reasonable if the causative } \\
\text { microorganism is } S \text {. aureus or fungus, provided that the added difficulty and risk } \\
\text { is not prohibitive }\end{array}$ & Ila & C & $127,246-249$ \\
\hline \multicolumn{4}{|c|}{$\begin{array}{l}\text { 3. When should permanent pacemaker systems be removed in patients undergoing surgery } \\
\text { for IE? }\end{array}$} \\
\hline $\begin{array}{l}\text { Complete removal of pacemaker or defibrillator systems, including all leads and } \\
\text { the generator, is indicated as part of the early management plan in patients with } \\
\text { IE and likely infection of the device or leads }\end{array}$ & I & B & $4,5,250-257$ \\
\hline $\begin{array}{l}\text { Complete removal of pacemaker or defibrillator systems, including all leads and } \\
\text { the generator, is reasonable in patients with right- or left-sided valvular IE } \\
\text { caused by S. aureus or fungi, even without evidence of device or lead infection }\end{array}$ & Ila & B & $4,5,250,252-258$ \\
\hline $\begin{array}{l}\text { Complete removal of pacemaker or defibrillator systems, including all leads and } \\
\text { the generator, is reasonable in patients undergoing surgery for valvular IE } \\
\text { caused by any organism }\end{array}$ & Illb & C & $4,5,256$ \\
\hline
\end{tabular}
caused by any organism

4. Should patients with a known indication for a pacemaker receive a pacemaker system with epicardial leads when undergoing operation for active IE?

At the time of surgery for IE, implantation of a new pacemaker system with epicardial leads may be considered when the patient is pacer dependent and has effective antimicrobial coverage

5. Are there any safety concerns regarding use of mechanical valves in patients with IE?

Mechanical valves should be avoided in patients with IE and evidence of $\quad$ I $\quad$ C intracranial bleeding or large brain infarcts, and in patients who are very sick and anticipated to have a prolonged postoperative course

6. Is there any role for local antimicrobials or antiseptics during surgery for IE?

After completed debridement, generous irrigation of the surgical field with normal saline is recommended

\section{How should infected areas be drained?}

Whenever feasible, leaving infected areas open to the circulation or the pericardium is optimal from the standpoint of treating the infection

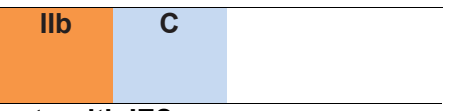

$\begin{array}{lll}\text { I } & \text { C } & 164\end{array}$

\section{How should operative specimens be handled?}

Operative specimens should be secured for examination by the pathologist to determine presence of organisms and inflammatory activity

Operative specimens should be used for microbiologic and molecular testing to

identify or confirm the pathogens and their sensitivity to antimicrobial therapy

9. What is the role of molecular testing with PCR in identifying pathogens?

Whenever there is clinical suspicion of IE and doubt about the causative organism, molecular testing can be useful to identify and confirm the pathogens or causative organisms in the operative specimens

10. What postoperative antimicrobial treatment is required, and for how long should the patient be treated? When perioperative cultures and organism sensitivity are known, the antimicrobial regimen and duration of treatment are reconsidered and decided upon

After surgery for active IE, standard duration of postoperative intravenous antimicrobial treatment is 6 weeks, counted from the day of surgery, but regimen and duration may be modified and adjusted depending on the organism and its sensitivity to antimicrobials, treatment response, and pathology For fungal IE, lifelong oral suppressive therapy is reasonable

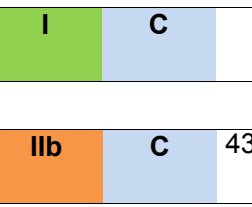

43

\begin{tabular}{|c|c|c|}
\hline I & B & $4,7,86,259$ \\
\hline I & A & $\begin{array}{l}4,7,58,86,259 \\
260\end{array}$ \\
\hline
\end{tabular}
Ila B 4,7,31,58, 259-264 
and it is therefore logical to consider placing permanent epicardial leads at the end of the operation. For patients at increased risk of becoming reinfected, for example, those on dialysis, injection drug users, or those with ongoing bacteremia at the time of pacemaker removal, such a strategy is even more attractive. Many considerations must be taken into account, including limited venous access, dialysis, pacemaker dependency, and need for left ventricular pacing. Pacing thresholds, however, may be higher with epicardial leads, causing more rapid draining of the pacemaker power supply. A discussion with an electrophysiologist preoperatively may be wise.

\section{Are There Any Safety Concerns Regarding Use of Mechanical Valves in Patients With IE? (Table 6-5)}

Committing a sick patient with IE to anticoagulation adds complexity to postoperative management and increases the risk of bleeding. Intracranial bleeding is the primary concern, but very sick patients also are at increased risk of bleeding from the gastrointestinal tract and other places postoperatively.

\section{Is There Any Role for Local Antimicrobials or Antiseptics During Surgery for IE? (Table 6-6)}

Debridement followed by irrigation is included in fundamental surgical principles for managing infections. Irrigation removes residual tissue debris and loose infected material and is an integral part of any valve operation. In addition to normal saline irrigation, many surgeons use local antiseptics and antimicrobials, and some even inject antimicrobials into the tissue around the infected area. There is no evidence for this practice specific to IE, either with regard to benefit or harm.

\section{How Should Infected Areas Be Drained? (Table 6-7)}

Draining the infected area is a fundamental surgical principle for managing infections. For invasive aortic IE, the answer is easy: leaving the infected area open to the pericardium is natural and intuitively better than patching and excluding infected areas and cavities. For mitral valve IE, when there is invasion into the atrioventricular groove, the options are sterilizing the cavity and closing it, allowing it to communicate with the atrium, or allowing communication to the ventricle (risk of aneurysm development) or drainage to the pericardium (risk of bleeding). Allowing communication to the ventricle is the least attractive alternative. Any cavity communicating with the circulation is a potential source of embolism, and if the cavity is communicating with the ventricle, there is risk of a growing pseudoaneurysm. These are difficult decisions for the surgeon, and only she or he can weigh the options and the associated risks and benefits and decide. Awareness of the options and risks provides the best guidance, and treatment is usually individualized based on appearance and the specific technical problems in a given patient.

\section{How Should Operative Specimens Be Handled? (Table 6-8)}

Operative specimens offer another opportunity to identify the pathogen and test its sensitivity to antimicrobials. In blood culture-negative IE, operative specimens are particularly valuable. Specimens should be handled properly and divided between pathology and microbiology for microscopy and cultures. Pathology, looking for inflammation, neovascularization, and organisms on staining, remains the gold standard for IE (see Von Reyn and colleagues $^{86}$ and the Duke criteria ${ }^{50,52}$ ). Molecular testing with PCR should be considered whenever there is uncertainty regarding the causative microorganism (see next question). A retrieved embolus may also provide pathogen diagnosis.

\section{What Is the Role of Molecular Testing With PCR in Identifying Pathogens? (Table 6-9)}

Identifying the specific pathogen is central to selecting appropriate antimicrobial therapy. Comorbid conditions and the often complicated and prolonged illnesses of patients with IE necessitate careful consideration of culture results before assigning causative status to microorganisms isolated in various cultures. In the case of culture-negative IE, microbial nucleic acid sequencing has been shown to be useful in identifying fastidious microorganisms and nonculturable pathogens (eg, Tropheryma whipplei [agent of Whipple disease], Coxiella burnetii [agent of Q fever], and Bartonella spp. [agent of cat scratch disease]). Molecular testing involves amplification by PCR, followed by DNA sequencing of any amplified product. Bacterial DNA sequencing may identify the causative microorganism in many cases of IE in which blood and valve cultures have failed. Sequencing cannot provide susceptibility results, but in the future, PCR and sequencing may prove to be the primary test for identifying pathogens in excised cardiac valves.

\section{QUESTIONS RELATED TO POSTOPERATIVE MANAGEMENT \\ What Postoperative Antimicrobial Treatment Is Required, and for How Long Should the Patient Be Treated? (Table 6-10)}

Postoperative antimicrobial treatment and duration should be a decision made in concert with infectious disease specialists using recent guidelines as the general framework. ${ }^{3,4,7}$ Standard duration of postoperative intravenous antimicrobial treatment is 6 weeks when the infection is active at the time of surgery, but this may be modified by clinical scenarios. Some have suggested that uncomplicated IE caused by susceptible pathogens can be treated for as little as 2 weeks. It has also been suggested 
that in patients with IE caused by enterococci, duration of treatment with antimicrobials associated with important harmful side effects, for example, aminoglycosides, can be shorter or avoided after surgical control of the infection source. Longer duration of treatment may be justified for more invasive infections, difficult-to-treat organisms, or presence of hardware and satellite infections, such as osteomyelitis.

For fungal infections, lifelong oral suppression has been suggested. Long-term, even lifelong, suppression also has been used for vascular graft and other implant infections. The efficiency of these practices is not well studied.

\section{What Is the Need for Follow-up and Additional Screening for Infectious Foci That Could Cause Recurrent Infection/IE? (Table 7-1)}

Postoperatively, we should review patients for probable sources of bacteremia and sanitize those, for example, sanitation of the teeth and mouth. Patients with IE caused by $S$ gallolyticus often have colon polyps or colon cancer and should undergo colonoscopy. Repeat echocardiogram before discharge should be routine.

During the first 6 months after surgery, when there is risk of relapse, patients should be followed by an infectious disease specialist. It is unknown whether patients operated on during the active phase of IE before completing their full course of preoperative antimicrobials are at increased risk of recurrent IE.

After 6 months, continued follow-up with a cardiologist is more appropriate. Because of worse tissue quality when the infection is active, after surgery there is increased risk of valve dehiscence, paravalvular leak, and pseudoaneurysm formation, all good reasons for follow-up echocardiograms to verify healing. Patients also are at increased risk of persistent and recurrent IE. Most patients with IE receive bioprosthetic valves or an allograft with limited durability, so careful long-term follow-up with a cardiologist is important.

Drug abuse is associated with increased risk of relapse and recurrent, difficult-to-cure IE. Rehabilitation, seamless transition of care, and mobilization of social support are essential for any chance of success.

\section{What Is the Risk of Relapse and Recurrent IE?}

(Table 7-2)

Several long-term follow-up studies include a diverse population of patients, NVE and PVE in any location, medically and surgically treated patients, and injection drug users, yet still have a limited number of patients. There is, however, no doubt that patients who have been treated for IE have a higher risk of recurrent infection, in the magnitude of $1 \%$ to $3 \%$ per patient-year.

Often these studies provide limited information about risk of relapse versus recurrence and lack a good description of the follow-up. The microorganism primarily defines relapse versus recurrence: IE caused by the same microorganism suggests relapse, whereas IE caused by a different microorganism suggests recurrence. We distinguish between early and late infection after implantation of a prosthetic heart valve, with early defined as within 1 year and late as after 1 year or more. Several studies have demonstrated 2 phases, an early hazard phase corresponding to relapse and a longer-term constant phase. One benefit of using allografts for aortic IE has been eliminating the early hazard phase.

\section{QUESTIONS RELATED TO RESIDUAL CONTROVERSIES}

\section{Should Surgical Treatment Be Offered to Injection Drug Users With IE? (Table 7-3)}

Narcotic addiction is a huge public health issue in the United States, and managing IE in these patients is only the tip of the iceberg. It is well documented that injection drug use is associated with IE, particularly right-sided IE. Drugaddicted patients are younger on average and most often at low surgical risk; the main issue is high risk of relapse and recurrent IE. Although operative risk is not higher, drugaddicted patients have a greater probability of death in the year after operation than do nonaddicted patients.

A major limitation of current medical care for injection drug users is that appropriate treatment for addiction is very difficult to access because of a lack of providers and facilities and lack of insurance and other means to pay for the scarce resources that may be available. Injection drug use is a very serious comorbidity that must be included and weighed in decision-making and be treated, mobilizing and taking advantage of all available resources and options for drug rehabilitation.

\section{Should Surgical Treatment Be Offered to Patients With IE on Dialysis? (Table 7-4)}

Patients on dialysis are 10 to 18 times more likely to develop IE than the general population, and their operative risk is greater and long-term outcomes worse than for patients who are not on dialysis. Nevertheless, it is reasonable to offer surgery when the additional burden of comorbidities is not overwhelming.

Patients in renal failure will calcify biologic implants faster than patients with good renal function, an argument used for avoiding such implants. Choice of valve, however, must be seen in the context of anticipated longevity of the patient and be weighed against the risks associated with use of a mechanical prosthesis and anticoagulation in a given patient. In support of this conclusion, several studies, including one devoted to IE, demonstrate that survival of patients on dialysis after valve surgery is not affected by valve choice. 
TABLE 7. Surveillance and special considerations for patients with IE

\begin{tabular}{|c|c|c|c|}
\hline Recommendations & COR & LOE & References \\
\hline \multicolumn{4}{|c|}{$\begin{array}{l}\text { 1. What is the need for follow-up and additional screening for infectious foci that could cause } \\
\text { recurrent infection/lE? }\end{array}$} \\
\hline $\begin{array}{l}\text { Primary infectious focus and microorganism portal of entry must be treated } \\
\text { during or just after the IE episode, including follow-up and screening for } \\
\text { underlying infectious foci and morbidities }\end{array}$ & I & B & $3,4,7$ \\
\hline $\begin{array}{l}\text { IE caused by Streptococcus gallolyticus is an indication for colonoscopy within a } \\
\text { reasonable time after operation }\end{array}$ & I & B & $3,4,71,72,267-270$ \\
\hline Patients with a history of injection drug use should be treated for their addiction & I & B & $3,4,57,242$ \\
\hline $\begin{array}{l}\text { After surgery for IE, eradication of the pathogen is essential and should be } \\
\text { verified by follow-up for } 6 \text { months with an infectious disease specialist }\end{array}$ & I & C & 3 \\
\hline $\begin{array}{l}\text { After valve surgery for IE, cure of the infection should be documented by } \\
\text { echocardiogram, and the patient should follow up with a cardiologist }\end{array}$ & $\mathbf{I}$ & C & 3 \\
\hline \multicolumn{4}{|l|}{ 2. What is the risk of relapse and recurrent IE? } \\
\hline $\begin{array}{l}\text { Patients who have undergone surgery for IE should be informed about the } \\
\text { increased risk of recurrent IE and the need for prophylaxis }\end{array}$ & I & B & $3,179,200,271-277$ \\
\hline \multicolumn{4}{|l|}{ 3. Should surgical treatment be offered to injection drug users with IE? } \\
\hline $\begin{array}{l}\text { Normal indications for surgery are reasonable to apply to patients who are } \\
\text { intravenous drug users. Decision-making must take the addiction into account, } \\
\text { and management must include treatment of the addiction }\end{array}$ & Ila & C & $\begin{array}{l}3,4,7,57,201,238 \\
242,278\end{array}$ \\
\hline \multicolumn{4}{|l|}{ 4. Should surgical treatment be offered to patients with IE on dialysis? } \\
\hline $\begin{array}{l}\text { Normal indications for surgery are also reasonable to apply to patients on } \\
\text { dialysis, but their additional comorbidity must be factored into their risk and } \\
\text { outcome assessment }\end{array}$ & Ila & C & $279-285$ \\
\hline $\begin{array}{l}\text { Patients with renal failure have shorter durability of bioprostheses and allografts } \\
\text { because of early calcification, and this may be considered in the choice of an } \\
\text { allograft or a bioprosthesis versus a mechanical valve }\end{array}$ & Ila & B & 280,281 \\
\hline \multicolumn{4}{|l|}{ 5. Should surgical treatment be offered to patients with IE and liver cirrhosis? } \\
\hline $\begin{array}{l}\text { Normal indications for surgery are reasonable to apply to patients with liver } \\
\text { cirrhosis, but their additional comorbidity must be factored into their risk and } \\
\text { outcome assessment }\end{array}$ & Ila & C & $87,286,287$ \\
\hline \multicolumn{4}{|l|}{ 6. Who should get antibiotic prophylaxis for IE? } \\
\hline $\begin{array}{l}\text { Patients who have undergone surgery for IE constitute a high-risk group for } \\
\text { recurrent IE and should be recommended for IE prophylaxis according to } \\
\text { guidelines }\end{array}$ & Illb & B & $3-5,88,288$ \\
\hline \multicolumn{4}{|l|}{ 7. How should patients with remote IE be managed? } \\
\hline $\begin{array}{l}\text { Normal indications for valve repair or replacement apply to patients with healed } \\
\text { or remote IE, but conditions predisposing for IE should be diagnosed and } \\
\text { treated }\end{array}$ & I & C & \\
\hline
\end{tabular}

COR, Classification of recommendations; $L O E$, level of evidence; $I E$, infective endocarditis.

\section{Should Surgical Treatment Be Offered to Patients With IE and Liver Cirrhosis? (Table 7-5)}

Liver cirrhosis is a risk factor for IE. In a recent multicenter Spanish study, nearly $10 \%$ of IE patients had liver cirrhosis. ${ }^{87}$ The importance of this comorbidity should be weighed in decision-making. The added operative risk associated with liver cirrhosis is related to its severity, as accessed by the Child-Pugh or Model for End-Stage Liver Disease score.

\section{Who Should Get Antibiotic Prophylaxis for IE? (Table 7-6)}

Current guidelines recommend restricting prophylaxis to the highest risk patients, defined as those with the highest incidence of IE or highest risk of adverse outcomes from
IE. ${ }^{3,4}$ Patients at greatest risk include those with prosthetic valves, previous IE, cyanotic congenital heart disease, and congenital heart disease repaired with prosthetic material. Antibiotic prophylaxis is not recommended for other forms of valvular or congenital heart disease.

As per guidelines from the $\mathrm{AHA}^{3}{ }^{3}$ evidence for prophylaxis has been found to be reasonable only for dental procedures that involve manipulation of gingival tissue, manipulation of the periapical region of the teeth, or perforation of the oral mucosa. In the case of other prosthetic material (excluding surgically created palliative systemic pulmonary shunts or conduits), such as annuloplasty rings, neochords, atrial septal closure devices, and mitral valve repair clips, there have been only sporadic case reports of infected devices. Given the low 
prevalence of infection and scarcity of data, there is no definitive evidence that prophylaxis in these patients is warranted.

The National Institute for Health and Care Excellence, United Kingdom guidelines ${ }^{88}$ take an even more radical departure from the previous prophylaxis standards in not recommending antibiotic prophylaxis for dental or nondental procedures (eg, respiratory, gastrointestinal, and genitourinary).

A surgical aspect to weigh is the consequences of another episode of IE. It will be higher risk and more devastating the more previous operations and the more prosthetic material the patient has in the heart.

\section{How Should Patients With Remote IE Be Managed? (Table 7-7)}

Patients with valvular disease and a history of endocarditis or treated and healed IE should be treated on the merits of their functional deficit. These patients are at greater risk of IE, but whether that risk is high enough to affect decisionmaking is unclear. We identified no study devoted to remote IE, but many studies in which remote or healed IE cases were included. Early after a complete course of treatment there may be uncertainty about residual infection. Whenever that is the case, it is important to carefully examine the operative specimens for inflammation and residual bacteria and to consider molecular testing (PCR). The findings will guide additional antimicrobial treatment.

\section{IDENTIFIED KNOWLEDGE GAPS}

For each recommendation the wording and level of evidence express the certainty inviting further research. In this section, we highlight a few that we believe are particularly important at this point in time.

1. Studies of timing of surgery for IE in patients with neurologic complications have so far not provided clear answers to optimal timing and risk stratification. These patients are at risk of complications not only during surgery but also before and after. Studies of the impact of intracranial bleeding on risk of open heart surgery related to symptoms (symptomatic, asymptomatic), context (primary bleed, hemorrhagic conversion of ischemic stroke), size of the bleed (micro, small, large), and so on, should allow better assessment of risk. Because benefits of early surgery have been widely recognized, the current trend is to offer earlier surgery to patients with neurologic complications.

2. Risk of embolism has remained a somewhat controversial indication for surgery and deserves more study. Kang and colleagues ${ }^{47}$ showed that the main advantage of earlier surgery was prevention of embolic events, but this did not affect short-term survival. Present indications focus on the size, mobility, and location of vegetations, but vegetations are not the only source of embolism. Although logic suggests immediate surgery for this indication, supporting data are still insufficient. Additional studies of new events, complications, and pathology progression occurring during the interval between diagnosis and operation are needed.

3. Imaging is still not perfect, particularly for mitral valve PVE, and there is more to learn about new imaging modalities. Improved and more precise diagnosis of invasive disease and advanced pathology are desirable for planning the operation and assessing the need for complex reconstruction. This will also allow better assessment of risk and prognosis.

4. Good contemporary studies of risk of relapse and recurrence in the era of earlier surgical interventions during the active phase of IE are needed. Recent studies have questioned whether allografts truly are better than prosthetic valves and conduits for any patient with IE.

5. Studies specific to IE of the possible benefits of local antiseptics and antimicrobials are lacking.

6. Information about the spectrum of infections, pathogens, and associated pathologies after implantation of transcatheter valves and other transcatheter devices is sparse. There are reports of an increased occurrence of IE after implantation of percutaneous prosthetic valves in the pulmonic position; these valve infections seem to respond better to antimicrobial treatment than anticipated for PVE in general.

7. Patients with a history of IE or remote IE present in different ways. Most show up with functional valve issues after the active infection has been cured with antimicrobials, and some have signs of invasive pathology with pseudoaneurysm and cavities. Long-term risks associated with these lesions are not well studied, and indications for intervention beyond those normally applicable to valve dysfunction have not been defined.

\section{Conflict of Interest Statement}

Authors have nothing to disclose with regard to commercial support.

\footnotetext{
References

1. Svensson LG, Gillinov AM, Weisel RD, Keshavjee S, Bacha EA, Moon MR, et al. The American Association for Thoracic Surgery Consensus Guidelines: Reasons and purpose. J Thorac Cardiovasc Surg. 2016;151:935-9.e1.

2. Institute of Medicine. Clinical Practice Guidelines We Can Trust. Washington, DC: National Academies Press; 2011.

3. Baddour LM, Wilson WR, Bayer AS, Fowler VG Jr, Tleyjeh IM, Rybak MJ et al. Infective endocarditis in adults: diagnosis, antimicrobial therapy, and management of complications: a scientific statement for healthcare professionals from the American Heart Association. Circulation. 2015;132:1435-86.

4. Habib G, Lancellotti P, Antunes MJ, Bongiorni MG, Casalta JP, Del Zotti F, et al. 2015 ESC Guidelines for the management of infective endocarditis: The Task Force for the Management of Infective Endocarditis of the European Society of Cardiology (ESC). Endorsed by: European Association for Cardio-
} 
Thoracic Surgery (EACTS), the European Association of Nuclear Medicine (EANM). Eur Heart J. 2015;36:3075-128.

5. Nishimura RA, Otto CM, Bonow RO, Carabello BA, Erwin JP 3rd, Guyton RA, et al. 2014 AHA/ACC Guideline for the Management of Patients With Valvular Heart Disease: executive summary: a report of the American College of Cardiology/American Heart Association Task Force on Practice Guidelines. Circulation. 2014;129:2440-92.

6. Byrne JG, Rezai K, Sanchez JA, Bernstein RA, Okum E, Leacche M, et al. Surgical management of endocarditis: the society of thoracic surgeons clinical practice guideline. Ann Thorac Surg. 2011;91:2012-9.

7. Gould FK, Denning DW, Elliott TS, Foweraker J, Perry JD, Prendergast BD, et al. Guidelines for the diagnosis and antibiotic treatment of endocarditis in adults: a report of the Working Party of the British Society for Antimicrobial Chemotherapy. J Antimicrob Chemother. 2012;67:269-89.

8. Svensson LG, Adams DH, Bonow RO, Kouchoukos NT, Miller DC, O'Gara PT, et al. Aortic valve and ascending aorta guidelines for management and quality measures. Ann Thorac Surg. 2013;95:S1-66.

9. Chirouze C, Alla F, Fowler VG Jr, Sexton DJ, Corey GR, Chu VH, et al. Impact of early valve surgery on outcome of Staphylococcus aureus prosthetic valve infective endocarditis: analysis in the International Collaboration of Endocarditis-Prospective Cohort Study. Clin Infect Dis. 2015;60:741-9.

10. Galvez-Acebal J, Almendro-Delia M, Ruiz J, de Alarcon A, MartinezMarcos FJ, Reguera JM, et al. Influence of early surgical treatment on the prognosis of left-sided infective endocarditis: a multicenter cohort study. Mayo Clin Proc. 2014;89:1397-405.

11. Lalani T, Chu VH, Park LP, Cecchi E, Corey GR, Durante-Mangoni E, et al. Inhospital and 1-year mortality in patients undergoing early surgery for prosthetic valve endocarditis. JAMA Intern Med. 2013;173:1495-504.

12. Sy RW, Kritharides L. Health care exposure and age in infective endocarditis: results of a contemporary population-based profile of 1536 patients in Australia. Eur Heart J. 2010;31:1890-7.

13. Curlier E, Hoen B, Alla F, Selton-Suty C, Schubel L, Doco-Lecompte T, et al. Relationships between sex, early valve surgery and mortality in patients with left-sided infective endocarditis analysed in a population-based cohort study Heart. 2014;100:1173-8.

14. Tleyjeh IM, Kashour T, Zimmerman V, Steckelberg JM, Wilson WR, Baddour LM. The role of valve surgery in infective endocarditis management: a systematic review of observational studies that included propensity score analysis. Am Heart J. 2008;156:901-9.

15. Tleyjeh IM, Ghomrawi HM, Steckelberg JM, Hoskin TL, Mirzoyev Z, Anavekar NS, et al. The impact of valve surgery on 6-month mortality in left-sided infective endocarditis. Circulation. 2007;115:1721-8.

16. Aksoy O, Sexton DJ, Wang A, Pappas PA, Kourany W, Chu V, et al. Early surgery in patients with infective endocarditis: a propensity score analysis. Clin Infect Dis. 2007:44:364-72.

17. Vikram HR, Buenconsejo J, Hasbun R, Quagliarello VJ. Impact of valve surgery on 6-month mortality in adults with complicated, left-sided native valve endocarditis: a propensity analysis. JAMA. 2003;290:3207-14.

18. Karchmer AW, Bayer AS. Editorial commentary: surgical therapy for Staphylococcus aureus prosthetic valve endocarditis: proceed with caution (Caveat Emptor). Clin Infect Dis. 2015;60:750-2.

19. Fernandez-Hidalgo N, Almirante B, Tornos P, Gonzalez-Alujas MT, Planes AM, Larrosa MN, et al. Prognosis of left-sided infective endocarditis in patients transferred to a tertiary-care hospital-prospective analysis of referral bias and influence of inadequate antimicrobial treatment. Clin Microbiol Infect. 2011;17:769-75.

20. Lalani T, Cabell CH, Benjamin DK, Lasca O, Naber C, Fowler VG Jr, et al. Analysis of the impact of early surgery on in-hospital mortality of native valve endocarditis: use of propensity score and instrumental variable methods to adjust for treatment-selection bias. Circulation. 2010; 121:1005-13

21. Sy RW, Bannon PG, Bayfield MS, Brown C, Kritharides L. Survivor treatment selection bias and outcomes research: a case study of surgery in infective endocarditis. Circ Cardiovasc Qual Outcomes. 2009;2:469-74.

22. Kanafani ZA, Kanj SS, Cabell CH, Cecchi E, de Oliveira Ramos A, LejkoZupanc $\mathrm{T}$, et al. Revisiting the effect of referral bias on the clinical spectrum of infective endocarditis in adults. Eur J Clin Microbiol Infect Dis. 2010;29: 1203-10.

23. Steckelberg JM, Melton LJ 3rd, Ilstrup DM, Rouse MS, Wilson WR. Influence of referral bias on the apparent clinical spectrum of infective endocarditis. Am J Med. 1990;88:582-8.
24. Tleyjeh IM, Ghomrawi HM, Steckelberg JM, Montori VM, Hoskin TL, Enders F, et al. Conclusion about the association between valve surgery and mortality in an infective endocarditis cohort changed after adjusting for survivor bias. J Clin Epidemiol. 2010;63:130-5.

25. Kouchoukos NT, Blackstone EH, Hanley FL, Kirklin J. Cardiac Surgery. 4th ed. Philadelphia: Elsevier; 2012.

26. Austin PC, Platt RW. Survivor treatment bias, treatment selection bias, and propensity scores in observational research. J Clin Epidemiol. 2010;63:136-8.

27. Blackstone EH. Comparing apples and oranges. J Thorac Cardiovasc Surg. 2002;123:8-15.

28. Robins JM, Hernan MA, Brumback B. Marginal structural models and causal inference in epidemiology. Epidemiology. 2000;11:550-60.

29. Conn HO, Snyder N, Atterbury CE. The Berkson bias in action. Yale J Biol Med. 1979;52:141-7.

30. Osler W. The Gulstonian lectures, on malignant endocarditis. Br Med J. 1885;1: 467-70.

31. Murdoch DR, Corey GR, Hoen B, Miro JM, Fowler VG Jr, Bayer AS, et al. Clinical presentation, etiology, and outcome of infective endocarditis in the 21st century: the International Collaboration on Endocarditis-Prospective Cohort Study. Arch Intern Med. 2009;169:463-73.

32. Hoen B, Duval X. Clinical practice. Infective endocarditis. N Engl J Med. 2013; 368:1425-33.

33. Bashore TM, Cabell C, Fowler V Jr. Update on infective endocarditis. Curr Probl Cardiol. 2006;31:274-352.

34. Gaca JG, Sheng S, Daneshmand MA, O’Brien S, Rankin JS, Brennan JM, et al. Outcomes for endocarditis surgery in North America: a simplified risk scoring system. J Thorac Cardiovasc Surg. 2011;141:98-106, e1-2.

35. Bouza E, Menasalvas A, Munoz P, Vasallo FJ, del Mar Moreno M, Garcia Fernandez MA. Infective endocarditis-a prospective study at the end of the twentieth century: new predisposing conditions, new etiologic agents, and still a high mortality. Medicine (Baltimore). 2001;80:298-307.

36. Hoen B, Alla F, Selton-Suty C, Beguinot I, Bouvet A, Briancon S, et al. Changing profile of infective endocarditis: results of a 1-year survey in France. JAMA. 2002;288:75-81

37. Moreillon P, Que YA. Infective endocarditis. Lancet. 2004:363:139-49.

38. Cabell CH, Jollis JG, Peterson GE, Corey GR, Anderson DJ, Sexton DJ, et al. Changing patient characteristics and the effect on mortality in endocarditis. Arch Intern Med. 2002;162:90-4.

39. Tleyjeh IM, Steckelberg JM, Murad HS, Anavekar NS, Ghomrawi HM, Mirzoyev Z, et al. Temporal trends in infective endocarditis: a population-based study in Olmsted County, Minnesota. JAMA. 2005;293:3022-8.

40. Hill EE, Herijgers $P$, Claus $P$, Vanderschueren S, Herregods MC, Peetermans WE. Infective endocarditis: changing epidemiology and predictors of 6-month mortality: a prospective cohort study. Eur Heart J. 2007:28:196-203.

41. Mylonakis E, Calderwood SB. Infective endocarditis in adults. $N$ Engl J Med. 2001;345:1318-30.

42. Cabell CH, Abrutyn E, Fowler VG Jr, Hoen B, Miro JM, Corey GR, et al. Use of surgery in patients with native valve infective endocarditis: results from the International Collaboration on Endocarditis Merged Database. Am Heart J. 2005; 150:1092-8.

43. Hussain ST, Shrestha NK, Gordon SM, Houghtaling PL, Blackstone EH, Pettersson GB. Residual patient, anatomic, and surgical obstacles in treating active left-sided infective endocarditis. J Thorac Cardiovasc Surg. 2014;148: 981-8.e4.

44. David TE, Gavra G, Feindel CM, Regesta T, Armstrong S, Maganti MD. Surgical treatment of active infective endocarditis: a continued challenge. J Thorac Cardiovasc Surg. 2007:133:144-9.

45. Manne MB, Shrestha NK, Lytle BW, Nowicki ER, Blackstone E, Gordon SM, et al. Outcomes after surgical treatment of native and prosthetic valve infective endocarditis. Ann Thorac Surg. 2012;93:489-93.

46. Thuny F, Grisoli D, Collart F, Habib G, Raoult D. Management of infective endocarditis: challenges and perspectives. Lancet. 2012;379:965-75.

47. Kang DH, Kim YJ, Kim SH, Sun BJ, Kim DH, Yun SC, et al. Early surgery versus conventional treatment for infective endocarditis. N Engl J Med. 2012; 366:2466-73.

48. Gordon SM, Pettersson GB. Native-valve infective endocarditis-when does it require surgery? N Engl J Med. 2012;366:2519-21.

49. Tleyjeh IM, Abdel-Latif A, Rahbi H, Scott CG, Bailey KR, Steckelberg JM, et al. A systematic review of population-based studies of infective endocarditis. Chest. 2007;132:1025-35. 
50. Durack DT, Lukes AS, Bright DK. New criteria for diagnosis of infective endocarditis: utilization of specific echocardiographic findings. Duke Endocarditis Service. Am J Med. 1994;96:200-9.

51. Habib G, Derumeaux G, Avierinos JF, Casalta JP, Jamal F, Volot F, et al. Value and limitations of the Duke criteria for the diagnosis of infective endocarditis. $J$ Am Coll Cardiol. 1999;33:2023-9.

52. Li JS, Sexton DJ, Mick N, Nettles R, Fowler VG Jr, Ryan T, et al. Proposed modifications to the Duke criteria for the diagnosis of infective endocarditis. Clin Infect Dis. 2000;30:633-8.

53. Prendergast BD. Diagnostic criteria and problems in infective endocarditis. Heart. 2004;90:611-3.

54. Pettersson GB, Hussain ST, Shrestha NK, Gordon S, Fraser TG, Ibrahim KS, et al. Infective endocarditis: an atlas of disease progression for describing, staging, coding, and understanding the pathology. J Thorac Cardiovasc Surg. 2014; 147:1142-9.e2.

55. Lopez J, Sevilla T, Vilacosta I, Sarria C, Revilla A, Ortiz C, et al. Prognostic role of persistent positive blood cultures after initiation of antibiotic therapy in leftsided infective endocarditis. Eur Heart J. 2013;34:1749-54.

56. Elgharably H, Hussain ST, Shrestha NK, Blackstone EH, Pettersson GB. Current hypotheses in cardiac surgery: biofilm in infective endocarditis. Sem Thorac Surg. 2015. http://dx.doi.org/10.1053/j.semtcvs.

57. Shrestha NK, Jue J, Hussain ST, Jerry JM, Pettersson GB, Menon V, et al. Injection drug use and outcomes after surgical intervention for infective endocarditis. Ann Thorac Surg. 2015;100:875-82.

58. Houpikian P, Raoult D. Blood culture-negative endocarditis in a reference center: etiologic diagnosis of 348 cases. Medicine (Baltimore). 2005;84:162-73.

59. Neugarten J, Baldwin DS. Glomerulonephritis in bacterial endocarditis. Am J Med. 1984;77:297-304.

60. Hussain ST, Blackstone EH, Pettersson GB. Successful allograft root rereplacement for prosthetic valve endocarditis with improvement of renal function in a Jehovah's Witness patient. J Thorac Cardiovasc Surg. 2014;148: e199-200.

61. Dickerman SA, Abrutyn E, Barsic B, Bouza E, Cecchi E, Moreno A, et al. The relationship between the initiation of antimicrobial therapy and the incidence of stroke in infective endocarditis: an analysis from the ICE Prospective Cohort Study (ICE-PCS). Am Heart J. 2007;154:1086-94.

62. Hubert S, Thuny F, Resseguier N, Giorgi R, Tribouilloy C, Le Dolley Y, et al. Prediction of symptomatic embolism in infective endocarditis: construction and validation of a risk calculator in a multicenter cohort. J Am Coll Cardiol. 2013; 62:1384-92.

63. Thuny F, Di Salvo G, Belliard O, Avierinos JF, Pergola V, Rosenberg V, et al. Risk of embolism and death in infective endocarditis: prognostic value of echocardiography: a prospective multicenter study. Circulation. 2005;112:69-75.

64. Di Salvo G, Habib G, Pergola V, Avierinos JF, Philip E, Casalta JP, et al. Echocardiography predicts embolic events in infective endocarditis. J Am Coll Cardiol. 2001;37:1069-76.

65. Leitman M, Dreznik Y, Tyomkin V, Fuchs T, Krakover R, Vered Z. Vegetation size in patients with infective endocarditis. Eur Heart J Cardiovasc Imaging. 2012;13:330-8.

66. Hess A, Klein I, Iung B, Lavallee P, Ilic-Habensus E, Dornic Q, et al. Brain MRI findings in neurologically asymptomatic patients with infective endocarditis. AJNR Am J Neuroradiol. 2013:34:1579-84.

67. Cooper HA, Thompson EC, Laureno R, Fuisz A, Mark AS, Lin M, et al. Subclinical brain embolization in left-sided infective endocarditis: results from the evaluation by MRI of the brains of patients with left-sided intracardiac solid masses (EMBOLISM) pilot study. Circulation. 2009;120:585-91.

68. Duval X, Iung B, Klein I, Brochet E, Thabut G, Arnoult F, et al. Effect of early cerebral magnetic resonance imaging on clinical decisions in infective endocarditis: a prospective study. Ann Intern Med. 2010;152:497-504. W175.

69. Barsic B, Dickerman S, Krajinovic V, Pappas P, Altclas J, Carosi G, et al. Influence of the timing of cardiac surgery on the outcome of patients with infective endocarditis and stroke. Clin Infect Dis. 2013;56:209-17.

70. Patel FM, Das A, Banerjee AK. Neuropathological complications of infective endocarditis : study of autopsy material. Neurol India. 2001;49:41-6.

71. Leport C, Bure A, Leport J, Vilde JL. Incidence of colonic lesions in Streptococcus bovis and enterococcal endocarditis. Lancet. 1987;1:748.

72. Reynolds JG, Silva E, McCormack WM. Association of Streptococcus bovis bacteremia with bowel disease. J Clin Microbiol. 1983;17:696-7.
73. Murray HW, Roberts RB. Streptococcus bovis bacteremia and underlying gastrointestinal disease. Arch Intern Med. 1978;138:1097-9.

74. Desch S, Freund A, de Waha S, Eitel I, Lurz P, Stiermaier T, et al. Outcome in patients with left-sided native-valve infective endocarditis and isolated large vegetations. Clin Cardiol. 2014;37:626-33.

75. Orvin K, Goldberg E, Bernstine H, Groshar D, Sagie A, Kornowski R, et al. The role of FDG-PET/CT imaging in early detection of extra-cardiac complications of infective endocarditis. Clin Microbiol Infect. 2015;21: 69-76.

76. Pigrau C, Almirante B, Flores X, Falco V, Rodriguez D, Gasser I, et al. Spontaneous pyogenic vertebral osteomyelitis and endocarditis: incidence, risk factors, and outcome. Am J Med. 2005;118:1287.

77. Mekontso Dessap A, Zahar JR, Voiriot G, Ali F, Aissa N, Kirsch M, et al. Influence of preoperative antibiotherapy on valve culture results and outcome of endocarditis requiring surgery. $J$ Infect. 2009;59:42-8.

78. De Feo M, Cotrufo M, Carozza A, De Santo LS, Amendolara F, Giordano S et al. The need for a specific risk prediction system in native valve infective endocarditis surgery. ScientificWorldJournal. 2012;2012:307571.

79. Wang TK, Oh T, Voss J, Gamble G, Kang N, Pemberton J. Comparison of contemporary risk scores for predicting outcomes after surgery for active infective endocarditis. Heart Vessels. 2015;30:227-34.

80. Cheitlin MD, Armstrong WF, Aurigemma GP, Beller GA, Bierman FZ, Davis JL, et al. ACC/AHA/ASE 2003 Guideline Update for the Clinical Application of Echocardiography: summary article. A report of the American College of Cardiology/American Heart Association Task Force on Practice Guidelines (ACC/AHA/ASE Committee to Update the 1997 Guidelines for the Clinical Application of Echocardiography). J Am Soc Echocardiogr. 2003; 16:1091-110.

81. Jassar AS, Bavaria JE, Szeto WY, Moeller PJ, Maniaci J, Milewski RK, et al Graft selection for aortic root replacement in complex active endocarditis: does it matter? Ann Thorac Surg. 2012;93:480-7.

82. Kim JB, Ejiofor J, Yammine M, Camuso JM, Walsh CW, Ando M, et al. Are homografts superior to conventional prosthetic valves in the setting of infective endocarditis involving the aortic valve? J Thorac Cardiovasc Surg. 2016;151: 1239-48.

83. Savage EB, Saha-Chaudhuri P, Asher CR, Brennan JM, Gammie JS. Outcomes and prosthesis choice for active aortic valve infective endocarditis: analysis of the Society of Thoracic Surgeons Adult Cardiac Surgery Database. Ann Thorac Surg. 2014;98:806-14.

84. Kirklin JK. Challenging homografts as the holy grail for aortic valve endocarditis. J Thorac Cardiovasc Surg. 2016;151:1230-1.

85. Sabik JF, Lytle BW, Blackstone EH, Marullo AG, Pettersson GB Cosgrove DM. Aortic root replacement with cryopreserved allograft for prosthetic valve endocarditis. Ann Thorac Surg. 2002;74:650-9; discussion 9.

86. Von Reyn CF, Levy BS, Arbeit RD, Friedland G, Crumpacker CS. Infective endocarditis: an analysis based on strict case definitions. Ann Intern Med. 1981; 94:505-18.

87. Ruiz-Morales J, Ivanova-Georgieva R, Fernandez-Hidalgo N, GarciaCabrera E, Miro JM, Munoz P, et al. Left-sided infective endocarditis in patients with liver cirrhosis. J Infect. 2015;71:627-41.

88. NICE. Prophylaxis against infective endocarditis: antimicrobial prophylaxis against infective endocarditis in adults and children undergoing interventional procedures (CG64). National Institute for Health and Care Excellence; March 2008. http://www.nice.org.uk/guidance/CG64.

89. Botelho-Nevers E, Thuny F, Casalta JP, Richet H, Gouriet F, Collart F, et al. Dramatic reduction in infective endocarditis-related mortality with a management-based approach. Arch Intern Med. 2009; 169:1290-8.

90. Habib G, Badano L, Tribouilloy C, Vilacosta I, Zamorano JL, Galderisi M, et al. Recommendations for the practice of echocardiography in infective endocarditis. Eur J Echocardiogr. 2010;11:202-19.

91. Mugge A, Daniel WG, Frank G, Lichtlen PR. Echocardiography in infective endocarditis: reassessment of prognostic implications of vegetation size determined by the transthoracic and the transesophageal approach. J Am Coll Cardiol. 1989;14:631-8.

92. Reynolds HR, Jagen MA, Tunick PA, Kronzon I. Sensitivity of transthoracic versus transesophageal echocardiography for the detection of native valve vegetations in the modern era. J Am Soc Echocardiogr. 2003;16: $67-70$. 
93. Ronderos RE, Portis M, Stoermann W, Sarmiento C. Are all echocardiographic findings equally predictive for diagnosis in prosthetic endocarditis? J Am Soc Echocardiogr. 2004; 17:664-9.

94. Tanis W, Teske AJ, van Herwerden LA, Chamuleau S, Meijboom F, Budde RP, et al. The additional value of three-dimensional transesophageal echocardiography in complex aortic prosthetic heart valve endocarditis. Echocardiography. 2015;32:114-25.

95. Bruun NE, Habib G, Thuny F, Sogaard P. Cardiac imaging in infectious endocarditis. Eur Heart J. 2014;35:624-32.

96. San Roman JA, Vilacosta I, Lopez J, Revilla A, Arnold R, Sevilla T, et al. Role of transthoracic and transesophageal echocardiography in right-sided endocarditis: one echocardiographic modality does not fit all. J Am Soc Echocardiogr. 2012;25:807-14.

97. Shapira Y, Weisenberg DE, Vaturi M, Sharoni E, Raanani E, Sahar G, et al. The impact of intraoperative transesophageal echocardiography in infective endocarditis. Isr Med Assoc J. 2007;9:299-302.

98. Knudsen JB, Fuursted K, Petersen E, Wierup P, Molgaard H, Poulsen SH, et al. Failure of clinical features of low probability endocarditis. The early echo remains essential. Scand Cardiovasc J. 2011;45:133-8.

99. Feuchtner GM, Stolzmann P, Dichtl W, Schertler T, Bonatti J, Scheffel H, et al. Multislice computed tomography in infective endocarditis: comparison with transesophageal echocardiography and intraoperative findings. J Am Coll Cardiol. 2009;53:436-44.

100. Fagman E, Perrotta S, Bech-Hanssen O, Flinck A, Lamm C, Olaison L, et al. ECG-gated computed tomography: a new role for patients with suspected aortic prosthetic valve endocarditis. Eur Radiol. 2012;22: 2407-14.

101. Saby L, Laas O, Habib G, Cammilleri S, Mancini J, Tessonnier L, et al. Positron emission tomography/computed tomography for diagnosis of prosthetic valve endocarditis: increased valvular $18 \mathrm{~F}$-fluorodeoxyglucose uptake as a novel major criterion. J Am Coll Cardiol. 2013;61: 2374-82.

102. Pizzi MN, Roque A, Fernandez-Hidalgo N, Cuellar-Calabria H, FerreiraGonzalez I, Gonzalez-Alujas MT, et al. Improving the diagnosis of infective endocarditis in prosthetic valves and intracardiac devices With $18 \mathrm{~F}$-fluordeoxyglucose positron emission tomography/computed tomography angiography: initial results at an infective endocarditis referral center. Circulation. 2015; 132:1113-26.

103. Lancellotti P, Habib G, Oury C, Nchimi A. Positron emission tomography/ computed tomography imaging in device infective endocarditis: ready for prime time. Circulation. 2015;132:1076-80.

104. Jault F, Gandjbakhch I, Rama A, Nectoux M, Bors V, Vaissier E, et al. Active native valve endocarditis: determinants of operative death and late mortality. Ann Thorac Surg. 1997;63:1737-41.

105. Nagpal A, Sohail M, Steckelberg JM. Prosthetic valve endocarditis: state of the heart. Clin Invest. 2012;2:803-17.

106. Wang A, Athan E, Pappas PA, Fowler VG Jr, Olaison L, Pare C, et al. Contemporary clinical profile and outcome of prosthetic valve endocarditis. JAMA. 2007;297:1354-61.

107. Hasbun R, Vikram HR, Barakat LA, Buenconsejo J, Quagliarello VJ. Complicated left-sided native valve endocarditis in adults: risk classification for mortality. JAMA. 2003;289:1933-40.

108. Funakoshi S, Kaji S, Yamamuro A, Tani T, Kinoshita M, Okada Y, et al. Impact of early surgery in the active phase on long-term outcomes in leftsided native valve infective endocarditis. J Thorac Cardiovasc Surg. 2011; 142:836-42.e1.

109. Musci M, Siniawski H, Pasic M, Weng Y, Loforte A, Kosky S, et al. Surgical therapy in patients with active infective endocarditis: seven-year single centre experience in a subgroup of 255 patients treated with the Shelhigh stentless bioprosthesis. Eur J Cardiothorac Surg. 2008;34:410-7.

110. Prendergast BD, Tornos P. Surgery for infective endocarditis: who and when? Circulation. 2010;121:1141-52.

111. Bedeir K, Reardon M, Ramlawi B. Infective endocarditis: perioperative management and surgical principles. J Thorac Cardiovasc Surg. 2014;147: 1133-41.

112. Olaison L, Pettersson G. Current best practices and guidelines indications for surgical intervention in infective endocarditis. Infect Dis Clin North Am. 2002; 16:453-75. xi.

113. Kiefer T, Park L, Tribouilloy C, Cortes C, Casillo R, Chu V, et al. Association between valvular surgery and mortality among patients with infective endocarditis complicated by heart failure. JAMA. 2011;306:2239-47.
114. Yu VL, Fang GD, Keys TF, Harris AA, Gentry LO, Fuchs PC, et al. Prosthetic valve endocarditis: superiority of surgical valve replacement versus medical therapy only. Ann Thorac Surg. 1994;58:1073-7.

115. Miro JM, Anguera I, Cabell CH, Chen AY, Stafford JA, Corey GR, et al. Staphylococcus aureus native valve infective endocarditis: report of 566 episodes from the International Collaboration on Endocarditis Merged Database. Clin Infect Dis. 2005;41:507-14.

116. Remadi JP, Habib G, Nadji G, Brahim A, Thuny F, Casalta JP, et al. Predictors of death and impact of surgery in Staphylococcus aureus infective endocarditis. Ann Thorac Surg. 2007;83:1295-302.

117. Sohail MR, Martin KR, Wilson WR, Baddour LM, Harmsen WS, Steckelberg JM. Medical versus surgical management of Staphylococcus aureus prosthetic valve endocarditis. Am J Med. 2006;119:147-54.

118. Chirouze C, Cabell CH, Fowler VG Jr, Khayat N, Olaison L, Miro JM, et al. Prognostic factors in 61 cases of Staphylococcus aureus prosthetic valve infective endocarditis from the International Collaboration on Endocarditis merged database. Clin Infect Dis. 2004;38:1323-7.

119. Attaran S, Chukwuemeka A, Punjabi PP, Anderson J. Do all patients with prosthetic valve endocarditis need surgery? Interact Cardiovasc Thorac Surg. 2012; 15:1057-61.

120. Wolff M, Witchitz S, Chastang C, Regnier B, Vachon F. Prosthetic valve endocarditis in the ICU. Prognostic factors of overall survival in a series of 122 cases and consequences for treatment decision. Chest. 1995;108: 688-94.

121. Melgar GR, Nasser RM, Gordon SM, Lytle BW, Keys TF, Longworth DL. Fungal prosthetic valve endocarditis in 16 patients. An 11-year experience in a tertiary care hospital. Medicine (Baltimore). 1997;76:94-103.

122. Habib G, Avierinos JF, Thuny F. Aortic valve endocarditis: is there an optimal surgical timing? Curr Opin Cardiol. 2007;22:77-83.

123. Spiliopoulos K, Haschemi A, Fink G, Kemkes BM. Infective endocarditis complicated by paravalvular abscess: a surgical challenge. An 11-year single center experience. Heart Surg Forum. 2010;13:E67-73.

124. David TE, Regesta T, Gavra G, Armstrong S, Maganti MD. Surgical treatment of paravalvular abscess: long-term results. Eur J Cardiothorac Surg. 2007;31: 43-8.

125. Thuny F, Beurtheret S, Mancini J, Gariboldi V, Casalta JP, Riberi A, et al. The timing of surgery influences mortality and morbidity in adults with severe complicated infective endocarditis: a propensity analysis. Eur Heart J. 2011; 32:2027-33.

126. Yankah AC, Pasic M, Klose H, Siniawski H, Weng Y, Hetzer R. Homograft reconstruction of the aortic root for endocarditis with periannular abscess: a 17-year study. Eur J Cardiothorac Surg. 2005;28:69-75.

127. Lytle BW, Sabik JF, Blackstone EH, Svensson LG, Pettersson GB, Cosgrove DM 3rd. Reoperative cryopreserved root and ascending aorta replacement for acute aortic prosthetic valve endocarditis. Ann Thorac Surg. 2002;74: S1754-7; discussion S92-9.

128. d'Udekem Y, David TE, Feindel CM, Armstrong S, Sun Z. Long-term results of operation for paravalvular abscess. Ann Thorac Surg. 1996;62:48-53.

129. Alonso-Valle H, Farinas-Alvarez C, Garcia-Palomo JD, Bernal JM, MartinDuran R, Gutierrez Diez JF, et al. Clinical course and predictors of death in prosthetic valve endocarditis over a 20-year period. J Thorac Cardiovasc Surg. 2010;139:887-93.

130. Hill EE, Herijgers $P$, Claus $P$, Vanderschueren S, Peetermans WE, Herregods MC. Abscess in infective endocarditis: the value of transesophageal echocardiography and outcome: a 5-year study. Am Heart J. 2007;154: 923-8.

131. Rohmann S, Erbel R, Darius H, Gorge G, Makowski T, Zotz R, et al. Prediction of rapid versus prolonged healing of infective endocarditis by monitoring vegetation size. J Am Soc Echocardiogr. 1991;4:465-74.

132. Habib G. Embolic risk in subacute bacterial endocarditis: determinants and role of transesophageal echocardiography. Curr Infect Dis Rep. 2005;7: 264-71.

133. Vilacosta I, Graupner C, San Roman JA, Sarria C, Ronderos R, Fernandez C, et al. Risk of embolization after institution of antibiotic therapy for infective endocarditis. J Am Coll Cardiol. 2002;39:1489-95.

134. Okonta KE, Adamu YB. What size of vegetation is an indication for surgery in endocarditis? Interact Cardiovasc Thorac Surg. 2012;15:1052-6.

135. Sanfilippo AJ, Picard MH, Newell JB, Rosas E, Davidoff R, Thomas JD, et al. Echocardiographic assessment of patients with infectious endocarditis: prediction of risk for complications. J Am Coll Cardiol. 1991;18: 1191-9. 
136. Musci M, Siniawski H, Pasic M, Grauhan O, Weng Y, Meyer R, et al. Surgical treatment of right-sided active infective endocarditis with or without involvement of the left heart: 20-year single center experience. Eur J Cardiothorac Surg. 2007;32:118-25.

137. Thuny F, Avierinos JF, Tribouilloy C, Giorgi R, Casalta JP, Milandre L, et al. Impact of cerebrovascular complications on mortality and neurologic outcome during infective endocarditis: a prospective multicentre study. Eur Heart J. 2007;28:1155-61.

138. Garcia-Cabrera E, Fernandez-Hidalgo N, Almirante B, Ivanova-Georgieva R, Noureddine M, Plata A, et al. Neurological complications of infective endocarditis: risk factors, outcome, and impact of cardiac surgery: a multicenter observational study. Circulation. 2013;127:2272-84

139. Thuny F, Habib G. When should we operate on patients with acute infective endocarditis? Heart. 2010;96:892-7.

140. Angstwurm K, Borges AC, Halle E, Schielke E, Einhaupl KM, Weber JR. Timing the valve replacement in infective endocarditis involving the brain. $J$ Neurol. 2004;251:1220-6.

141. Eishi K, Kawazoe K, Kuriyama Y, Kitoh Y, Kawashima Y, Omae T. Surgical management of infective endocarditis associated with cerebral complications. Multi-center retrospective study in Japan. J Thorac Cardiovasc Surg. 1995; 110:1745-55.

142. Gillinov AM, Shah RV, Curtis WE, Stuart RS, Cameron DE, Baumgartner WA, et al. Valve replacement in patients with endocarditis and acute neurologic deficit. Ann Thorac Surg. 1996;61:1125-9; discussion 30.

143. Ting W, Silverman N, Levitsky S. Valve replacement in patients with endocarditis and cerebral septic emboli. Ann Thorac Surg. 1991;51:18-21; discussion 2.

144. Kanter MC, Hart RG. Neurologic complications of infective endocarditis. Neurology. 1991;41:1015-20.

145. Piper C, Wiemer M, Schulte HD, Horstkotte D. Stroke is not a contraindication for urgent valve replacement in acute infective endocarditis. J Heart Valve Dis. 2001;10:703-11.

146. Ruttmann E, Willeit J, Ulmer H, Chevtchik O, Hofer D, Poewe W, et al. Neurological outcome of septic cardioembolic stroke after infective endocarditis. Stroke. 2006:37:2094-9.

147. Chu VH, Park LP, Athan E, Delahaye F, Freiberger T, Lamas C, et al. Association between surgical indications, operative risk, and clinical outcome in infective endocarditis: a prospective study from the International Collaboration on Endocarditis. Circulation. 2015:131:131-40.

148. Ohara T, Nakatani S, Kokubo Y, Yamamoto H, Mitsutake K, Hanai S, et al. Clinical predictors of in-hospital death and early surgery for infective endocarditis: results of CArdiac Disease REgistration (CADRE), a nation-wide survey in Japan. Int J Cardiol. 2013;167:2688-94.

149. Gelsomino S, Maessen JG, van der Veen F, Livi U, Renzulli A, Luca F, et al. Emergency surgery for native mitral valve endocarditis: the impact of septic and cardiogenic shock. Ann Thorac Surg. 2012;93: 1469-76.

150. Sonneville R, Mirabel M, Hajage D, Tubach F, Vignon P, Perez P, et al. Neurologic complications and outcomes of infective endocarditis in critically ill patients: the ENDOcardite en REAnimation prospective multicenter study. Crit Care Med. 2011;39:1474-81.

151. Bannay A, Hoen B, Duval X, Obadia JF, Selton-Suty C, Le Moing V, et al. The impact of valve surgery on short- and long-term mortality in left-sided infective endocarditis: do differences in methodological approaches explain previous conflicting results? Eur Heart J. 2011;32:2003-15.

152. Shang E, Forrest GN, Chizmar T, Chim J, Brown JM, Zhan M, et al. Mitral valve infective endocarditis: benefit of early operation and aggressive use of repair. Ann Thorac Surg. 2009;87:1728-33; discussion 34

153. Heiro M, Nikoskelainen J, Engblom E, Kotilainen E, Marttila R, Kotilainen P. Neurologic manifestations of infective endocarditis: a 17year experience in a teaching hospital in Finland. Arch Intern Med. 2000; 160:2781-7.

154. Anderson DJ, Goldstein LB, Wilkinson WE, Corey GR, Cabell CH, Sanders LL, et al. Stroke location, characterization, severity, and outcome in mitral vs aortic valve endocarditis. Neurology. 2003;61:1341-6.

155. Hui FK, Bain M, Obuchowski NA, Gordon S, Spiotta AM, Moskowitz S, et al. Mycotic aneurysm detection rates with cerebral angiography in patients with infective endocarditis. J Neurointerv Surg. 2015;7:449-52.

156. Sorabella RA, Han SM, Grbic M, Wu YS, Takyama H, Kurlansky P, et al. Early operation for endocarditis complicated by preoperative cerebral emboli is not associated with worsened outcomes. Ann Thorac Surg. 2015;100:501-8.
157. Okita Y, Minakata K, Yasuno S, Uozumi R, Sato T, Ueshima K, et al. Optimal timing of surgery for active infective endocarditis with cerebral complications: a Japanese multicentre studydagger. Eur J Cardiothorac Surg. 2016.

158. Yoshioka D, Toda K, Sakaguchi T, Okazaki S, Yamauchi T, Miyagawa S, et al Valve surgery in active endocarditis patients complicated by intracranial haemorrhage: the influence of the timing of surgery on neurological outcomes. Eur J Cardiothorac Surg. 2014;45:1082-8.

159. Masuda J, Yutani C, Waki R, Ogata J, Kuriyama Y, Yamaguchi T. Histopathological analysis of the mechanisms of intracranial hemorrhage complicating infective endocarditis. Stroke. 1992;23:843-50.

160. Morita K, Sasabuchi Y, Matsui H, Fushimi K, Yasunaga H. Outcomes after early or late timing of surgery for infective endocarditis with ischaemic stroke: a retrospective cohort study. Interact Cardiovasc Thorac Surg. 2015;21:604-9.

161. Yoshioka D, Sakaguchi T, Yamauchi T, Okazaki S, Miyagawa S, Nishi H, et al. Impact of early surgical treatment on postoperative neurologic outcome for active infective endocarditis complicated by cerebral infarction. Ann Thorac Surg. 2012;94:489-95; discussion 96.

162. Misfeld M, Girrbach F, Etz CD, Binner C, Aspern KV, Dohmen PM, et al. Surgery for infective endocarditis complicated by cerebral embolism: a consecutive series of 375 patients. J Thorac Cardiovasc Surg. 2014;147:1837-44.

163. Kamalakannan D, Muhammed B, Gardin J. Anticoagulation in infective endocarditis. A survey of infectious disease specialists and cardiologists. Infect Dis Clin Pract. 2005;13:122-6.

164. Goldstein JN, Greenberg SM. Should anticoagulation be resumed after intracerebral hemorrhage? Cleve Clin J Med. 2010;77:791-9.

165. Immediate anticoagulation of embolic stroke: brain hemorrhage and management options. Cerebral Embolism Study Group. Stroke. 1984;15:779-89.

166. Tunkel AR, Kaye D. Neurologic complications of infective endocarditis. Neurol Clin. 1993;11:419-40.

167. Ananthasubramaniam K, Beattie JN, Rosman HS, Jayam V, Borzak S. How safely and for how long can warfarin therapy be withheld in prosthetic heart valve patients hospitalized with a major hemorrhage? Chest. 2001;119:478-84.

168. Wilson WR, Geraci JE, Danielson GK, Thompson RL, Spittell JA Jr, Washington JR 2nd, et al. Anticoagulant therapy and central nervous system complications in patients with prosthetic valve endocarditis. Circulation. 1978:57:1004-7.

169. Lieberman A, Hass WK, Pinto R, Isom WO, Kupersmith M, Bear G, et al. Intracranial hemorrhage and infarction in anticoagulated patients with prosthetic heart valves. Stroke. 1978;9:18-24.

170. Carpenter JL, McAllister CK. Anticoagulation in prosthetic valve endocarditis South Med J. 1983;76:1372-5.

171. Tornos P, Almirante B, Mirabet S, Permanyer G, Pahissa A, Soler-Soler J. Infective endocarditis due to Staphylococcus aureus: deleterious effect of anticoagulant therapy. Arch Intern Med. 1999;159:473-5.

172. Snygg-Martin U, Gustafsson L, Rosengren L, Alsio A, Ackerholm P, Andersson R, et al. Cerebrovascular complications in patients with left-sided infective endocarditis are common: a prospective study using magnetic resonance imaging and neurochemical brain damage markers. Clin Infect Dis. 2008:47:23-30.

173. Rasmussen RV, Snygg-Martin U, Olaison L, Buchholtz K, Larsen CT, Hassager C, et al. Major cerebral events in Staphylococcus aureus infective endocarditis: is anticoagulant therapy safe? Cardiology. 2009;114:284-91.

174. Anavekar NS, Tleyjeh IM, Mirzoyev Z, Steckelberg JM, Haddad C Khandaker $\mathrm{MH}$, et al. Impact of prior antiplatelet therapy on risk of embolism in infective endocarditis. Clin Infect Dis. 2007;44:1180-6.

175. Chan KL, Dumesnil JG, Cujec B, Sanfilippo AJ, Jue J, Turek MA, et al. A randomized trial of aspirin on the risk of embolic events in patients with infective endocarditis. J Am Coll Cardiol. 2003;42:775-80.

176. Chan KL, Tam J, Dumesnil JG, Cujec B, Sanfilippo AJ, Jue J, et al. Effect of long-term aspirin use on embolic events in infective endocarditis. Clin Infect Dis. 2008;46:37-41

177. Kung VW, Jarral OA, Shipolini AR, McCormack DJ. Is it safe to perform coronary angiography during acute endocarditis? Interact Cardiovasc Thorac Surg. 2011;13:158-67.

178. Roselli EE, Pettersson GB, Blackstone EH, Brizzio ME, Houghtaling PL, Hauck R, et al. Adverse events during reoperative cardiac surgery: frequency, characterization, and rescue. J Thorac Cardiovasc Surg. 2008;135:316-23. 23.e1-6.

179. Voldstedlund M, Fuursted K, Bruun NE, Arpi M. Comparison of heart valve culture between two Danish endocarditis centres. Scand J Infect Dis. 2012;44: 405-13. 
180. Olaison L, Hogevik H, Myken P, Oden A, Alestig K. Early surgery in infective endocarditis. QJM. 1996;89:267-78.

181. Fayad G, Vincentelli A, Leroy G, Devos P, Amr G, Prat A, et al. Impact of antimicrobial therapy on prognosis of patients requiring valve surgery during active infective endocarditis. J Thorac Cardiovasc Surg. 2014;147: 254-8.

182. Pettersson GB, Martino D, Blackstone EH, Nowicki ER, Houghtaling PL, Sabik JF 3rd, et al. Advising complex patients who require complex heart operations. J Thorac Cardiovasc Surg. 2013;145:1159-69.e3.

183. Oxorn DC. Intraoperative echocardiography. Heart. 2008;94:1236-43.

184. Yao F, Han L, Xu ZY, Zou LJ, Huang SD, Wang ZN, et al. Surgical treatment of multivalvular endocarditis: twenty-one-year single center experience. $J$ Thorac Cardiovasc Surg. 2009;137:1475-80.

185. Grimm RA, Stewart WJ. The role of intraoperative echocardiography in valve surgery. Cardiol Clin. 1998;16:477-89. ix.

186. Eltzschig HK, Rosenberger P, Loffler M, Fox JA, Aranki SF, Shernan SK Impact of intraoperative transesophageal echocardiography on surgical deci sions in 12,566 patients undergoing cardiac surgery. Ann Thorac Surg. 2008; $85: 845-52$.

187. Silva F, Arruda R, Nobre A, Mendes M, Lemos A, Gallego J, et al. Impact of intraoperative transesophageal echocardiography in cardiac surgery: retrospective analysis of a series of 850 examinations. Rev Port Cardiol. 2010;29: 1363-82.

188. de Kerchove L, Vanoverschelde JL, Poncelet A, Glineur D, Rubay J, Zech F, et al. Reconstructive surgery in active mitral valve endocarditis: feasibility, safety and durability. Eur J Cardiothorac Surg. 2007:31:592-9.

189. Shimokawa T, Kasegawa H, Matsuyama S, Seki H, Manabe S, Fukui T, et al Long-term outcome of mitral valve repair for infective endocarditis. Ann Thorac Surg. 2009;88:733-9; discussion 9.

190. Doukas G, Oc M, Alexiou C, Sosnowski AW, Samani NJ, Spyt TJ. Mitral valve repair for active culture positive infective endocarditis. Heart. 2006;92:361-3.

191. Feringa HH, Shaw LJ, Poldermans D, Hoeks S, van der Wall EE, Dion RA, et al. Mitral valve repair and replacement in endocarditis: a systematic review of literature. Ann Thorac Surg. 2007:83:564-70.

192. Ruttmann E, Legit C, Poelzl G, Mueller S, Chevtchik O, Cottogni M, et al Mitral valve repair provides improved outcome over replacement in active infective endocarditis. J Thorac Cardiovasc Surg. 2005;130:765-71.

193. Zegdi R, Debieche M, Latremouille C, Lebied D, Chardigny C, Grinda JM, et al Long-term results of mitral valve repair in active endocarditis. Circulation. 2005;111:2532-6.

194. Feringa HH, Bax JJ, Klein P, Klautz RJ, Braun J, van der Wall EE, et al. Outcome after mitral valve repair for acute and healed infective endocarditis. Eur J Cardiothorac Surg. 2006:29:367-73.

195. Iung B, Rousseau-Paziaud J, Cormier B, Garbarz E, Fondard O, Brochet E, et al Contemporary results of mitral valve repair for infective endocarditis. J Am Coll Cardiol. 2004;43:386-92.

196. Muehrcke DD, Cosgrove DM 3rd, Lytle BW, Taylor PC, Burgar AM, Durnwald CP, et al. Is there an advantage to repairing infected mitral valves? Ann Thorac Surg. 1997;63:1718-24.

197. David TE. Aortic valve repair for active infective endocarditis. Eur J Cardiothorac Surg. 2012;42:127-8.

198. Mayer K, Aicher D, Feldner S, Kunihara T, Schafers HJ. Repair versus replacement of the aortic valve in active infective endocarditis. Eur J Cardiothorac Surg. 2012:42:122-7.

199. Moon MR, Miller DC, Moore KA, Oyer PE, Mitchell RS, Robbins RC, et al Treatment of endocarditis with valve replacement: the question of tissue versus mechanical prosthesis. Ann Thorac Surg. 2001;71:1164-71.

200. Haydock D, Barratt-Boyes B, Macedo T, Kirklin JW, Blackstone E. Aortic valve replacement for active infectious endocarditis in 108 patients. A comparison of freehand allograft valves with mechanical prostheses and bioprostheses. $J$ Thorac Cardiovasc Surg. 1992;103:130-9.

201. Kaiser SP, Melby SJ, Zierer A, Schuessler RB, Moon MR, Moazami N, et al. Long-term outcomes in valve replacement surgery for infective endocarditis. Ann Thorac Surg. 2007:83:30-5.

202. Lytle BW, Priest BP, Taylor PC, Loop FD, Sapp SK, Stewart RW, et al. Surgical treatment of prosthetic valve endocarditis. J Thorac Cardiovasc Surg. 1996; 111:198-207; discussion 10.

203. Sheikh AM, Elhenawy AM, Maganti M, Armstrong S, David TE, Feindel CM Outcomes of surgical intervention for isolated active mitral valve endocarditis. $J$ Thorac Cardiovasc Surg. 2009;137:110-6.
204. Grinda JM, Mainardi JL, D'Attellis N, Bricourt MO, Berrebi A, Fabiani JN et al. Cryopreserved aortic viable homograft for active aortic endocarditis Ann Thorac Surg. 2005;79:767-71.

205. El-Hamamsy I, Clark L, Stevens LM, Sarang Z, Melina G, Takkenberg JJ, et al. Late outcomes following freestyle versus homograft aortic root replacement: results from a prospective randomized trial. J Am Coll Cardiol. 2010;55:368-76.

206. Musci M, Weng Y, Hubler M, Amiri A, Pasic M, Kosky S, et al. Homograf aortic root replacement in native or prosthetic active infective endocarditis: twenty-year single-center experience. J Thorac Cardiovasc Surg. 2010;139: 665-73.

207. Siniawski H, Lehmkuhl H, Weng Y, Pasic M, Yankah C, Hoffmann M, et al Stentless aortic valves as an alternative to homografts for valve replacement in active infective endocarditis complicated by ring abscess. Ann Thorac Surg. 2003; 75:803-8; discussion 8.

208. Perrotta S, Lentini S. In patients with severe active aortic valve endocarditis, is a stentless valve as good as the homograft? Interact Cardiovasc Thorac Surg. 2010;11:309-13.

209. McGiffin DC, Galbraith AJ, McLachlan GJ, Stower RE, Wong ML, Stafford EG, et al. Aortic valve infection. Risk factors for death and recurren endocarditis after aortic valve replacement. J Thorac Cardiovasc Surg. 1992; 104:511-20.

210. Avierinos JF, Thuny F, Chalvignac V, Giorgi R, Tafanelli L, Casalta JP, et al Surgical treatment of active aortic endocarditis: homografts are not the cornerstone of outcome. Ann Thorac Surg. 2007;84:1935-42.

211. Mihaljevic T. Invited commentary. It would not be wise to completely abandon the use of homograft root replacement in particular in patients with prosthetic valve endocarditis and aortic root abscess. Ann Thorac Surg. 2007; 84:1942.

212. Leyh RG, Knobloch K, Hagl C, Ruhparwar A, Fischer S, Kofidis T, et al Replacement of the aortic root for acute prosthetic valve endocarditis: prosthetic composite versus aortic allograft root replacement. J Thorac Cardiovasc Surg. 2004:127:1416-20.

213. Dearani JA, Orszulak TA, Schaff HV, Daly RC, Anderson BJ, Danielson GK. Results of allograft aortic valve replacement for complex endocarditis. J Thorac Cardiovasc Surg. 1997;113:285-91.

214. Moon MR. Prosthetic valve selection in patients with left-sided endocarditis: bioprosthetic or mechanical valves? Curr Opin Cardiol. 2014;29:127-32.

215. Gross C, Klima U, Mair R, Brucke P. Aortic homografts versus mechanical valves in aortic valve replacement in young patients: a retrospective study. Ann Thorac Surg. 1998;66:S194-7.

216. Gulbins H, Kilian E, Roth S, Uhlig A, Kreuzer E, Reichart B. Is there an advantage in using homografts in patients with acute infective endocarditis of the aortic valve? J Heart Valve Dis. 2002;11:492-7.

217. Klieverik LM, Yacoub MH, Edwards S, Bekkers JA, Roos-Hesselink JW Kappetein AP, et al. Surgical treatment of active native aortic valve endocarditis with allografts and mechanical prostheses. Ann Thorac Surg. 2009;88:1814-21.

218. Evans CF, Gammie JS. Surgical management of mitral valve infective endocarditis. Semin Thorac Cardiovasc Surg. 2011;23:232-40.

219. Sheikh AM, Elhenawy AM, Maganti M, Armstrong S, David TE, Feindel CM. Outcomes of double valve surgery for active infective endocarditis. $J$ Thorac Cardiovasc Surg. 2009;138:69-75.

220. Gillinov AM, Diaz R, Blackstone EH, Pettersson GB, Sabik JF, Lytle BW, et al. Double valve endocarditis. Ann Thorac Surg. 2001;71:1874-9.

221. David TE. Surgical management of aortic root abscess. J Card Surg. 1997;12 262-6; discussion 6-9.

222. Siniawski H, Grauhan O, Hofmann M, Pasic M, Weng Y, Yankah C, et al. Aortic root abscess and secondary infective mitral valve disease: results of surgical endocarditis treatment. Eur J Cardiothorac Surg. 2005;27:434-40.

223. Pettersson GB, Hussain ST, Ramankutty RM, Lytle BW, Blackstone EH Reconstruction of fibrous skeleton: technique, pitfalls and results. Multimed Man Cardiothorac Surg. 2014;2014.

224. Leontyev S, Borger MA, Modi P, Lehmann S, Seeburger J, Doenst T, et al. Surgical management of aortic root abscess: a 13-year experience in 172 patients with 100\% follow-up. J Thorac Cardiovasc Surg. 2012;143:332-7.

225. De Oliveira NC, David TE, Armstrong S, Ivanov J. Aortic and mitral valve replacement with reconstruction of the intervalvular fibrous body: an analysis of clinical outcomes. J Thorac Cardiovasc Surg. 2005;129:286-90.

226. David TE, Kuo J, Armstrong S. Aortic and mitral valve replacement with reconstruction of the intervalvular fibrous body. J Thorac Cardiovasc Surg. 1997;114 766-71; discussion 71-2 
227. Davierwala PM, Binner C, Subramanian S, Luehr M, Pfannmueller B, Etz C, et al. Double valve replacement and reconstruction of the intervalvular fibrous body in patients with active infective endocarditis. Eur J Cardiothorac Surg. 2014;45:146-52.

228. Kim SW, Park PW, Kim WS, Sung K, Lee YT, Jun TG, et al. Long-term results of aortomitral fibrous body reconstruction with double-valve replacement. Ann Thorac Surg. 2013;95:635-41.

229. Navia JL, Al-Ruzzeh S, Gordon S, Fraser T, Aguero O, Rodriguez L. The incorporated aortomitral homograft: a new surgical option for double valve endocarditis. J Thorac Cardiovasc Surg. 2010;139:1077-81.

230. Akinosoglou K, Apostolakis E, Koutsogiannis N, Leivaditis V, Gogos CA. Right-sided infective endocarditis: surgical management. Eur J Cardiothorac Surg. 2012;42:470-9.

231. Gaca JG, Sheng S, Daneshmand M, Rankin JS, Williams ML, O’Brien SM, et al. Current outcomes for tricuspid valve infective endocarditis surgery in North America. Ann Thorac Surg. 2013;96:1374-81.

232. Jiang SL, Li BJ, Zhang T, Ren CL, Wang Y, Chen TT, et al. Surgical treatment of isolated right-sided infective endocarditis. Tex Heart Inst J. 2011;38:639-42.

233. Dawood MY, Cheema FH, Ghoreishi M, Foster NW, Villanueva RM, Salenger R, et al. Contemporary outcomes of operations for tricuspid valve infective endocarditis. Ann Thorac Surg. 2015;99:539-46.

234. Miro JM, del Rio A, Mestres CA. Infective endocarditis and cardiac surgery in intravenous drug abusers and HIV-1 infected patients. Cardiol Clin. 2003;21: 167-84, v-vi.

235. Baraki H, Saito S, Al Ahmad A, Fleischer B, Schmitto J, Haverich A, et al. Surgical treatment for isolated tricuspid valve endocarditis- long-term follow-up at a single institution. Circ J. 2013;77:2032-7.

236. Carozza A, De Santo LS, Romano G, Della Corte A, Ursomando F, Scardone M, et al. Infective endocarditis in intravenous drug abusers: patterns of presentation and long-term outcomes of surgical treatment. J Heart Valve Dis. 2006;15: 125-31.

237. Frontera JA, Gradon JD. Right-side endocarditis in injection drug users: review of proposed mechanisms of pathogenesis. Clin Infect Dis. 2000;30: 374-9.

238. Thalme A, Westling K, Julander I. In-hospital and long-term mortality in infective endocarditis in injecting drug users compared to non-drug users: a retrospective study of 192 episodes. Scand J Infect Dis. 2007;39:197-204.

239. Yamane K, Hirose H, Bogar LJ, Cavarocchi NC, Diehl JT. Surgical treatment of infective endocarditis in patients undergoing chronic hemodialysis. J Heart Valve Dis. 2012;21:774-82.

240. Arbulu A, Holmes RJ, Asfaw I. Surgical treatment of intractable right-sided infective endocarditis in drug addicts: 25 years experience. $J$ Heart Valve Dis. 1993;2:129-37; discussion 38-9.

241. Kamaledeen A, Young C, Attia RQ. What are the differences in outcomes between right-sided active infective endocarditis with and without left-sided infection? Interact Cardiovasc Thorac Surg. 2012;14:205-8.

242. Rabkin DG, Mokadam NA, Miller DW, Goetz RR, Verrier ED, Aldea GS. Longterm outcome for the surgical treatment of infective endocarditis with a focus on intravenous drug users. Ann Thorac Surg. 2012;93:51-7.

243. Tarola CL, Losenno KL, Chu MW. Complex tricuspid valve repair for infective endocarditis: leaflet augmentation, chordae and annular reconstruction. Multimed Man Cardiothorac Surg. 2015;2015.

244. Gottardi R, Bialy J, Devyatko E, Tschernich H, Czerny M, Wolner E, et al. Midterm follow-up of tricuspid valve reconstruction due to active infective endocarditis. Ann Thorac Surg. 2007;84:1943-8.

245. Hagl C, Galla JD, Lansman SL, Fink D, Bodian CA, Spielvogel D, et al. Replacing the ascending aorta and aortic valve for acute prosthetic valve endocarditis: is using prosthetic material contraindicated? Ann Thorac Surg. 2002;74: S1781-5; discussion S92-9.

246. LeMaire SA, Coselli JS. Options for managing infected ascending aortic grafts. J Thorac Cardiovasc Surg. 2007;134:839-43.

247. Tang GH, Pinney SP, Broumand SR, Adams DH, Anyanwu AC. Excellent outcomes with use of synthetic vascular grafts for treatment of mycotic aortic pseudoaneurysms after heart transplantation. Ann Thorac Surg. 2011;92: 2112-6.

248. Shah DK, Li Z, Park SJ, Daly RC, Dearani JA, Schaff HV, et al. Replacement of the infected composite aortic root prosthesis. Ann Thorac Surg. 2011;92:1651-5.

249. Tossios P, Karatzopoulos A, Tsagakis K, Sapalidis K, Grosomanidis V, Kalogera A, et al. Treatment of infected thoracic aortic prosthetic grafts with the in situ preservation strategy: a review of its history, surgical technique, and results. Heart Lung Circ. 2014;23:24-31.
250. Sohail MR, Uslan DZ, Khan AH, Friedman PA, Hayes DL, Wilson WR, et al Infective endocarditis complicating permanent pacemaker and implantable cardioverter-defibrillator infection. Mayo Clin Proc. 2008;83:46-53.

251. Tarakji KG, Wilkoff BL. Cardiac implantable electronic device infections facts, current practice, and the unanswered questions. Curr Infect Dis Rep. $2014 ; 16: 425$.

252. Athan E, Chu VH, Tattevin P, Selton-Suty C, Jones P, Naber C, et al. Clinical characteristics and outcome of infective endocarditis involving implantable cardiac devices. JAMA. 2012;307:1727-35.

253. Viganego F, O’Donoghue S, Eldadah Z, Shah MH, Rastogi M, Mazel JA, et al. Effect of early diagnosis and treatment with percutaneous lead extraction on survival in patients with cardiac device infections. Am J Cardiol. 2012;109: 1466-71.

254. Pichlmaier M, Knigina L, Kutschka I, Bara C, Oswald H, Klein G, et al. Complete removal as a routine treatment for any cardiovascular implantable electronic device-associated infection. J Thorac Cardiovasc Surg. 2011;142:1482-90.

255. Rundstrom H, Kennergren C, Andersson R, Alestig K, Hogevik H. Pacemaker endocarditis during 18 years in Goteborg. Scand J Infect Dis. 2004;36:674-9.

256. Baddour LM, Epstein AE, Erickson CC, Knight BP, Levison ME, Lockhart PB, et al. Update on cardiovascular implantable electronic device infections and their management: a scientific statement from the American Heart Association. Circulation. 2010;121:458-77.

257. Baddour LM, Cha YM, Wilson WR. Clinical practice. Infections of cardiovascular implantable electronic devices. N Engl J Med. 2012;367:842-9.

258. Madhavan M, Sohail MR, Friedman PA, Hayes DL, Steckelberg JM Wilson WR, et al. Outcomes in patients with cardiovascular implantable electronic devices and bacteremia caused by Gram-positive cocci other than Staphylococcus aureus. Circ Arrhythm Electrophysiol. 2010;3:639-45.

259. Shrestha NK, Ledtke CS, Wang H, Fraser TG, Rehm SJ, Hussain ST, et al. Heart valve culture and sequencing to identify the infective endocarditis pathogen in surgically treated patients. Ann Thorac Surg. 2015;99:33-7.

260. Fournier PE, Thuny F, Richet H, Lepidi H, Casalta JP, Arzouni JP, et al Comprehensive diagnostic strategy for blood culture-negative endocarditis: a prospective study of 819 new cases. Clin Infect Dis. 2010;51:131-40.

261. Boussier R, Rogez S, Francois B, Denes E, Ploy MC, Garnier F. Two-step bacterial broad-range polymerase chain reaction analysis of heart valve tissue improves bacteriological diagnosis of infective endocarditis. Diagn Microbiol Infect Dis. 2013;75:240-4.

262. Greub G, Lepidi H, Rovery C, Casalta JP, Habib G, Collard F, et al. Diagnosis of infectious endocarditis in patients undergoing valve surgery. Am J Med. 2005; 118:230-8.

263. Marin M, Munoz P, Sanchez M, del Rosal M, Alcala L, Rodriguez-Creixems M et al. Molecular diagnosis of infective endocarditis by real-time broad-range polymerase chain reaction (PCR) and sequencing directly from heart valve tissue. Medicine (Baltimore). 2007;86:195-202.

264. Vollmer T, Piper C, Horstkotte D, Korfer R, Kleesiek K, Dreier J. 23S rDNA real-time polymerase chain reaction of heart valves: a decisive tool in the diagnosis of infective endocarditis. Eur Heart J. 2010;31:1105-13.

265. Dahl A, Rasmussen RV, Bundgaard H, Hassager C, Bruun LE, Lauridsen TK, et al. Enterococcus faecalis infective endocarditis: a pilot study of the relationship between duration of gentamicin treatment and outcome. Circulation. 2013; 127:1810-7.

266. Olaison L, Schadewitz K. Swedish Society of Infectious Diseases Quality Assurance Study Group for E. Enterococcal endocarditis in Sweden, 1995 1999: can shorter therapy with aminoglycosides be used? Clin Infect Dis. 2002:34:159-66.

267. Thomsen RW, Farkas DK, Friis S, Svaerke C, Ording AG, Norgaard M, et al Endocarditis and risk of cancer: a Danish nationwide cohort study. Am J Med. 2013;126:58-67.

268. Gupta A, Madani R, Mukhtar H. Streptococcus bovis endocarditis, a silent sign for colonic tumour. Colorectal Dis. 2010;12:164-71.

269. Rusniok C, Couve E, Da Cunha V, El Gana R, Zidane N, Bouchier C, et al Genome sequence of Streptococcus gallolyticus: insights into its adaptation to the bovine rumen and its ability to cause endocarditis. J Bacteriol. 2010; 192:2266-76

270. Boleij A, van Gelder MM, Swinkels DW, Tjalsma H. Clinical Importance of Streptococcus gallolyticus infection among colorectal cancer patients: systematic review and meta-analysis. Clin Infect Dis. 2011;53:870-8.

271. Thuny F, Giorgi R, Habachi R, Ansaldi S, Le Dolley Y, Casalta JP, et al. Excess mortality and morbidity in patients surviving infective endocarditis. Am Heart J. 2012;164:94-101. 
272. Hasegawa MI, Kyo S, Asano H, Imanaka K. Surgery for active, culture negative endocarditis. Asian Cardiovasc Thorac Ann. 2004;12:316-9.

273. Mullany CJ, Chua YL, Schaff HV, Steckelberg JM, Ilstrup DM, Orszulak TA, et al. Early and late survival after surgical treatment of culture-positive active endocarditis. Mayo Clin Proc. 1995;70:517-25.

274. Fedoruk LM, Jamieson WR, Ling H, Macnab JS, Germann E, Karim SS, et al. Predictors of recurrence and reoperation for prosthetic valve endocarditis after valve replacement surgery for native valve endocarditis. J Thorac Cardiovasc Surg. 2009; 137:326-33.

275. Martinez-Selles M, Munoz P, Estevez A, del Castillo R, GarciaFernandez MA, Rodriguez-Creixems M, et al. Long-term outcome of infective endocarditis in non-intravenous drug users. Mayo Clin Proc. 2008;83: 1213-7.

276. Mansur AJ, Dal Bo CM, Fukushima JT, Issa VS, Grinberg M, Pomerantzeff PM. Relapses, recurrences, valve replacements, and mortality during the long-term follow-up after infective endocarditis. Am Heart J. 2001;141:78-86.

277. Tornos MP, Permanyer-Miralda G, Olona M, Gil M, Galve E, Almirante $\mathrm{B}$, et al. Long-term complications of native valve infective endocarditis in non-addicts. A 15-year follow-up study. Ann Intern Med. 1992; 117:567-72.

278. Westling K, Aufwerber E, Ekdahl C, Friman G, Gardlund B, Julander I, et al. Swedish guidelines for diagnosis and treatment of infective endocarditis. Scand J Infect Dis. 2007;39:929-46.

279. Nori US, Manoharan A, Thornby JI, Yee J, Parasuraman R, Ramanathan V. Mortality risk factors in chronic haemodialysis patients with infective endocarditis. Nephrol Dial Transplant. 2006;21:2184-90.

280. Rankin JS, Milford-Beland S, O'Brien SM, Edwards FH, Peterson ED, Glower DD, et al. The risk of valve surgery for endocarditis in patients with dialysis-dependent renal failure. J Heart Valve Dis. 2007;16:617-22; discussion 22 .
281. Leither MD, Shroff GR, Ding S, Gilbertson DT, Herzog CA. Long-term survival of dialysis patients with bacterial endocarditis undergoing valvular replacement surgery in the United States. Circulation. 2013;128:344-51.

282. Abbott KC, Agodoa LY. Hospitalizations for bacterial endocarditis after initiation of chronic dialysis in the United States. Nephron. 2002;91:203-9.

283. Doulton T, Sabharwal N, Cairns HS, Schelenz S, Eykyn S, O'Donnell P, et al. Infective endocarditis in dialysis patients: new challenges and old. Kidney Int. 2003;64:720-7.

284. Maraj S, Jacobs LE, Maraj R, Kotler MN. Bacteremia and infective endocarditis in patients on hemodialysis. Am J Med Sci. 2004;327:242-9.

285. McCarthy JT, Steckelberg JM. Infective endocarditis in patients receiving longterm hemodialysis. Mayo Clin Proc. 2000;75:1008-14.

286. Hung TH, Hsieh YH, Tseng KC, Tsai CC. The risk for bacterial endocarditis in cirrhotic patients: a population-based 3-year follow-up study. Int J Infect Dis. 2013;17:e391-3.

287. Jacob KA, Hjortnaes J, Kranenburg G, de Heer F, Kluin J. Mortality after cardiac surgery in patients with liver cirrhosis classified by the Child-Pugh score. Interact Cardiovasc Thorac Surg. 2015;20:520-30.

288. Wilson W, Taubert KA, Gewitz M, Lockhart PB, Baddour LM, Levison M, et al. Prevention of infective endocarditis: guidelines from the American Heart Association: a guideline from the American Heart Association Rheumatic Fever, Endocarditis, and Kawasaki Disease Committee, Council on Cardiovascular Disease in the Young, and the Council on Clinical Cardiology, Council on Cardiovascular Surgery and Anesthesia, and the Quality of Care and Outcomes Research Interdisciplinary Working Group. Circulation. 2007;116:1736-54.

Key Words: AATS guidelines, infective endocarditis, infection, valve disease, cardiac surgery, native valve endocarditis, prosthetic valve endocarditis 


\section{APPENDIX E1. INVITED EXPERTS}

\section{Cardiac Surgery}

Michael A. Borger, MD, PhD

Director, Cardiovascular Institute

Columbia University Medical Center

New York, NY

James S. Gammie, MD

Chair, Division of Cardiac Surgery

University of Maryland

Baltimore, Md

Hartzell V. Schaff, MD

Chair, Division of Cardiovascular Surgery

Mayo Clinic College of Medicine

Rochester, Minn

Thoralf M. Sundt III, MD

Chair, Division of Cardiac Surgery

Massachusetts General Hospital

Boston, Mass

\section{Cardiology}

James D. Thomas, MD

Director, Center for Heart Valve Disease

Northwestern University Feinberg School of Medicine

Chicago, Ill

\section{Anesthesiology}

Colleen G. Koch, MD, MS, MBA

Chair, Department of Anesthesiology and Critical Care Medicine

Johns Hopkins Medicine

Baltimore, Md

\section{Imaging}

Xavier Duval, MD, PhD

Hôpital Universitaire Bichat

Départment d'Epidémiologie et Recherche Clinique

Université Paris Diderot

Paris, France

Benjamin Y. Cheong, MD

CHI St. Luke's Health

Baylor St. Luke's Medical Center

Houston, Tex

\section{Infectious Disease}

Larry M. Baddour, MD

Professor of Medicine

Division of Infectious Diseases

Mayo Clinic College of Medicine

Rochester, Minn

Adolf W. Karchmer, MD

Chief, Division of Infectious Diseases

Beth Israel Deaconess Medical Center

Harvard Medical School

Boston, Mass

Vance G. Fowler, MD

Professor of Medicine and Molecular Genetics and Microbiology

Department of Medicine

Duke University Medical Center

Durham, NC

\section{Neurology}

Amy A. Pruitt, MD

Professor of Neurology and Division Chief, General Neurology Unit

Hospital of the University of Pennsylvania

Philadelphia, $\mathrm{Pa}$ 